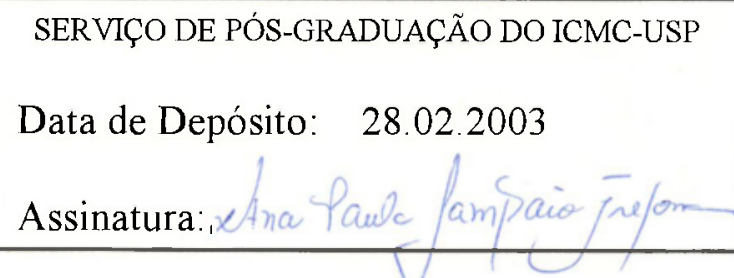

\title{
Visualização como Suporte à Exploração de uma Base de Dados Pluviométricos
}

\author{
Vinícius Marques Alves Branco
}

Orientadora: Profa. Dra. Maria Cristina Ferreira de Oliveira

Dissertação apresentada ao Instituto de Ciências Matemáticas e de Computação - ICMC-USP, como parte dos requisitos para obtenção do titulo de Mestre em Ciências de Computação e Matemática Computacional.

USP - São Carlos

Fevereiro/2003 
A Comissão Julgadora:

Profa. Dra. Maria Cristina Ferreira de Oliveira

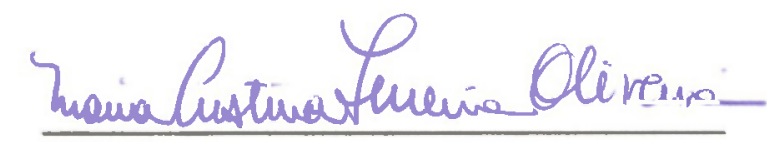

Profa. Dra. Agma Juci Machado Traina

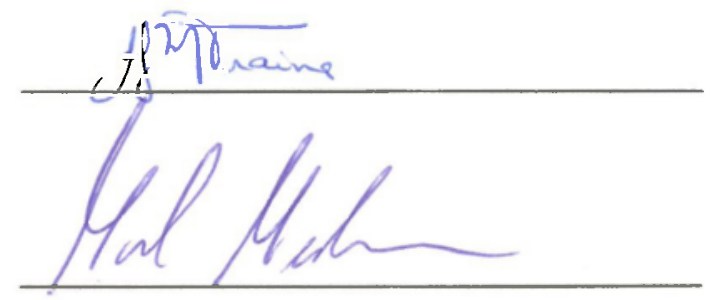

Prof. Dr. Manoel Gomes de Mendonça Neto 


\section{AgRadecimentos}

A Deus. (Engraçado ... esta é a primeira vez que te agradeço por escrito!)

Aos meus pais, Paulo e Lourdes. Aos meus irmãos, Erik, Edyno c Paulinho. Como sempre fica algo por dizer, para não correr o risco, restrinjo-me a agradecer: Obrigado!!! Obrigado pelo companheirismo nesta jornada (vocês sabem de qual me refiro ...). Obrigado por torná-la mais branda e agradável.

Aos avós, tios, tias e primos. Obrigado pelo incentivo e confiança.

Aos amigos de Salvador, Campo Grande e Sào Carlos, que em momentos distintos da vida, me fizeram feliz e agradecido a Deus por tê-los. Muito obrigado a todos!

Aos professores da graduação na URMS. Pelo apoio e confiança, agradeço em especial ao Marcelo IIenriques, Paulo Pagliosa e Marcelo Siqueira. Este último, exemplo de como a forma apaixonada de se conduzir a vida profissional consegue incentivar e motivar a busca da nossa própria realização. Marcelo, muito obrigado!

A Cristina, pela sempre zelosa e atenciosa maneira de conduzir o trabalho. Pela gentil e equilibrada forma de administrar austeridade e brandura. Gentileza e equilíbrio estes, próprios de seu caráter. Obrigado, Cristina!

Ao Milton e Edilson pela orientaçào e suporte no decorrer do projeto.

Aos colegas de pós. Especialmente, Indomada (Douglas), ao Japa (Renato), Carlitius (Carlos) e Marcelo, pelo companheirismo e apoio nas horas dificeis (e nas fáceis também ...). Indomada, pra você ... sem palavras. I,embra-se de quando chegamos aqui de "mala e cuia"? ..

Aos funcionários e professores do IC MC pela competência e atenção. De alguns professores, levo a mais completa admiração.

À USP pela oportunidade.

A Capes pelo apoio financeiro.

A todos que, de alguma forma, contribuiram para a realização deste trabalho. 


\section{ÍNDICE}

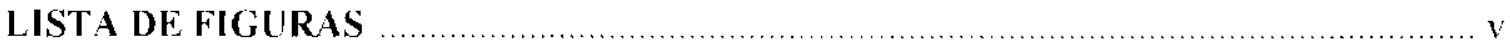

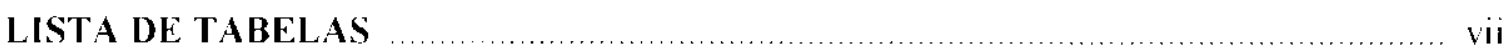

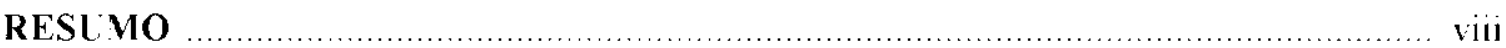

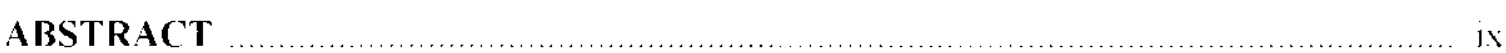

1 INTRODUC $\tilde{A} O$

2 VISUALIZAÇÃO DE INFORMAÇÃO

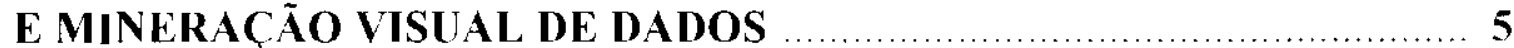

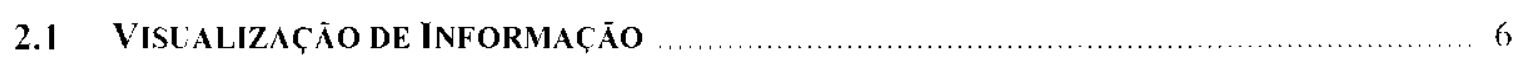

2.1.I Conjuntos de Dados ......................................................................... 8

2.1.1.1 Tabelas de Dados .............................................................

2.1.1.2 Caracterização dos Dados .................................................. 10

2.1.2 Técnicas para Visualização Exploratória de Dados Multidimensionais ....... 12

2.1.2.1 Coordenadas Paralelas: Projeções Geomćtricas .............................. 13

2.1.2.2 Técnicas Orientadas a Pixcls .................................................. 16

2.1 .2 .3 Stick tigures: lconograficas ............................................... 20

2.1.2.4 Dimensional Stacking: Hicrárquicas ............................................. 21

2.1.2.5 Técnicas Baseadas em Grafos ................................................. 23

2.2 EXtração de Conhlacimento e mineração de dados …................................ 24

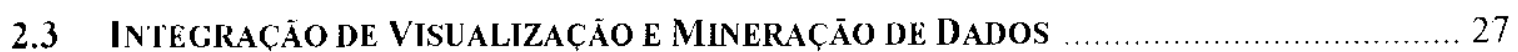

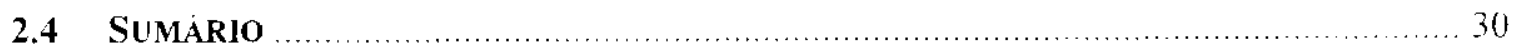

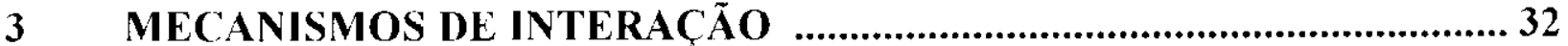

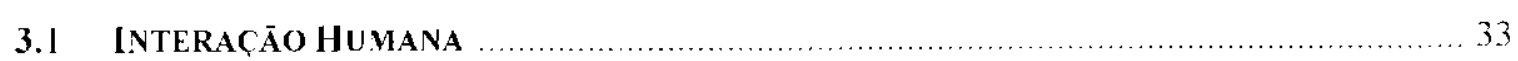

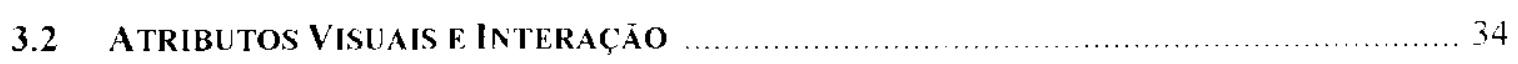

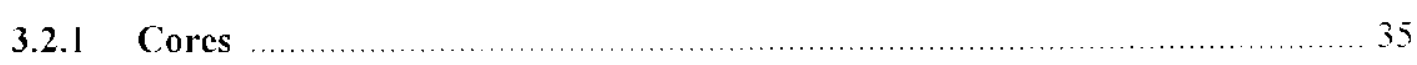

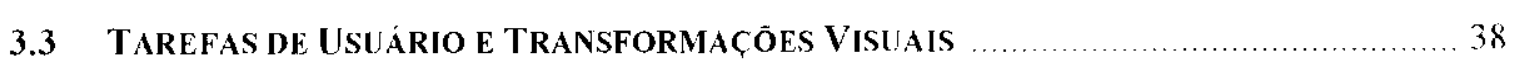

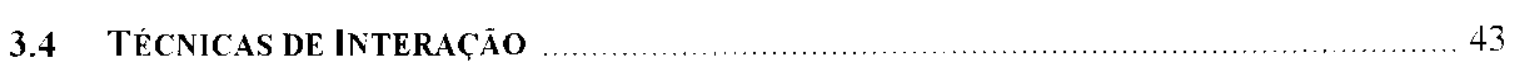

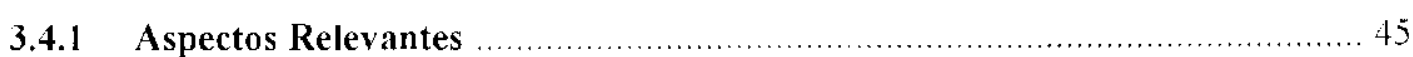

3.4.2 Classificacão de Técnicas de Interação .............................................. 46

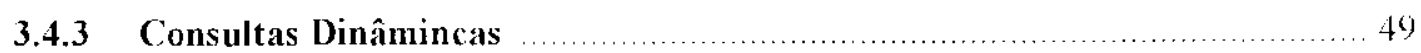

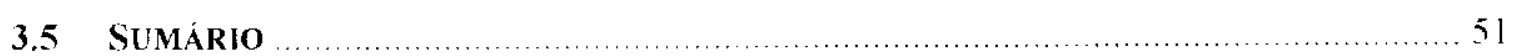




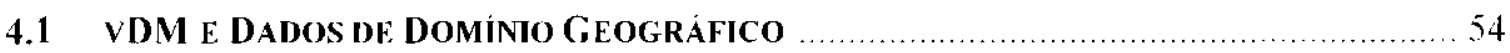

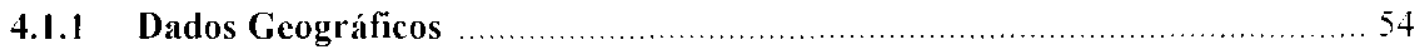

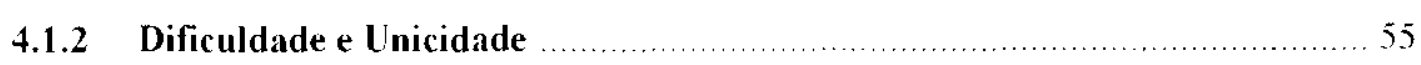

4.2 Análise EXPloratória aplicada a tMa BaSe de DAdos Pluviometricos ........58

4.2.1 O Problema da Classificação Climática ……....................................... 58

4.2.2 Escopo do Projeto ........................................................................... 59

4.2.3 Arquitetura e Aspectos de Implementação do InfoVis ............................... 61

4.2.4 Implementaçāo do Aplicativo de Exploração Visual ...................................66

4.2.4.I Tratamento da Fonte de Dados ...................................................66 66

4.2.4.2 Componente de Interação: Consultas Dinâmicas ……....................... 71

4.2.4.3 Componente de Visualização: Técnica Orientada a Pixcls ................... 76

4.3 SUMÁRIO

5 CONCLUSÕES

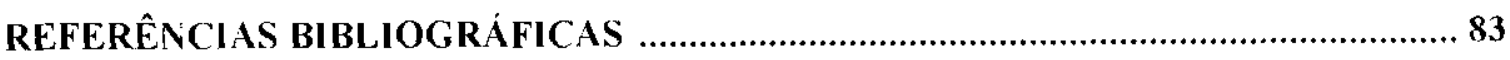




\section{LISTA DE Figuras}

2.I Modelo de Referência de Visualização de Card et al. |Car 1999| ...................................... 07

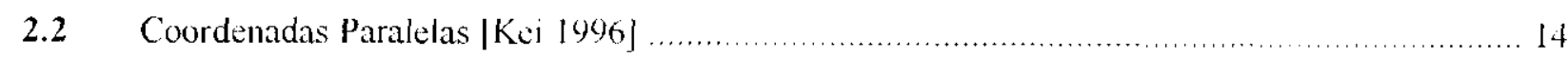

2.3 Exemplo de seleçào de Itens em aplicação com Coordenadas Paralelas [Eds 1999] ............... 15

2.4 Sobreposição de linhas com apresentação de 473 itens |Ins $1997 \mid$................................. 1.5

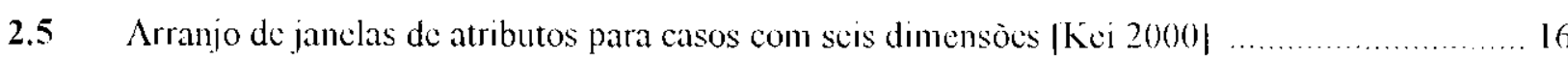

2.6 Identificação de correlação e dependências funcionais no VisDB |Kei 1996| ....................... 16

2.7 Esquema básico do arranjo "Padrôes Recursivos"

2.8 Esquemas de arranjo de pixels: (a) em espiral simples |Kei 1994|. com curvas de (b) Peano-Hilbert e (c) Morton |Kei 1996| .............................................. I9

2.9 Esquema com cixos para identificar distâncias positivas e negativas $\mid$ Kei $1996 \mid \ldots \ldots \ldots \ldots \ldots \ldots$ I9............

2.10 (a) Formato circular para distribuição dos pixels:

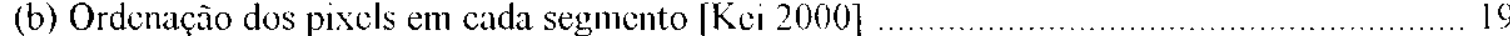

2.11 (a) İcone que representa 5 variáveis; (b) Familia de ícones [Won 1997| ...........................20

2.12 Imagem da região dos Grandes Lagos com ícones de 5 dimensões |Ank 2001| ................... 21

2.13 Modelo Conccitual da Técnica Dimensional Siacking |Ank 2001] .................................. 22

2.14 Visualização da Dimensional Stacking aplicada ao
conjunto de dados "Íris Flower" |Hof 1999]

2.15 Exemplos de aplicações de Visualizações 2D de grafos: (a) grafo otimizado para agrupamentos; (b) Grafo aciclico-direcionado |Ank 200|] ................................ 24

2.16 Exemplo de aplicação de Visualização 3D de grafos:

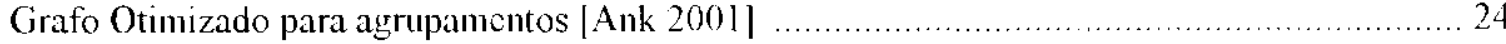

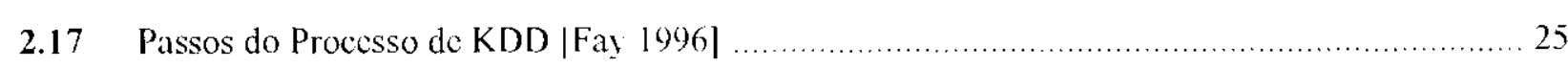

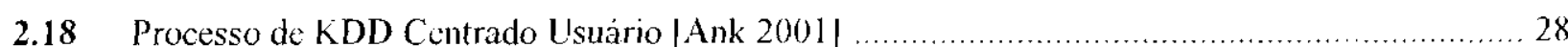

2.19 Categorias de Mineração Visual de Dados |Ank 200l] ................................................... 30

3.1 Atributos visuais que promovem fácil distinção entre elementos |Men 2001| .....................35

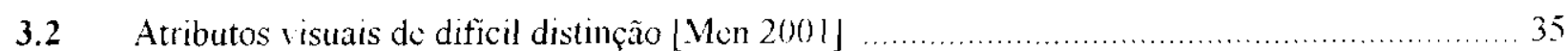

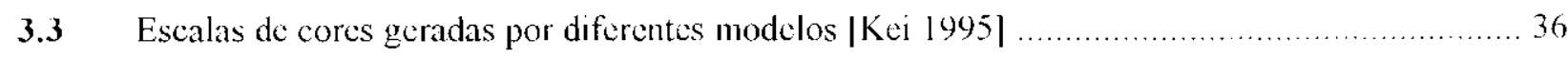

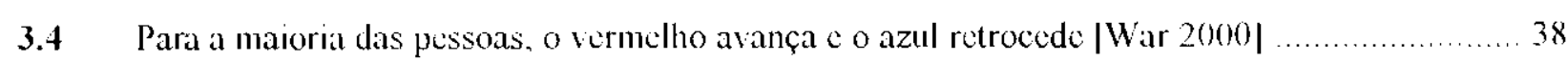

3.5 Captura de tela da Aplicação FilmFinder |Alıl 1994| ............................................ Ho

3.6 "Information Mural" usando visào geral+detalhe para visualizar uma longa seqüiência de mensagens, geradas por um programa rodando um Bubble. Sort $\mid$ Jer $1995 \mid$........................ 42 
3.7 (a) Principio de funcionamento c

(b) Visão do usuário em uma técnica de distorção [Spe 200) ] _.................................... 42

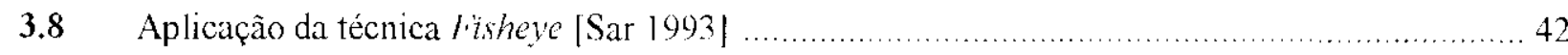

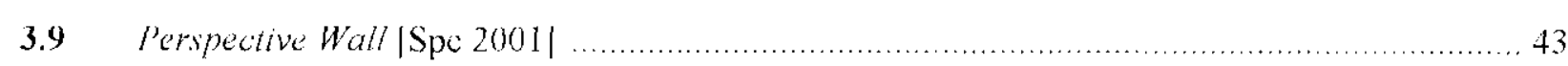

3.10 Estrutura em árvore de um site, vista na técnica Hyperbolic Tree |Ank 2001] ...................... 43

3.11 Ambientes Interativos: (a) Sistema de Engenharia Genetica Cage/Gem e

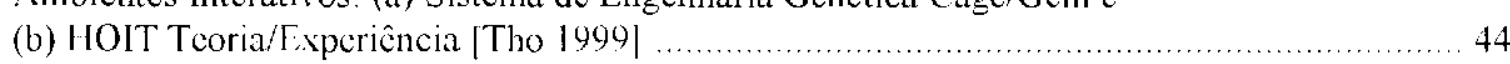

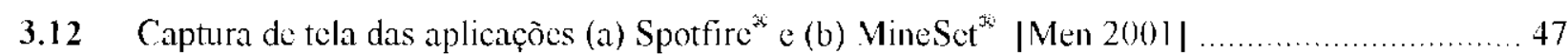

3.13 Principio de Funcionamento da técnica Brushing [Spe 2001] .................................... 48

3.14 Sobreposição de lentes na técnica Magic Lens. A Imagem destaca os itens que combinam “altos salários" E "baixas taxas" [Fis 1995$]$.......................................... 49

3.15 (a) Range Slider: (b) Alphas Sider [Car 1994] ............................................................ 51

4.1 Visão de alto nível da arquitetura organizacional da plataforma InfoVis |Oli $2002 \mid \ldots \ldots \ldots \ldots \ldots . . .64$

4.2 Arquitetura Genćrica de um Aplicativo do Inforis [Oli 2002] ........................................65

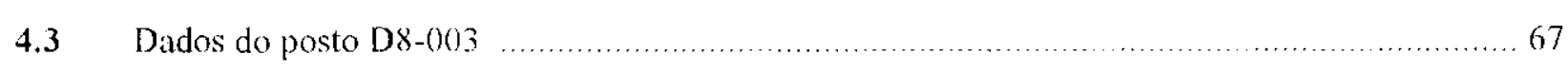

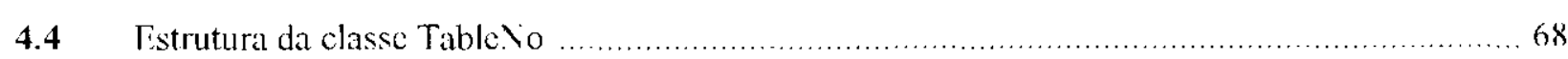

4.5 Objeto TableNo com dados do posto D8-003. visto num JTable .................................... 69

4.6 (a) Opçõcs de Filtro para uma tabela exemplo;

(b) Configuração das Consultas Dinâmicas após a seleção dos controles ............................ 7 I

4.7 (a) Ranges/ider: (b) Grupo ('heck Box; (c) Mcmu Pomup para escolha de controle ............... 72

4.8 Estrutura da classe IndexEstru com valores de exemplo ............................................ 73

4.9 Filtragens utilizando Consultas Dinâmicas: (a) scleção de um município:

(b) scleção de uma bacia hidrográfica: o

(c) seqüencia correspondente ao deslize do Range Shicler do filtro de altitude ........................ 74

4.10 Exemplo de seleção regional de postos com intervalo de anos suficiente para análise .............75

4.11 Exemplo de Visualização Múltipla de quatro postos ................................................ 76

4.12 (a) Área selecionada na Visualização dos dados de um posto:

(b) Imagem ampliada da região sclccionada:

(c) Opçôes do Menu Popup 


\section{LISTA DE TABELAS}

2.1 Descrição de uma tabela de dados [Car 1999] ……..................................................... 09

2.2 Sumário da caracterização de dados. exemplos de domínios diferentes $|\mathrm{Fre} 2000| \mid \ldots \ldots \ldots \ldots \ldots \ldots . .11$

4.1 Sumario das perspectivas de diferentes disciplinas nas atividades de DM e KDD [Yua 2001$]$ 


\section{RESUMO}

A atual evoluçào tecnologica permite gerar, coletar e armazenar uma enorme quantidade de dados, resultando em um grande acúmulo de informaçôes. Isto possibilita vislumbrar a extração de conhecimento útil por meio de um processo próprio denominado Descoberta de Conhecimeno em Bases de Dados e como passo deste, mineraçâo de dados. Técnicas de Visualização podem ser utilizadas neste contexto, fornecendo representações visuais e mecanismos de interação que exploram características próprias do ser humano para apoiar este processo. Da uniāo destes dois aspectos. mineração de dados e Visualização, surge um novo tema de estudo que vem recebendo destaque no meio acadèmico: Mineraçăo lisisul de Dados. Dependendo do dominio em que esta é aplicada, diversas particularidades sobressaem. Dados de domínio geográfico apresentam caracteristicas espaciais e temporais que tornam a descoberta de conhecimento dificil de ser realizada e the conferem propriedades únicas diante dos demais domínios. O presente trabalho aborda o uso de técnicas de Visualização em atividades de exploraçào c análise de dados com atributos espaciais e temporais, enfatizando as técnicas de interação inerentes à Visualização. O trabalho tem enfoque na aplicação de técnicas de visualização e interação para promover o tratamento dos dados contidos numa volumosa base de dados pluvionétricos. 


\begin{abstract}
Current technology allows the collection, generation and storage of vast amounts of data resulting in a huge quantity of potentially useful information. Effective knowledge may be extracted from such data with a process generally known as Knowledge lixtraction from Databases, of which data mining is one of the steps. Information Visualization techniques can produce visual representations from data with which users can interact using appropriate techniques. Such interactive representations may be tuned to exploit human visual and perceptual abilities to enhance data understanding and assist knowledge extraction processes. Visual Data Mining is a topic which originated from the integration of both approaches, data mining and data visualization, and has been deserving considerable attention from researchers from both areas. Particular issues arise from its application in different domains. Geographic data has temporal and spatial characteristics that pose particular problems to knowledge discovery processes and give it certain unique characteristics when compared to other domains. This work tackles the use of Visualization techniques to assist data exploration and analysis tasks, particularly handling data with spatial and temporal attributes and paying special attention to providing suitable interaction techniques. Focus has been on the application of visualization and interaction techniques to support treatment of a great database of precipitation data, which is part of a set of steps involved in a climate classification problem.
\end{abstract}




\section{CAPÍtULO 1}

\section{Introdução}

O constante e crescente avanço tecnológico observado na atualidade possibilita gerar, coletar e armazenar grandes volumes de dados em diversas áreas da atividade humana. Estima-se que são gerados aproximadamente 1 hexabve (1 milhăo de terahyles) de dados por ano em todo o mundo, e isto quer dizer que, no período entre 2001 a 2004, serão gerados mais dados do que em toda a história da humanidade até entào [Kei 2001]. Grande parte destes dados cstá armazenada em bancos de dados que também crescem rapidamente $\mathrm{cm}$ númcro c tamanho. É imediato vislumbrar a oportunidade representada pela análise efetiva destes dados; caso contrário, compreende-se que essas bases constituirào meros depósitos de dados. F́ assim que diversos pesquisadores têm se concentrado na criaçāo de novas técnicas de análise de dados, bem como na adaptação de técnicas tradicionais para aumentar a capacidade humana de manipulá-los adequadamente

Notoriamente, características como o grande volume de itens de dados, sua alfor dimensionalidade c a presença de estruturas complexas [Che 1996; Kei 1996; Fay 1998] introduzem dificuldades adicionais ao já dificil processo de extrair informação e conhecimento embutidos cm conjuntos de dados.

São chamadas de técnicas de mineraçồo de dados (data miming - DM) aquelas que fornecem suporte para descobrir, de forma automática ou semi-automática, informações uteis ocultas em enormes conjuntos de dados, que podem ser essenciais para suporte à decisão [Kei 
1994; Fay 1998]. Objetivos comuns às diferentes aplicações de mineração de dados incluem a detecção, interpretação e previsão de padrões quantitativos ou qualitativos presentes nos dados. Desta forma, mineração muitas vezes é utilizada como sinònimo de Descoherta de Conhecimento em Bases de Dados (Knowledge Discovery in Databases - KDD). Todavia KDD é aceita e entendida como um processo mais geral em que a mineração de dados constituise como um de seus passos, como aprescntado por Fayyad et al. [Fay 1996; Fay 1998]. Neste contexto, recursos para a exploração visual de bases de dados podem oferecer uma ferramenta importante, e muitas técnicas de visualização de dados multidimensionais têm sido desenvolvidas c até mesmo adaptadas de técnicas originais de outras disciplinas

Visualizaçuo se caracteriza como uma disciplina que reúne métodos que permitem interagir com representações visuais de dados, exibidas como imagens, para ganhar entendimento e introspeç̧ão sobre os dados c os fenômenos que eles representam [Sch 1998]. Da união de técnicas de Visualização e de mineração e análise de dados surge um novo paradigma para a exploração e descoberta, tratado na literatura como Mineraçăo Visual de Dacks (Visual Data Mining - - VDM). Em VDM, procura-se unir o visual e o analítico, acoplando técnicas da Visualização a técnicas de mineração de dados, com o objetivo de aprimorar o processo de descoberta de conhecimento [Hof 1997; Won 1999]. Atentando-se que o ser humano possui capacidades únicas para a percepção de padrões, exceções, tendências e relacionamentos, e cognição [Roh 1999; Won 1999; Mac 2000], principalmente no que se refere à visão, a visualização pode mostrar-se como relevante recurso para este processo. Salienta-se a importància da inclusão do ser humano no processo de mineração de dados, já que seu sistema de percepção processa diferentes tipos de dado de forma bastante flexivel, analisa eventos complexos com rapidez, reconhece automaticamente propriedades năo usuais e, ao mesmo tempo, desconsidera propriedades sem interesse. Adicionalmente, a partir de descrições vagas e informação imprecisa, o ser humano é capaz de traçar conclusòes utilizando seu conhecimento geral [Kei 1996]

Visto que a integração de tais habilidades da mente humana com a capacidade de processamento dos computadores possibilita a criaçào de um ambiente de descoberta poderoso [Won 1999], a interaçiò exerce papel fundamental nesta integraçào, mesmo porque é parte relevante da própria visualização. Soma-se a isto o fato de que processos tipicos de análise de 
dados requerem um volume considerável de entradas, por parte do usuário, para guiar o processo de descoberta c análise

Por ser apresentada como uma área de pesquisa relativamente recente, embora haja concentração no estudo de suas técnicas e na caracterização e definição de suas funcionalidades, devem ser considerados fatores também importantes como as peculiaridades pertinentes a cada domínio de aplicação e as particularidades dos usuários.

A descoberta de conhecimento em dominio geográfico apresenta dificuldades e caracteristicas que a tornam única quando comparada às demais áreas do conhecimento [Gah 20011. A natureza espacial dos dados geográficos, bem como sua associação a propriedades temporais, confere complexidade à identificação de relações e padrões nos dados. Como o entendimento conceitual deste dominio ainda concentra-se em um especialista, a Visualizaçăo mostra-se potencialmente vantajosa, visto que pode corroborar a integração do usuário ao contexto

Um trabalho de doutorado em andamento no âmbito do Grupo de Computação Grática c Processamento de Imagens ( $C G \& \mathbf{P l})$ do Instituto de Ciências Matemáticas e de Computaçâo Universidade de São Paulo (ICMC-USP), visa investigar a aplicação de técnicas de Visualização no processo de extração de conhecimento, concentrando-se em conjuntos de dados espaciais [Shi 2001; Shi 2001a]. Liste trabalho de mestrado integrou-se a esse projeto de doutorado, com o objetivo de propor formas de visualização do conteúdo de uma base de dados pluviométricos, enfatizando aspectos interativos, para promover o tratamento das informações que, num estágio mais avançado, permitirá a percepção de padrões nos dados e agrupamentos de clementos com características semelhantes. O resultado do estudo de técnicas e de sistemas de exploração visual de dados foi implementado em um aplicativo que apóia visualmente procedimentos comuns à exploração dos referidos dados num processo de classificação climática.

Este texto expõc, inicialmente, uma análise dos conceitos e terminologias envolvidos em Visualização, especialmente, Visualização de Informação e VDM. Tais assuntos são abordados no capitulo 2, juntamente a um levantamento de técnicas significativamente interessantes para excmplificar a categorizaçâo de técnicas para visualizaçào exploratória de dados multidimensionais. O cupímlo 3 apresenta os mecanismos de interação referentes à Visualização, destacando-se aspectos de interação humana, as tarefas essenciais e técnicas populares de 
interação, alem da caracterização de aspectos relevantes para o projeto destas técnicas de interação. No capitulo t é apresentado um estudo das particularidades envolvidas no processo de exploração de dados e descoberta de conhecimento no domínio de dados geográficos, e de como os assuntos tratados nos capitulos anteriores podem ser aplicados neste domínio. Esse capítulo apresenta também o desenvolvimento deste trabalho de mestrado, descrevendo os passos tomados para a implementaçào do aplicativo para o tratamento da base de dados pluviométricos, e, numa visão geral, o projeto lif́folis, ambiente no qual tal aplicativo está inserido. Por fim, o copinulo 5 traz as conclusōes alcançadas com o desenvolvimento deste trabalho de mestrado. 


\section{CAPÍTULO 2}

\section{Visualização de Informação e}

\section{Mineração Visual de Dados}

Mineração Visual de Dados é um tema que vem recebendo destaque no meio acadêmico tanto pelas expectativas atribuidas aos promissores benelicios oriundos de suas funcionalidades, quanto pelas difículdades características do processo, cujas técnicas se propōem a tratar. Unindo Análise Exploratoria Visual, uma das vertentes da Visualização de Informação, e Mineração de Dados, VDM objetiva auxiliar o processo de aquisição de conhecimento utilizando-se do representações gráficas para explorar e/ou analisar grandes bases de dados. Desta forma, envolve conceitos e termos referentes a estas duas áreas

Este capitulo apresenta os principais aspectos envolvidos com ambos os temas, Visualização de Informação e Mineração de Dados, nas seçòes 2.1 e 2.2, respectivamente. A seção 2.1 subdivide-se em seções que descrevem dois aspectos centrais da Visualização de Informaçào: os conjuntos de dados e as técnicas de visualizaçào propriamente ditas A seçiòn 2.3 encerra este capitulo analisando como pesquisadores vèm empenhando esforços na tentativa de integrar os dois temas descritos nas seções anteriores 


\subsection{Visualização de Informação}

Representações gráficas de toda sorte tem sido usadas como instrumento de comunicação desde os primórdios da humanidade. Com o advento da ciência as representações gráficas passam a embutir significado cada vez mais regido por convençòes, a exemplo de gráficos matemáticos e cartas cartográficas. Normalmente, estas representaçōes têm como propósito comunicar uma idéia que já existe. Todavia, tendo como propósito aproveitar as especiais características da percepção visual humana para a resolução de problemas lógicos, uma segunda abordagem possivel consiste em utilizar as representações gráficas para criar ou descobrir a própria idéia.

Dentre estas duas abordagens, esta última tem sofrido de forma mais impactante as inovaçôes geradas pela evoluçâo dos computadores, os quais proporcionam meios cada vez. mais eficientes de melhorar a geração das imagens destas representaçōes e de aumentar a interatividade em tempo-real, tendo, em paralelo, custo cada vez mais baixo. Este meio permite descriçòes grálicas que automaticamente reúnem milhares de objetos de dados em uma figura. revelando padròes ocultos

Entende-se por Visualização o processo de mapeamento de dados e informaçōes em um formato gráfico, baseando-se em representaçöes visuais e em mecanismos de interação, fazzendo uso de suporte computacional e objetivando a ampliação da cognição'. Card et al. [Car 1999] exprimem com concisão esta idéia: "o propósito da visualização é a percepção [insight], não figuras", sendo que os principais objetivos desta percepção são a descoberta, a tomada de decisôes e o entendimento

As etapas essenciais a serem consideradas no uso de determinada técnica de Visualização, ou no desenvolvimento de novas técnicas, podem ser identificadas por meio de modelos de referência de Visualização. Uma descrição de Visualização como uma sequência (figura 2.I) de mapeamentos "ajustáveis" de dados ${ }^{2}$ para uma representação visual é dada por Card et al. [Car 1999]. Ela possibilita a interaçăo do usuário com o espaço de informação, a fim de alcançar o que foi chamado de cristalizaçào do conhecimento.

\footnotetext{
Neste contexto. cogniçĭo significa aguisiçâo ou uso de conlıecimento

O modelo assume que os dados estarăo na forma de tabelas de registros.
} 


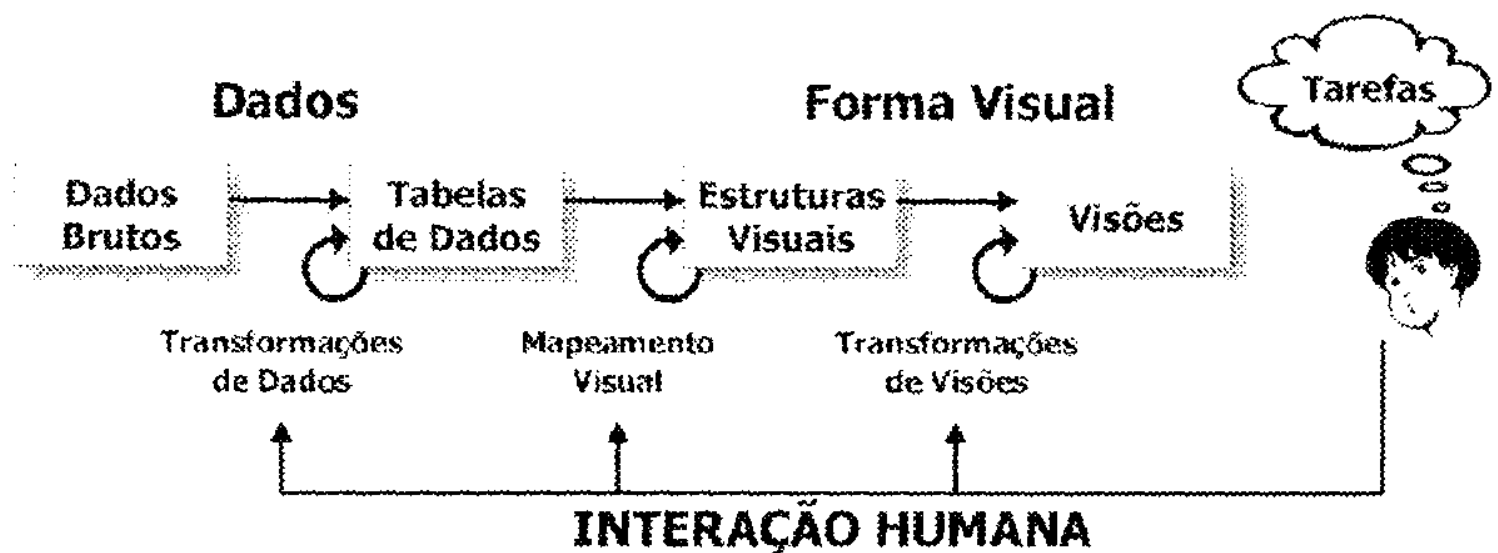

Figura 2.1 Hodelo de Referencia de lisualizaçà de C.ard el al. / 'ar 1999)

Muitas áreas de atuação humana estão interessadas na criação de artefatos visuais, c muilas destas atividades foram beneficiadas com a produção de visualizaçòes. Particularmente, a área científica vem se beneficiando do poder computacional e das visualizações sofisticadas alcançadas com ele, na chamada "Visualização Cientifica". Fsta classe de Visualização se baseia em dados produzidos por fenômenos "naturais", do mundo físico, ainda que esta não tenha sido necessariamente a sua concepçào original. O computador $\dot{\mathfrak{e}}$, então, usado para tornar visível alguma propriedade de objetos de interesse. Enquanto estas visualizaçôes podem derivar de abstraçóes do espaço físico, a inlormação é, todavia, inerentemente geométrica. Por exemplo, para representar as concentraçōes e a dinâmica de massas de ar na atmosfera pode-sc fazer uso de abstraçòes, mas elas säo bascadas num espaço fisico

Não obstante, há uma grande quantidade de informação não-tisica no mundo contemporâneo, tais como coleçòes de documentos e dados financeiros, que também demandam meios que proporcionem cognição. A diferença sobresselente está na total inexistència de um mapeamento espacial obvio, resultando num problema ainda maior do que o de tornar visíveis as propriedades do objeto de interesse: o de como mapear abstrações não-espaciais cm uma representação visual efetiva. $O$ esforço de estender a visualização para a área da abstração de fenòmenos não-fisicos recebe o nome de "Visualização de Informação", e tem sido motivado não só pelo grande acúmulo de informações na atualidade. mas também pela complexidade intrinseca ao processo de se alcançar um mapeamento visual eficaz 
Outra razào para a distinçào entre estas duas formas de Visualização, Visualização Cientifica e Visualização de Informação, diz respeito à própria evolução que as áreas têm apresentado [Car 1909]. Visualização de Informação nota-se originada pelo emprego de representações visuais para representar dados abstratos em diversas comunidades de pesquisa (abordada por estudos semiológicos, aplicada a dados estatisticos, etc.). e só mais tarde percebeu-se a convergencia para o uso de poder computacional nas representaçoes. Por sua vez, a Visualização Científica tem sua origem notoriamente ligada às ciências que abordam o espaço fisico (física, engenharia, elc.). A distinção entre estas vertentes da Visualização é aceita por grande parte dos autores encontrados na literatura de Visualizaçăo.

Uma ultima observação quanto ao papel da Visualização para a obtenção de cognição, refere-se ao fato dela fornecer uma faixa maior de elementos mais facilmente distinguiveis, quando comparada aos outros sentidos de percepção humana. Limbora, de forma mais ampla, a representação de dados abstratos possa ser realizada por meio de sistemas que abordem múltiplas formas de perceptibilidade, tais como sonificaçäo e ratilidade, é de senso comum que a Visualização seja apontada como um ponto inicial nesta discussão [Car 1999; Shn 1996].

\subsubsection{Conjuntos de Dados}

o elemento central no modelo de referência de Visualização da figura 2.I, é o mapeamento visual das tabelas de dados para a estrutura visual, servindo como intermediário entre as etapas que envolvem tratamento de dados e as etapas que lidam com a forma visual. As tabelas de dados baseiam-se em relações matemáticas, enquanto as estruturas visuais são baseadas nas propriedades gráficas efetivamente processadas pela visão humana. A terminologia encontrada na literatura, no que se refere a dados, não é consistente, já que vem sendo criada por muitas disciplinas (estatística, engenharia, cièncias de compulação, etc.) [Won 1997].

Card et. al. [Car 1999] propöem uma terminologia para dados, a fim de uniformizar o tratamento dos termos envolvidos neste assunto, ao passo que ressaltam a tentativa de apresentar um equilibrio entre formalidade c clareza. Segundo eles, a primeira relaciona-se com a precisăo (a qual é fator crítico quando se discute o assunto "dados"), porque diferenças sutis nos dados 
podem ocasionar grandes diferenças na escolha da visualização. Todavia, a clareza é importante. principalmente quando se está começando a ter conhecimento sobre as técnicas de Visualização

\subsubsection{Tabelas de Dados}

A aplicação de relações ou conjuntos de relações estruturadas para tornar mais fäcil o mapeamento para representações visuais é a estratégia mais comum para o tratamento de dados brutos (que apresentam um formato qualquer). Matematicamente, uma relação é um conjunto de tuplas:

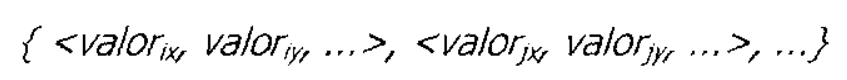

A representação puramente matemática omite descrições de informação que são importantes para a Visualização. Na terminologia de Card et al., as tabelas de dados combinam relações com metadados, os quais descrevem estas relações (similar às tabelas de dados de bancos de dados relacionais):

Tabela 2.1 Descricáo de umatabela de dudes / /

\begin{tabular}{|c|c|c|c|c|}
\hline & Caso $_{i}$ & $\mathrm{Caso}_{\mathrm{j}}$ & $\mathrm{Caso}_{k}$ & \\
\hline Variável ${ }_{x}$ & Valor $_{i x}$ & valor $_{j x}$ & valor $_{k x}$ & $\ldots$ \\
\hline Variável $_{y}$ & valor $_{\text {iy }}$ & valor $_{\text {iy }}$ & valor $_{\mathrm{ky}}$ & $\therefore$ \\
\hline$\ldots$ & $\ldots$ & $\ldots$ & $\ldots$ & $\ldots$ \\
\hline
\end{tabular}

Assim, a distribuição dos valores é feita por meio de uma matriz de $\operatorname{casos}^{3}$ e variáveis ${ }^{4}$, como representado na kabela 2.1, em que os casos são dispostos em colunas e as variáveis dispostas em linhas 5 . Normalmente, as tabelas de dados são formadas por casos independentes, ou seja, cada um deles representa uma única relação. Quando existe dependência entre casos, como nas relações pai/filho de uma árvore, eles podem ser reorganizados em um conjunto de casos independentes, de forma a obter um "flat file", numa técnica propria conhecida como "desnormalização" [Wit 2000]. Basicamente, esta técnica consiste na adição de um ou mais

F. encontrado na literatura lambém com os nomes instancias. registros e itens de dados

${ }^{4}$ É encontrada na literatura também cont os nomes atributos e dimensóes. dentre outros.

5 A cscolla de qual termo recebe orientaçào horizontal ou vertical varia na literatura 
atributos que registra $(\mathrm{m})$ o(s) relacionamento(s) de interesse entre os casos, o que sempre pode ser realizado com qualquer conjunto (finito) de relaçòes (finitas). IJma outra forma de organizar essas relações hierárquicas é descrevê-las por meio de arquivos estruturados e, então, visualizálas com técnicas especificas para esse tipo de dados (hierárquicos)

Wong e Bergeron [Won 1997$]$ utilizam os termos "multidimensional" e "multivariada" para referenciar a dimensionalidade das variáveis independentes e das variáveis dependentes, respectivamente, de um conjunto de dados. Todavia, na prática, esses termos são usados indistintamente para indicar os atributos (dimensões) associados a cada item de dados

Embora o volume de casos normalmente seja muito maior do que o número de variáveis, uma caracteristica cada vez mais comum nas bases de dados é a presença de um grande número de variáveis, ou dimensões (alta dimensionalidade). Por exemplo, para empresas terem Vantagem Competitiva sobre seus concorrentes, um fator diferencial é a posse de informação valiosa sobre clientes; na tentativa de obter esta informação, o que normalmente ocorre é a observação de muitos paràmetros no processo de coleta dos dados [Kei 2001]. Conseqüentemente, o que se tem são muitos atributos para a descrição da ocorrência dos casos. Como o numero de atributos é direlamente proporcional à dificuldade de analisar os dados, técnicas de redução de dimensionalidade configuram ferramentas importantes para promover uma maximização dos resultados da análise. Entre os exemplos de técnicas de redução de dimensionalidade estâo a "Análise de Componentes Principais" (técnica estatística) e a Fastmap [Fal 1995], que buscam identificar os atributos mais relevantes.

\subsubsection{Caracterização dos Dados}

Num processo de visualização, a determinação de qual técnica deve ser empregada em uma determinada aplicação ou situação merece bastante atenção. Uma caracterização dos dados seria a consideração inicial na escolha de uma técnica de visualização. Na tentativa de enquadramento de aplicaçòes em técnicas, alguns autores propõem certas classificações. Shneiderman [Shn 1996], por exemplo, classificou as técnicas segundo os tipos de dados e as tarefas a serem realizadas pelo usuário. Segundo ele, os dados podem ser: temporais, unidimensionais (ID), bidimensionais (2D), tridimensionais (3D), multidimensionais ( $\mathrm{DD}$ ), dirigidas à visualização de hierarquias e de relacionamentos (grafos). Ireitas e Wagner [Fre 
19957 apresentam uma proposta de caracterização de dados baseada em critérios como: classe (tipo) de informação, tipos de valores, e natureza e dimensão do domínio (vide resumo na tahela 2.2).

Tahela 2.2 Sumario da caracterizago de dados exemplos de dominios diferentes llye 2001/

\begin{tabular}{|c|c|c|}
\hline Critério & Classe * & Exemplo \\
\hline \multirow{5}{*}{ Classe de Informação } & Categoria & Gênero \\
\hline & Escalar & Temperatura \\
\hline & Vetorial & \multirow{2}{*}{$\begin{array}{l}\text { Grandezas físicas associadas à } \\
\text { dinâmica de fluidos }\end{array}$} \\
\hline & Tensorial & \\
\hline & Relacionamento & Link num hiperdocumento \\
\hline \multirow{3}{*}{ Tipo de Valores } & Alfanumérico & Gênero \\
\hline & Numérico (inteiro, real) & Temperatura \\
\hline & Simbólico & Link num hiperdocumento \\
\hline \multirow{3}{*}{ Natureza do Domínio } & Discreto & Marcas de automóveis \\
\hline & Contínuo & Superficie de um terreno \\
\hline & Contínuo-discretizado & Anos (tempo discretizado) \\
\hline \multirow{4}{*}{ Dimensão do Domínio } & 10 & $\begin{array}{l}\text { Fenômeno ocorrendo no } \\
\text { tempo }\end{array}$ \\
\hline & $2 \mathrm{D}$ & Superfície de um terreno \\
\hline & 30 & Volume de dados médicos \\
\hline & $n-D$ & Dados de uma população \\
\hline
\end{tabular}

De forma geral, os valores assumidos pelas variáveis podem ser classificados nos formatos básicos nominal e quantitativo. O primeiro apresenta valores claramente distintos, discretos e enumeraveis. O segundo representa valores numéricos, continuos, sobre os quais podem ser aplicadas operaçôes aritméticas. Os dados nominais podem ser categêricos, em que os valores não têm uma relação de ordem (ex.: "verde", "vermelho", azul"; "GM", "riat", "Ford"), ou ordinais, apresentando relação de ordem (ex.: "segunda", "terça", "quarta"; "básico", "intermediário", "avançado"). Por sua vez, os dados quantitativos podem ser inrevalos, nos quais os valores são ordenados e medidos em unidades fixas e iguais (ex: : ano); podem ser uma razão, em que os valores são ordenados em um escala de medidas na qual é definido inerentemente um valor de referência zero (ex.: distancias); e alguns sub-tiposs particulares, tais como datas, horas e coordenadas espaciais.

Esta caracterização mais genérica, torna mais compreensivel como podem ocorrer as transformaçòes nos dados apontadas no modelo de referência de Card et al. Por exemplo, uma variável originalmente quantitativa, tal como o tempo de duração de um filme $[0,360]$, pode ter 
seus valores separados em faixas como ("curto", "médio", "longo"), denotando agora um tipo de variavel nominal/ordinal

\subsubsection{Técnicas para Visualização Exploratória de Dados Multidimensionais}

Como visto anteriormente, Visualização de Informação pode ser entendida como uma extensão das aplicações científicas de Visualização, atendendo a uma tendência do uso de gráficos potentes para permitir a interpretação de informações complexas c a dedução de novos conhecimentos, explorando a natural capacidade de percepção do ser humano [Fre 2001]. Aplicando-se em inumeras atividades profissionais, acadêmicas e de pesquisa, Visualização de Informação denota o conjunto de técnicas usadas para mapear graficamente informações abstratas multidimensionais - de natureza não gráfica e não necessariamente geradas por um fenômeno fisico - armazenadas em grandes bases de dados [Kei 1996]. Ainda assim, encontrar formas de representação de grandes quantidades de dados multidimensionais, centradas no ser humano, isto é, capazes de efetivamente auxiliar os usuários no processo interativo de análise e interpretação [Kei 1994], permanece um desafio

Antes mesmo do uso de computadores para criar visualizaçōes, a visualização de dados de duas ou três dimensões com alguma semântica inerente, já era realizada, e suas técnicas têm sido usadas por muitos anos, como bem ilustrado por Tufte [Tuf 1983; Tuf 1990]. Quando computadores começaram a ser usados para criar visualizações, também começou o desenvolvimento de muitas técnicas novas, bem cono a extensão de técnicas existentes, para que trabalhem com grandes volumes de dados e permitam interação. Porém, para a maioria dos dados armazenados em base de dados, não há um mapeamento adequado no sistema de coordenadas cartesianas, visto que os dados nào têm uma semântica inerente no espaço bidimensional ou tridimensional. Desta forma, bases de dados relacionais sào consideradas, genericamente, como conjuntos de dados multidimensionais, com os atributos da base de dados correspondendo às dimensões, ou variáveis [Kei 1996].

Keim e Kriegel [Kei 1996] e Wong e Bergeron [Won 1997] enumeram técnicas bem conhecidas para visualização de conjuntos de dados multidimensionais e as descrevem segundo 
critérios diferenciados, ainda que com alguns elementos em comum. Assim, as técnicas de Visualização de Informaçào recebem diferentes taxonomias, variando entre autores. Ainda em [Kei 1996], os autores agruparam as técnicas de exploraçào visual de dados em seis categorias, segundo a abordagem adotada para o mapeamento dos dados em uma representação visual: Projeçoes Geométricas, Orientadas a Pixels, Iconográficas, Hierárquicas, Baseadas em Grafos e Hibridas

Em algumas técnicas, a representação visual reflete diretamente caracteristicas próprias dos dados. Exemplos disto são as técnicas hierárquicas Come Tree [Rob 1991] e TreeMap [Joh 1991], em que a própria natureza dos dados apresenta uma correlação explicita entre niveis e/ou subconjuntos (ex.: estruturas de diretórios em sistemas de arquivos; ligaçăo entre documentos de um site da Web), embora essas técnicas sejam aplicáveis também a dados que nâo apresentam natureza hierárquica. Por outro lado, as técnicas podem justamente apontar relaçõcs que estão implicitas nos dados. As próximas seçoes exemplificam técnicas representativas de cada categoria, como forma de ilustrar as principais caracteristicas de cada grupo. A exceção está na categoria denominada "hibrida", que configura justamente uma mescla de caracteristicas dos outros grupos de técnicas.

\subsubsection{Coordenadas Paralelas: Projeções Geométricas}

Em Projeçôes Gcométricas, o objetivo é identificar projeçôes de interesse em conjuntos de dados multidimensionais. Em particular, uma técnica bastante utilizada denomina-se Coordenadas Paralelas (J'arallel (coordinates). Inicialmente apresentada por Inselberg [Ins 1985] como uma técnica de Geometria Computacional, e posteriormente contextualizada em Visualização de Informação [Weg 1990], Coordenadas Paralelas destaca-se justamente pela perspectiva multidimensional conferida à representação visual. Nela, um espaço de dimensão $k$ é mapeado para um espaço visual bidimensional, usando $k$ eixos eqüidistantes e paralelos a um dos eixos principais ( $x$ ou y). Cada cixo representa uma dimensão do conjunto de dados, sobre o qual é mapeado linearmente, do menor ao maior, o intervalo de valores de dados correspondente. Cada item de dado é exibido como uma linha poligonal que intercepta cada eixo no ponto correspondente ao valor do atributo associado ao eixo. A figura 2.2 apresenta um esquema 
básico de Coordenadas Paralelas e a figura 2.3 exemplifica seu uso por meio da implementaçào cm uma aplicação.

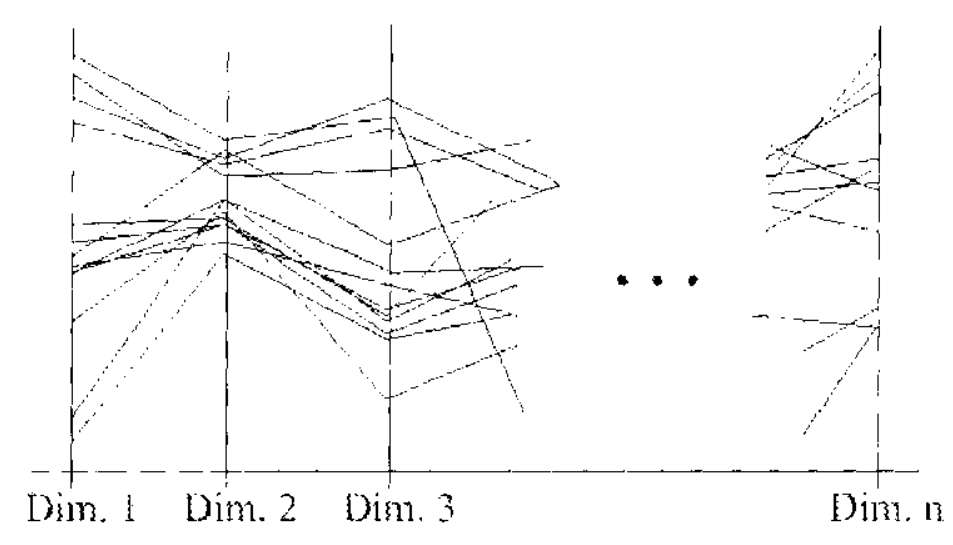

Fizura 2.2 Coordenadas I'aralolas / Kei 1996)

Visto que gera uma representação planar, esta técnica transforma relações multivariadas em padrões bidimensionais [Weg 1996; Ins 1997], os quais permitem que sejam identificadas caracteristicas como diferenças na distribuição de dados e correlaçòes entre atributos. A figura 2.3 ilustra a presença destas caracteristicas: no eixo rotulado "precipitation", vê-sc uma concentração de linhas em um determinado intervalo de valores; correlações entre atributos podem ser identificadas, a exemplo das de formato $X$ (cruzamento de linhas) entre os eixos "sea levet" e "hmmidity $700 \mathrm{hPa}$ " (eixos 3 e 4), denotando a existência de uma correlaçâo inversa entre os atributos correspondentes [Ins 1997].

Embora simples, a técnica Coordenadas Paralelas mostra-se poderosa para identificar diferentes distribuições de dados e dependencia funcional entre atributos. Em contrapartida, apresenta problemas como a sobreposição de linhas para grandes volumes de dados (figura 2.4) e, por conseguinte, uma baixa quantidade de itens de dados que podem ser apresentados simultaneamente sem a ocorrência de congestionamento visual (cerca de 1.000 itens) [Kei 1996] 


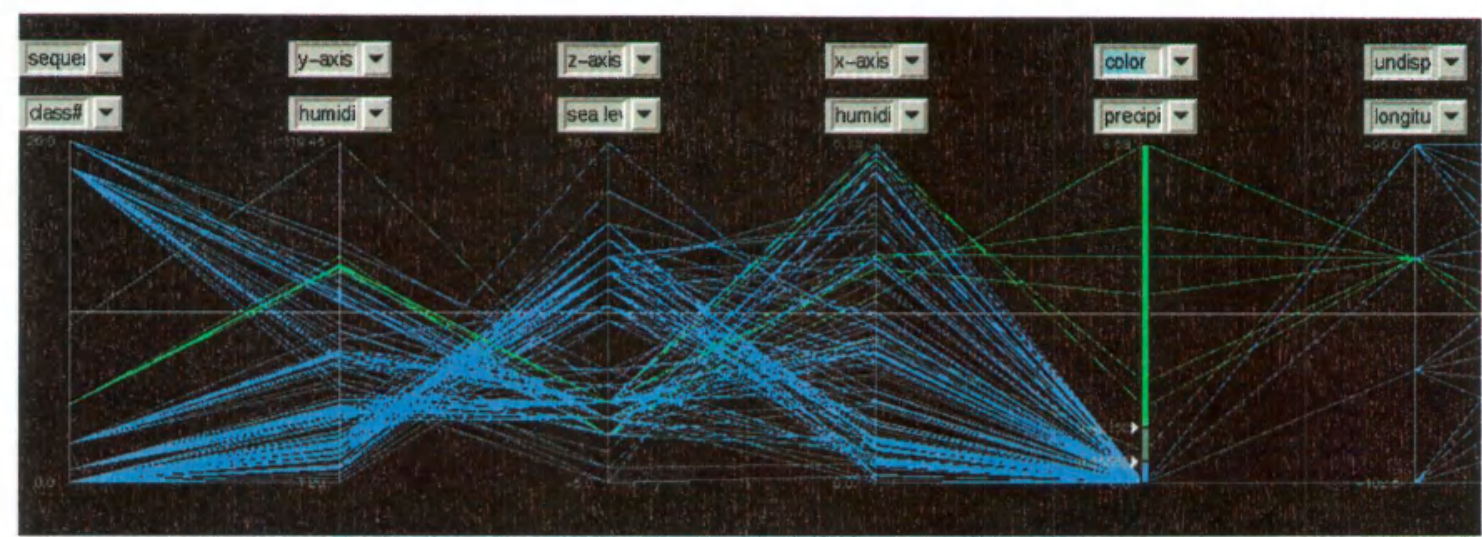

Figura 2.3 - Exemplo de seleção de itens em aplicação com Coordenadas Paralelas [Eds 1999]

No intuito de minimizar este problema ou evitar a ocorrência de outros, espera-se de implementações da técnica algumas funcionalidades. Um exemplo simples é o uso de cores para destacar/selecionar itens de dados, como se pode observar na figura 2.3. Outras funcionalidades desejáveis, incluindo recursos de interação adequados, seriam [Ale 1998]: visibilidade (esconder ou não certos itens ou dimensões); permutação entre dimensões (no caso, eixos); dimensões reescaláveis; zoom (para promover melhor visualização de faixas de conjuntos de dados de maior interesse); informação de dados sob demanda; múltiplas visualizações simultâneas, inclusive com acoplamento de outras técnicas; animações; aplicação de diferentes tipos de operações interativamente e/ou automaticamente (adotando-se, por exemplo, scripts ${ }^{6}$ ); etc.

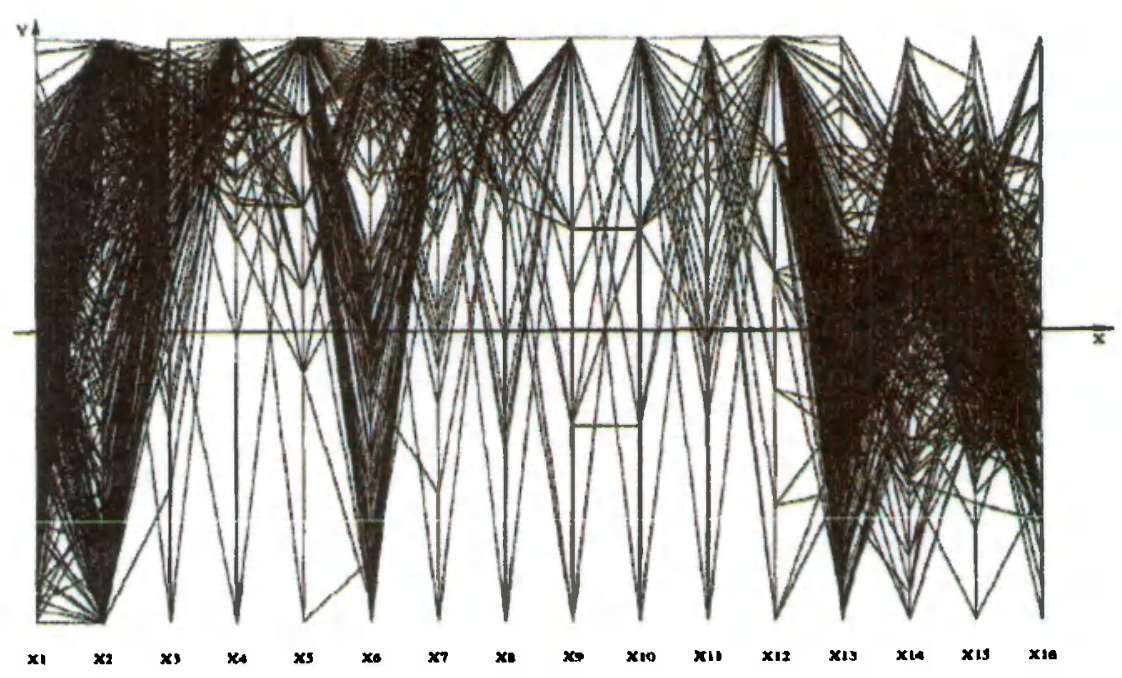

Figura 2.4 - Sobreposição de linhas com apresentação de 473 itens [Ins 1997]

\footnotetext{
${ }^{6}$ Entende-se por script, uma sequência de operações previamente definida, estabelecendo um roteiro de execuções.
} 


\subsubsection{Técnicas Orientadas a Pixels}

Em técnicas baseadas em pixels, a idéia básica consiste em usar um pixel para representar cada valor de atributo, colorindo-o conforme um mapa de cores previamente fixado de acordo com a faixa de possíveis valores do atributo, sendo que cada um destes atributos tem sua representação visual exibida em sub-janelas individuais na visualização [Kei 1994a; Kei 1996]. Para conjuntos de dados com $m$ atributos, a tela é dividida em $m$ janelas, como ilustrado na figura 2.5. Correlação e dependência funcional podem ser detectadas pela análise de regiões correspondentes nas múltiplas janelas [Kei 1996; Kei 2000], a exemplo da correlação observada entre as dimensões MinAngle e RightAngle na figura 2.6.

Se um único atributo for apresentado em uma janela com resolução de 1280x1024, é possível exibir mais de um milhão de valores simultaneamente. E esta é uma das vantagens deste tipo de técnica: a grande quantidade de informação que pode ser exibida simultaneamente.

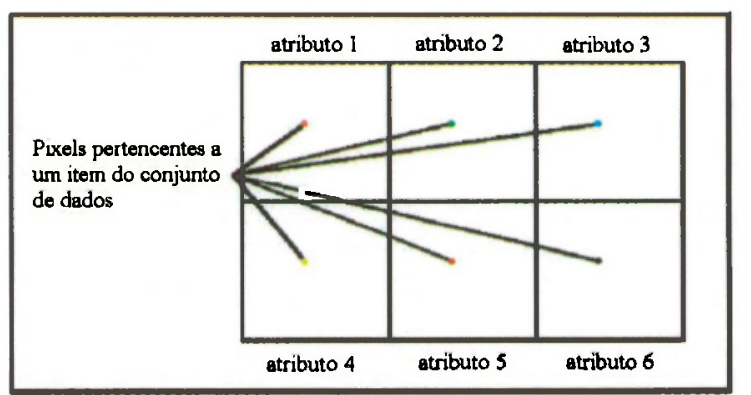

Figura 2.5 - Arranjo de janelas de atributos para casos com seis dimensões [Kei 2000]

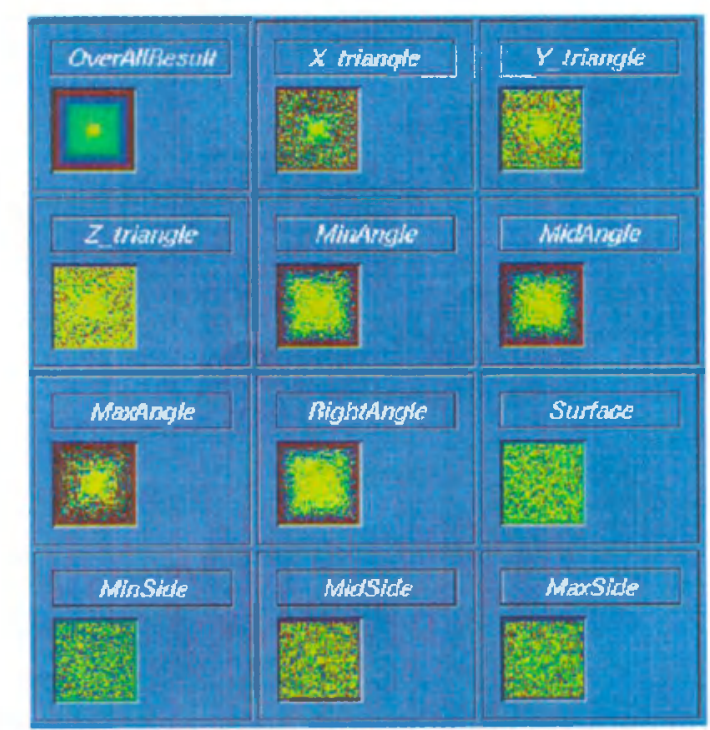

Figura 2.6 - Identificação de correlação e dependências funcionais no VisDB [Kei 1996] 
Para o sucesso na aplicaçăo desse tipo de técnica, alguns aspectos precisam receber atenção [Kei 1994; Kei 1994a; Kei 1996; Kei 2000]:

- Arranjo dos pixels nas jamelas. Visto que cada valor de atributo é representado por um pixel, uma questão fundamental é como "arranjar", ou seja, a forma de distribuir os pixels na tela. De fato, "arranjar" é mapear um conjunto de dados unidimensionais (um atributo) nas duas dimensōes da tela. Tal mapeamento deve ser executado de maneira a fornecer boas propriedades de agrupamento (clustering), e mantendo algum significado semântico, favorecendo a percepção de relações existentes entre os dados. Desta forma, as técnicas recebem diferentes arranjos segundo diferentes propósitos e condições

Quando se quer visualizar um grande conjunto de dados, pode-se utilizar as técnicas ditas "query-imlependent", que ordenam todo o conjunto de dados de acordo com algum(ns) atributo(s) e adotam um preenchimento de tela padrão (esquerda-direita/cima-baixo) para o arranjo dos valores de dados. Tais técnicas são úteis especialmente para dados com uma ordenação natural inerente, como séries temporais, podendo ser visualizados diretamente de uma base de dados. A técnica denominada "Padrōes Recursivos" (figura 2.7) baseia-se num esquema recursivo genérico, que permite que padrões de baixo nivel sejam usados como blocos para construir padrões de mais alto nivel, constituindo uma séric de níveis de padrões. Como exemplo, numa série de dados temporais, em que se executaria diversas coletas diárias de um mesmo parâmetro, primeiramente seria desejável que os -dados de um dia sejam agrupados (arranjados proximamente), depois estes dias formariam semanas, depois meses, anos, e assim sucessivamente.

Quando nào há a referida ordenação e o objetivo é uma exploração interativa de um banco de dados, a visualização poderá ser feita considerando a relaçăo entre os itens de dados e o resultado de uma consulta, utilizando-se as técnicas "query-dependent". Neste caso, além dos itens de dados que satisfazem a consulta, é de interesse mostrar também aqueles que se aproximam da resposta. Ao invés do valor do atributo, o que é exibido é uma distancia calculada entre os dados e o(s) valor(es) estabelecido(s) na consulta, ordenados segundo uma distância global - calculada pela combinação das distâncias de cada atributo, ponderadas por um peso correspondente, que determina a relevância dada ao atributo -...., de modo que os atributos referentes a um item de dado em particular ocupam a mesma posição nas suas respectivas janelas. A disposiçào desta ordenaçâo, ou seja, o arranjo dos itens de dados, centraliza os itens mais relevantes no meio da jancla (itens que atendem integralmente a consulta, têm distância 
global igual a zero), e arranja os itens de dados menos relevantes em direção à parte externa da jancla, seguindo esquemas como espirais simples (figmra 2.8a) ou curvas de Peano-Hilbert (figura 2.8h) ou Morton (figura 2.8c).

Técnicas que utilizam eixos com valores positivos e negativos (figura 2.9), nas quais cada eixo representa um atributo, acrescentam uma informação de direção das distâncias (se o valor do atributo varia para mais ou para menos). Contudo, a quantidade de itens exibidos é menor, e algumas regiōes do gráfico podem ficar $\mathrm{sem}$ preenchimento em virtude da probabilidade da distribuição dos valores de distância, entre positivo e negativo, não ser uniforme

- Mapeamente de cores. O uso de cor permite um número maior de JNDs (.MHs Noticiable lifferences), se comparado à escala de cinzas. As JNDs são as cores percebidas como diferentes e configura-se em grande desafio determinar uma escala de cores que maximize o seu número, e que também seja natural para o usuário. A meta é evitar que relações entre atributos liquem ocultas e que artefatos visuais, que induzem à interpretações equivocadas, sejam introduzidos

- Formate das janelas. Consoante com o formato da tela do computador, o formato retangular para as janelas garante um bom uso de espaço desprezivel. Todavia, o estabelecimento de relaçōes entre atributos pode ser dificultado pela distancia relativa entre as janelas na tela. A forma circular é um formato alternativo ao retangular, adotado na técnica denominada circk segments (figura 2.10a). Cada atributo é, então, visualizado em um segmento do círculo, com valores posicionados a partir do seu centro e seguindo o caminho dado pelas draw limes, ortogonais às halying limes (figura 2.10h), que são as linhas que separam os segmentos.

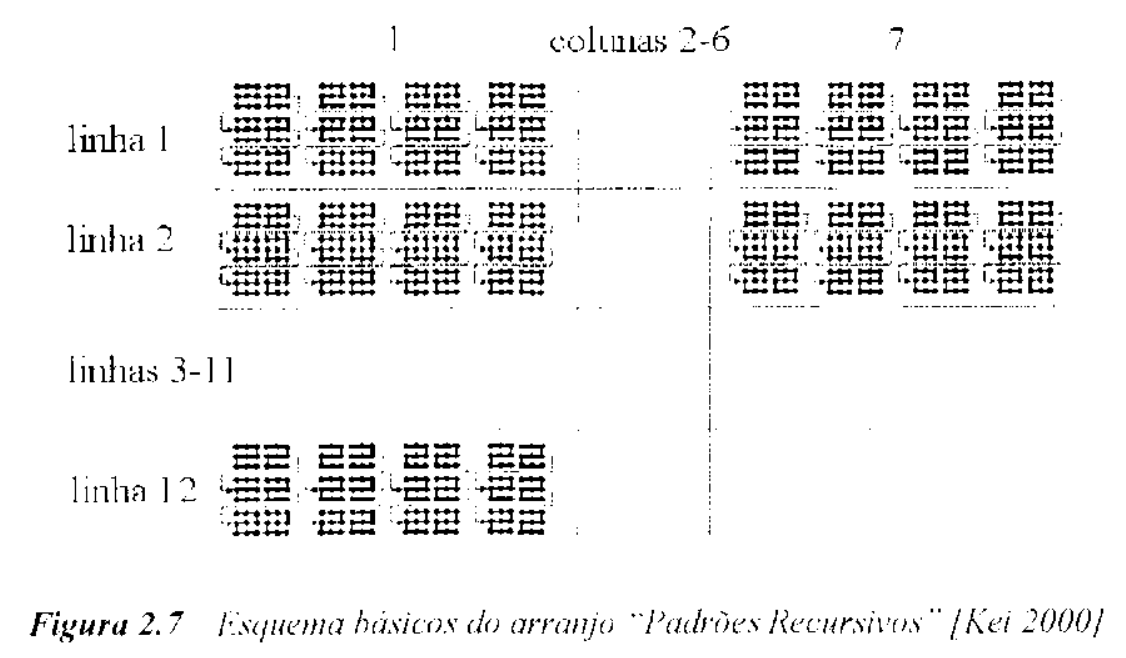




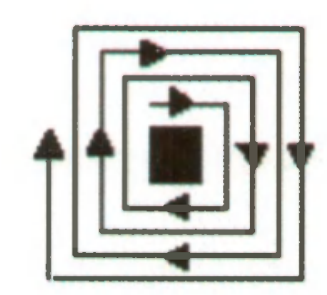

(a)

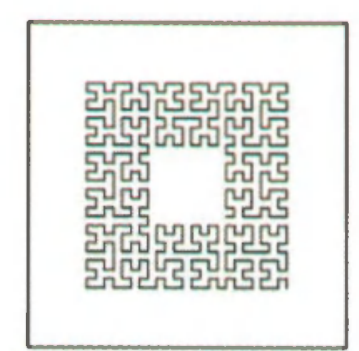

(b)

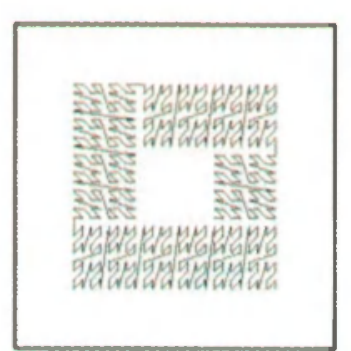

(c)

Figura 2.8 - Esquemas de arranjo de pixels: (a) em espiral simples [Kei 1994] com curvas de (b) Peano-Hilbert e (c) Morton [Kei 1996]
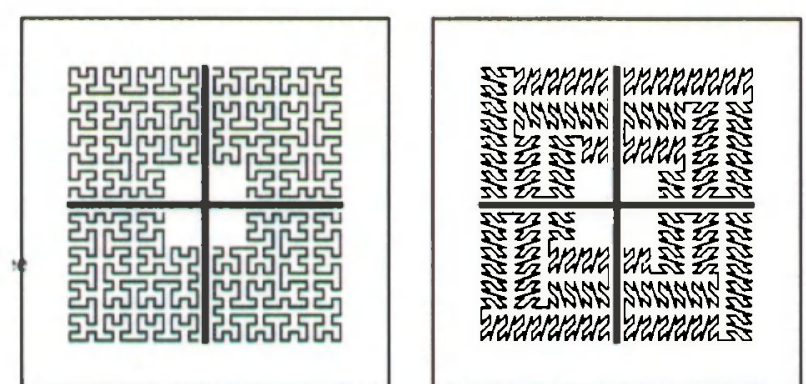

Figura 2.9 - Esquema com eixos para identificar distâncias positivas e negativas [Kei 1996]

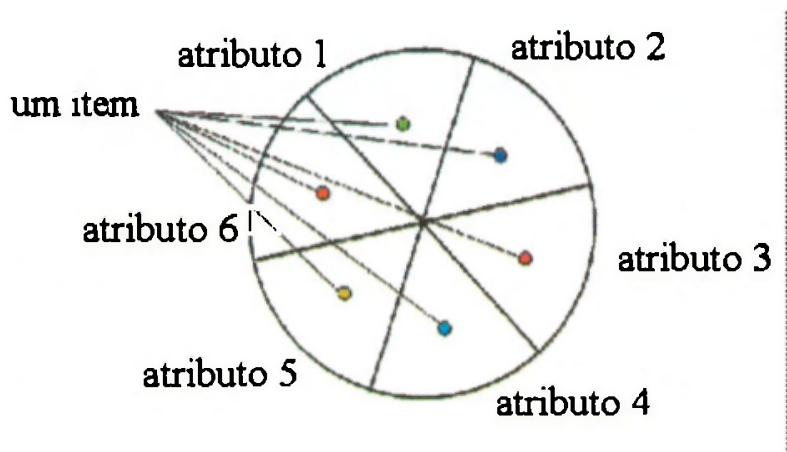

(a)

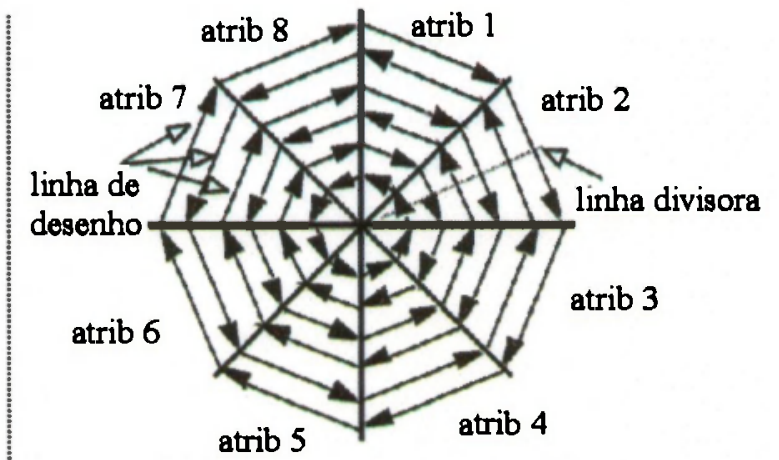

(b)

Figura 2.10 - (a) Formato circular para distribuição dos pixels; (b) Ordenação dos pixels em cada segmento [Kei 2000] 


\subsubsection{Stick Figures: Iconográficas}

As técnicas desta classe têm como principal característica o uso de ícones como forma de mapear os valores dos atributos de um item de dado multidimensional. Cada característica visual do ícone corresponde a um atributo.

Apresentada por Pickett e Grinstein [Pic 1988], a Stick Figures utiliza as duas dimensões da tela para mapear duas dimensões dos dados e as demais dimensões são mapeadas para os ângulos e/ou comprimentos de segmentos de um ícone formado por múltiplos segmentos de reta. A figura 2.lla apresenta um ícone com uma configuração que apresenta 5 variáveis, na qual uma dimensão é mapeada pela inclinação do corpo do ícone, e a orientações das varetas permitem mapear outras quatro dimensões. Uma família de Stick Figures é ilustrada na figura $2.11 \mathrm{~b}$, em que cada uma tem um corpo e 4 segmentos. Outras formas de representar dimensões nestes ícones seria por meio da variação de cores e espessuras das varetas.

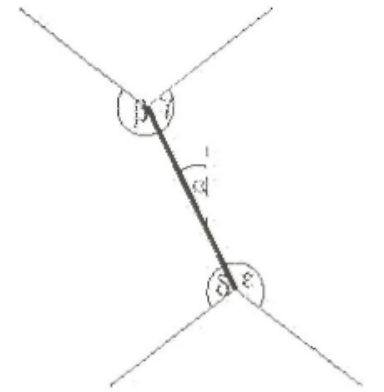

(a)

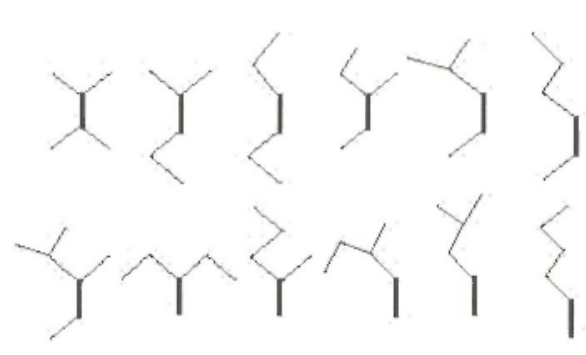

(b)

Figura 2.11 (a) Ícone que representa 5 varióveis; (b) Família de icones [Won 1997]

Quando mapeados na tela, os ícones (um para cada item de dado) formam texturas que variam de acordo com as características dos dados, permitindo a exploração da capacidade humana de perceber e distinguir texturas em imagens complexas [Won 1997], ao passo que os padrões percebidos na imagem podem, então, indicar dependência funcional entre os atributos visualizados [Kei 1996; Won 1997]. A figura 2.12 exibe uma imagem formada pela plotagem de ícones que representam 5 variáveis, exemplificando como estas texturas podem ser formadas. 


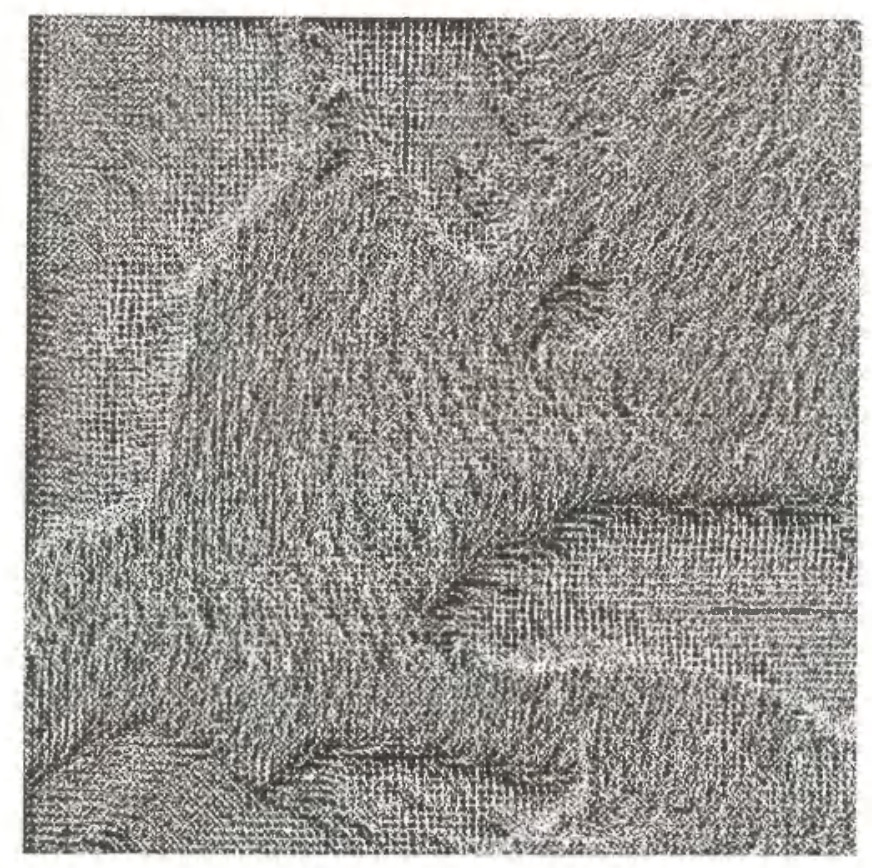

Figura 2.12 Imagem da Região dos Grandes Lagos com ícones de 5 dimensões [Ank 2001]

Dependendo da configuração adotada, esta técnica consegue demonstrar grande quantidade de itens de dados, mas há limitações quanto à quantidade de dimensões que podem ser mapeadas sem que haja detrimento na capacidade de representar características detectáveis dos dados. Outra problemática diz respeito ao fato de que o reconhecimento de um importante padrão na imagem depende da seleção de um mapeamento adequado dos parâmetros dos dados para os parâmetros visuais. O número destes possíveis mapeamentos visuais cresce em ordem fatorial em relação ao número de dimensões mapeadas, podendo tornar-se um grande gargalo no processo de visualização [Won 1997].

\subsubsection{Dimensional Stacking: Hierárquicas}

Nas técnicas hierárquicas de visualização, o espaço n-dimensional dos dados (não necessariamente de natureza hierárquica) é dividido em subespaços que são organizados e exibidos na forma de hierarquia, projetando ou embutindo estes espaços uns dentro dos outros.

Na técnica Dimensional Stacking, o espaço n-dimensional (discreto) é sub-dividido em espaços bidimensionais. Uma das maiores vantagens da Dimensional Stacking, em relação a 
outras técnicas hierárquicas, é que ela não precisa de funções ou regras extras para que se possa plotar os dados na representação [Kei 1996] [Won 1997].

A figura 2.13 um esquema conceitual da Dimensional Stacking com um mapeamento de quatro atributos. A figura 2.14 apresenta um exemplo de sua aplicação no conjunto de dados "Iris Plant Flower", em que: cada cor representa um tipo de flor (com alguns quadrados com classificações mistas); no nível mais externo estão representados os comprimentos das pétalas (eixo-x) e sépalas (eixo-y), determinantes para a classificação da flor; e, no nível mais interno, estão as medidas de altura das mesmas partes da flor, seguindo a mesma orientação dos eixos.

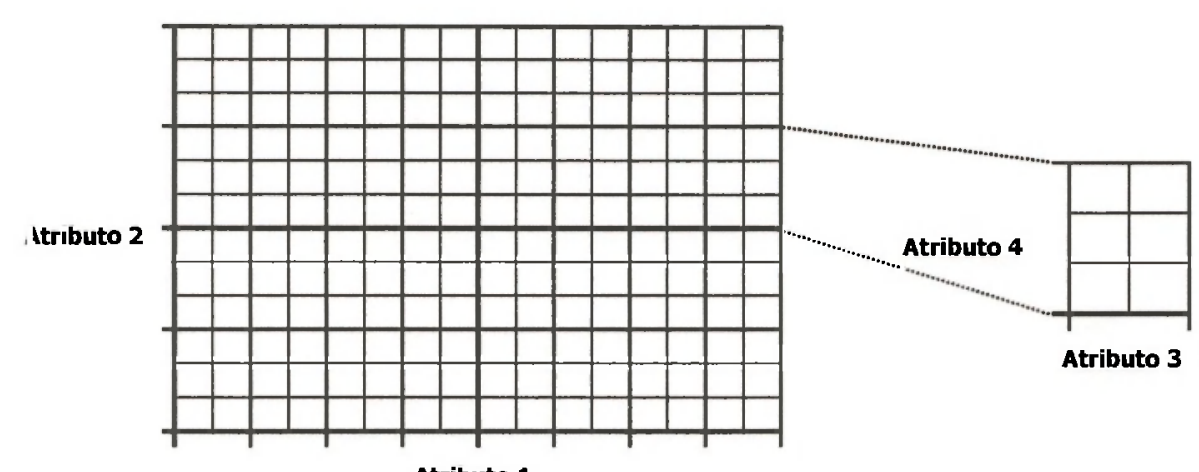

Figura 2.13 - Modelo Conceitual da Técnica Dimensional Stacking [Ank 2001]

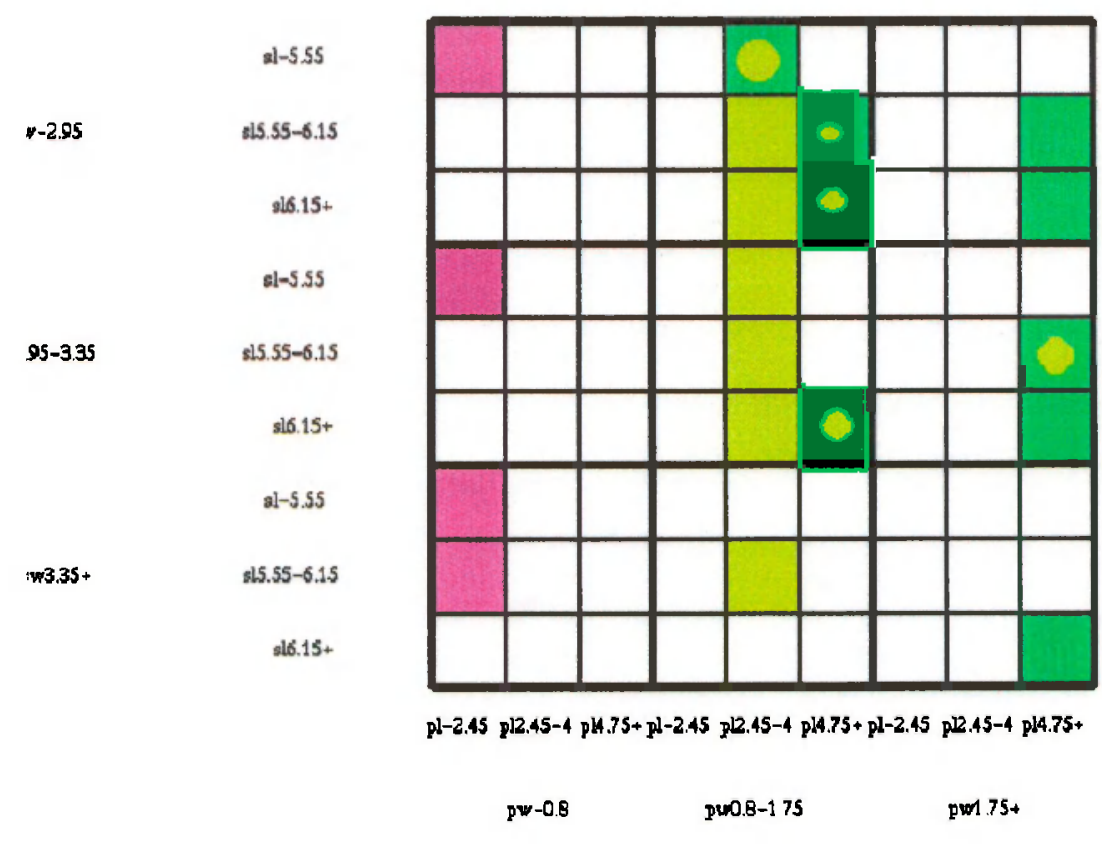

Figura 2.14 - Visualização da Dimensional Stacking aplicada ao conjunto de dados "Iris Flower" [Hof 1999] 
O uso desta técnica é particularmente interessante na deteção de agrupamentos, de pontos com comportamentos discrepantes, e de padrões [Hof 1999]. Todavia, há limitações referentes ao número de atributos a serem visualizadas (acima de 9 torna-se bastante difícil) e ao número de valores distintos que um mesmo atributo pode assumir. Além disso, a eficácia do processo de análise depende diretamente do arranjo hierárquico dos atributos (normalmente, os atributos mais importantes devem estar posicionados mais externamente) e dos critérios de categorização dos dados [Kei 1996; Won 1997; War 1994]. Esta última restrição é uma limitação artificial imposta pelo dispositivo grático, que pode ser minimizada pelo uso de técnicas de interação adequadas

\subsubsection{Técnicas Baseadas em Grafos}

A idéia básica desta categoria é visualizar grafos volumosos usando técnicas que mapeiem as características (direcionado/não-direcionado, cíclico/acíclico, etc.) de um dado grafo, de maneira clara e rápida. As técnicas podem ser sub-divididas segundo a dimensionalidade visual da representação: 2-D ou 3-D

As visualizações geradas dependem de muitos fatores que refletem características inerentes aos grafos, muitas delas refletindo definiçòes próprias da teoria dos grafos. Emm relação ao desenho de grafos 2-D tem-se como propriedades (existentes ou não): a planaridade (não cruzamento de linhas - arestas), a ortogonalidade (somente linhas ortogonais) e a propriedade de distribuição em grade (coordenadas dos vértices são números inteiros). As propriedades estéticas, objetivando a otimização são: número mínimo de cruzamentos, exibição otima de simetria, exibição ótima de agrupamentos, número mínimo de curvas em grafos com poli-linhas, distribuição uniforme dos vértices, e comprimento uniforme das arestas. A figura 2.15 exemplifica o uso das técnicas para representação de grafos em 2-D, adequando-se as propriedades descritas acima ao objetivo (tipo) do grafo. A figura 2.16 apresenta uma representação em 3-D 


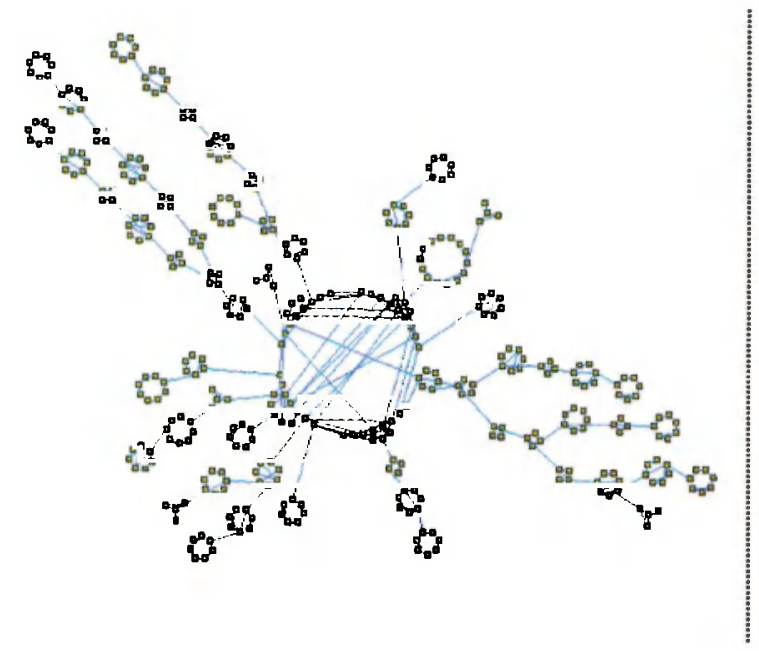

(a)

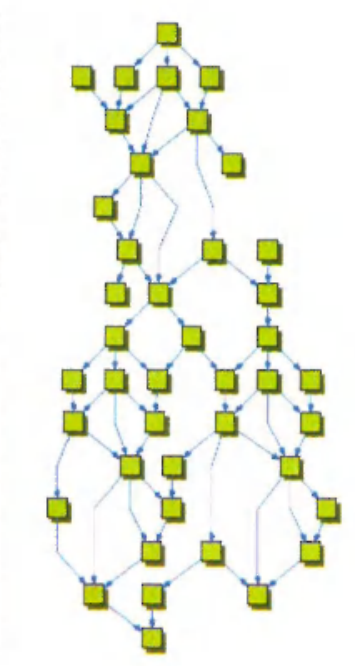

(b)

Figura 2.15 - Exemplos de aplicações de Visualizações 2D de grafos: (a) Grafo otimizado para agrupamentos; (b) Grafo acíclico não-direcionado [Ank 2001]

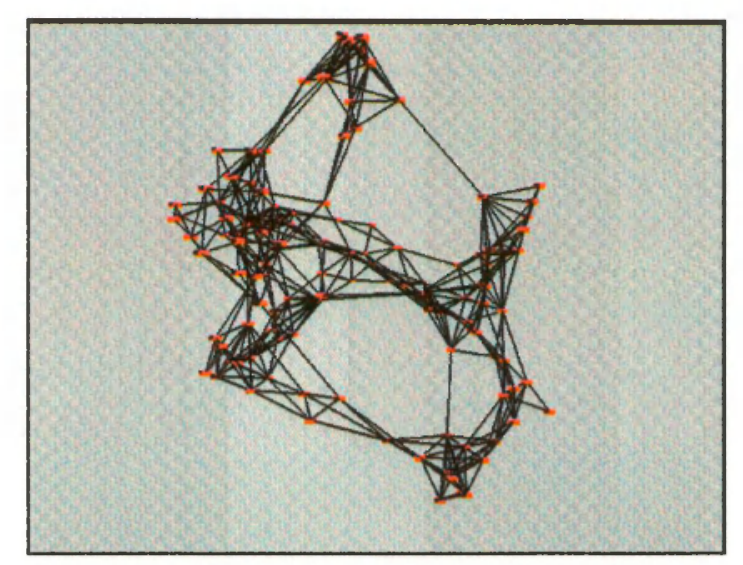

Figura 2.16 - Exemplo de aplicação de Visualização 3D de grafos. Grafo Otimizado para agrupamentos [Ank 2001]

\subsection{Extração de Conhecimento e Mineração de Dados}

Segundo Fayyad et al. [Fay 1996; Fay 1998], KDD é o processo global de identificar nos dados um padrão, um modelo ou uma estrutura válida, nova, potencialmente útil e interpretável. Embora os termos Descoberta de Conhecimento em Bases de Dados (Knowledge Discovery in Databases - KDD) e mineração de dados (data mining - DM) sejam muitas vezes considerados como tendo o mesmo significado, aqueles autores estabelecem uma clara distinção 
entre estes dois conceitos. DM é apontado como um passo particular na seqüência de passos envolvidos no processo de descoberta de conhecimento (figura 2.17). Como estabelecido no primeiro workshop da área, em 1989 ([Pia 1991] apud [Fay 19981), o termo KDD enfatiza que o conhecimento ( $k$ mowledge) é o produto final de um processo de descoberta guiado por dados.

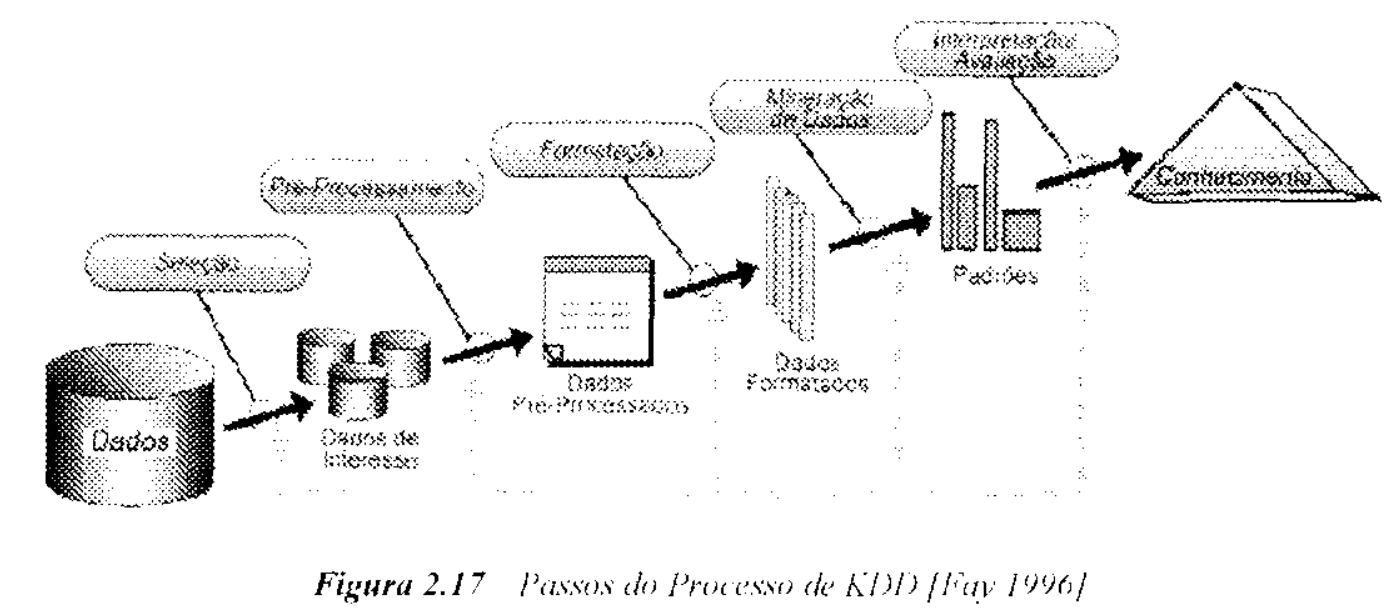

Como principal motivo para a "confusăo" entre os termos KDD e DM, tem-se que a mineração de dados é encarada como o núcleo do processo de KDD, sendo responsável pelo mapeamento dos dados para algum tipo de informação ou modelo. Salienta-se, porém, que mesmo sendo dada grande atenção às técnicas de DM, que podem representar entre $15 \%$ e $25 \%$ do esforço do processo de descoberta [And 1999], figura-se a importância de todos os passos para o sucesso do processo como um todo [Fay 1996].

A validade e o grau de interesse das muitas informaçŏes que podem ser extraidas dos conjuntos de dados são dependentes do domínio de aplicação e do usuário [Fay 1998]. O entendimento deste domínio, o levantamento de conhecimento prévio e a definição precisa do objetivo do usuário são aspectos importantes para a conduçào bem sucedida do processo de descoberta, influenciando, por exemplo, a escolha do método de DM a ser utilizado.

Além da relevância destes aspectos, o processo de descoberta de conhecimento apresenta como características importantes a interatividade e a iteratividade. Estas não requerem, necessariamente. uma sequência pré-definida, e compõem o processo por repetiçòes e experimentações ao longo de diversas etapas, exigindo a tomada de muitas decisôes pelo usuário. A figura 2.17 esquematiza os passos componentes do processo de KDD. Este percurso que 
transforma dados brutos em informação útil, ou conhecimento, caracteriza-se pclas divcrsas formas de processamento aplicados aos dados (passos do KDD) [Fay 1996]: seleção, préprocessamento, transformação, mineração de dados e Interpretação/Avaliação.

Segundo Keim e Kriegel [Kei 1996], o passo denominado mineraçăo de dados envolve a identificação de subconjuntos de um conjunto de dados e de hipóteses sobre os mesmos. É importante salientar que, para que as ferramentas de DM auxiliem a identificação destes dois elementos, pode não ser tào importante especificar formalmente as hipóteses e os contextos. DM pode ser interpretado, assim, como um processo interativo de geração de hipóteses. De forma alternativa, DM, simplificadamente, é o processo de pesquisar e analisar grandes volumes de dados, identificando estruturas regulares e irregulares [Kei 1994], constituindo mais um exercicio indutivo do que hipotético-dedutivo [Han 1998]. Lm função do tipo de informação extraida dos dados, técnicas de DM podem ser agrupadas em [Che 1996]: Regras de Associação, Generalização e Sumarização de Dados, Classificação de Dados, Agrupamento (Clustering) de Dados e Pesquisa por Similaridade Baseada em Padrões.

Resta salientar que DM e KDD são campos interdisciplinares, nos quais avanços significativos requerem o uso de técnicas de diversas áreas [Fay 1998], tais como Visualização, Inteligencia Artificial, Banco de Dados, Fstatistica e Computação de Alto Desempenho, as quais compartilham o objetivo de extração de conhecimento de alto nível a partir de conjuntos volumosos de dados brutos. As abordagens de KDD focalizam na extração de modelos dos dados sem necessariamente uma hipótese formulada a priori, diferentemente de abordagens tradicionais em Estatística. Focalizam, também, conjuntos com maior volume de dados do que os tradicionalmente manipulados pelas técnicas estatísticas. Em conseqüência, uma propriedade importante nos algoritmos é a escalabilidade [Fay 1996; Fay 1998], ou seja, a capacidade de continuar operando correta e adequadamente, à medida que o tamanho dos arquivos de dados aumenta. Questões pertinentes à localização, relação e organização dos dados, e da presença de dados com valores inesperados ou ausência de informação, podem inviabilizar a aplicação direta de métodos estatisticos clássicos [Han 1998], acabando por motivar a criação de novos métodos, bem como o desenvolvimento de técnicas integradas para um DM eficiente e eficaz [Che 1996]. 


\subsection{Integração de Visualização e Mineração de Dados}

Atualmente, as técnicas para visualização de dados são tidas como instrumentos indispensáveis ao processo de DM [Rez 2003]. Visualização tem apresentado função relevante nas tarefas de DM, como Visualização de Modelos de DM e Lixploração Visual dos Dados. Enquanto naquela estào as técnicas visuais para produzir descoberta de conhecimento entendível e interpretável por humanos, nesta estão caracterizadas a exploração interativa de conjunto de dados utilizando-se representaçòes gráficas, sem uma forte dependência de hipóteses e modelos, na tentativa de identificar padrões de interesse não conhecidos previamente

Keim [Kei 2001] define que uma exploração visual dos dados pode ser vista como um processo de geração de hipóteses, segundo o qual a visualização dos dados permite ao usuário adquirir percepçõcs dos dados, podendo provocar o surgimento de novas hipóteses, que, por sua vez, podem também ser confirmadas ou rejeitadas com o uso da exploração visual. Além disso, ele acrescenta que, comparada a técnicas automáticas de mineraçào de dados em estatística e máquinas de aprendizado, a exploração visual dos dados apresenta vantagens excedentes: lida mais facilmente com dados altamente heterogêneos e ruidosos; é intuitiva; e nâo requcrer maior entendimento de complexos algoritmos ou parâmetros matemáticos ou estatísticos.

A integração de técnicas de Mineração de Dados e Visualização é referenciada na literatura como Mineraçió lisual de Inados (Visual Data Mining - VDM) [Gan 1996; Kei 1996; Won 1999]. São utilizados também outros termos, como Discovery Visualization (DV) [Rib 1999] c Análisc Visual [Roh 1999]. Em VDM, o processo de análise é reforçado pelas vantagens oriundas da interação direta com o usuário e da orientação do processo pelo usuário, obtidas com o uso de técnicas de visualização [Kei 2000]. Sobretudo, quando técnicas de DM requerem grande interaçào com o usuário, e esta interação se mostra bastante complexa, técnicas de Visualização podem certamente ser exploradas para dar suporte ao processo de decisão, deixando de caracterizarem-se apenas como técnicas separadas de DM e Visualização, para contigurarem-se em técnicas de VDM [Won 1999].

Segundo Wong, existem, basicamente, duas formas de integrar Visualização e DM [Won 1999]: Acoplamento Forte, em que a Visualização e o processo analítico são integrados em uma única ferramenta, aproveitando os pontos fortes de cada uma das áreas; e Acoplamento Fraco, 
em que técnicas das duas áreas são simplesmente intercaladas, possibilitando um aproveitamento apenas parcial do potencial de cada uma. Com o uso de acoplamento forte, poder-se-ia ter, por exemplo, a tomada de decisões humanas guiadas por representaçôes visuais, no lugar de alguns passos matemáticos executados de forma automática pelo algoritmo que implementa o processo analítico. Algumas avaliações experimentais de acoplamento forte que combinam recursos de Visualização a algoritmos de agrupamento [Hin 1999], mostram que a combinação de técnicas visuais e automáticas melhora consideravelmente a eficiência do processo de DM e estimula um melhor entendimento dos resultados

Como visto na seçăo 2.2, o processo formado pelos passos do KDD apresenta como caracteristica uma grande iteratividade. A interatividade, estaria normalmente restrita aos passos iniciais do processo. Na visào de Ankerst e Keim [Ank 2001], o processo clássico de KDD pode ser estendido para que o usuário possa introduzir seu conhecimento do domínio em todos os passos do processo de KDD, no que foi chamado de "Processo de Descoberta de Conhecimento Centrado no Usuário" (figura 2.18)

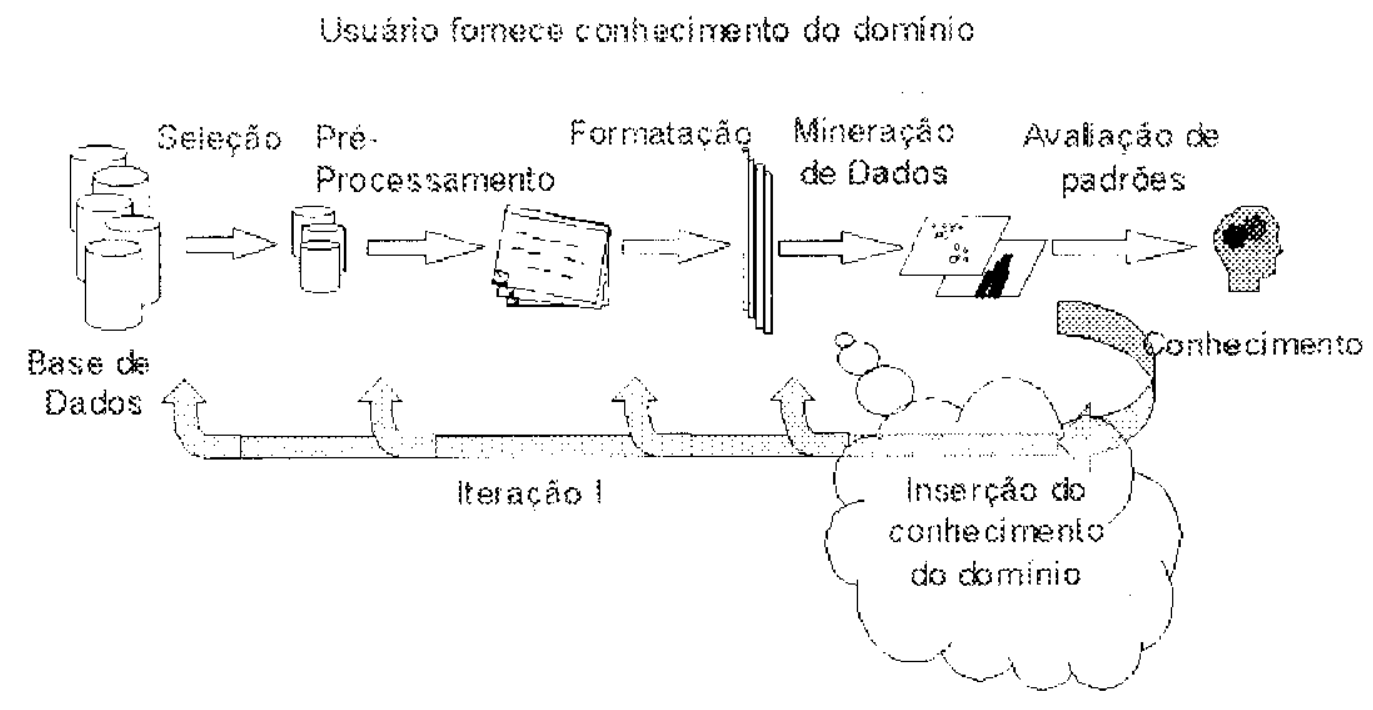

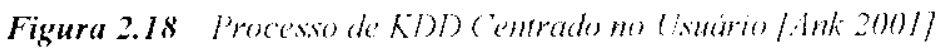

Ankerst [Ank 2000] definiu Mineraçào Visual de Dados como sendo "um passo no processo de KDD que utiliza Visualização como um canal de comunicação entre o computador e o usuário, para produzir padrões novos e interpretáveis". Nesta abordagem, a Visualização seria principalmente empregada nas duas fases essenciais do processo: mineração de dados e 
avaliação. Mincração de Dados, então, passa a ser um dos passos em que o usuário pode introduzir seu conhecimento de domínio no processo de KDD, ao invés de ser um passo meramente automatizado.

No intuito de promover uma melhor definição de VDM, Ankerst propôs também uma classificação de como as diversas abordagens de Visualização podem ser integradas ao processo de KDD. Fsta classificação baseia-se na seqüencia (em que momento) e no equilibrio entre as partes automáticas e interativas (visuais) do processo. São elas

- Visualizaçáo dos dados: os dados são visualizados sem prévia execução de algoritmos sofisticados. Por mcio de interação e operações na visualização, o usuário tcm total controle sobre a busca no espaço de busca, focalizando-o e/ou delimitando-o.

- Visualizaçào de resultados intermediários de uma mineraçăo: ocorre quando os algoritmos que executam uma análise dos dados não produzem padrōes finais, mas sim, padrões intermediarios que podem ser visualizados. Desta maneira, o usuário pode encontrar padrões de interesse na visualização, visto que esta promove um conhecimento do domínio e, por conseguinte, promove lambém um direcionamento da busca. Essa abordagem torna-se particularmente importante guando se observa que nào há algoritmos genéricos para mineração de dados, e que pode fornecer uma forma eficiente de avaliar e validar o andamento do processo.

- Visualizaçió de résullados da mineraçào: corresponde às visualizações subseqüentes à extração de padrões nos dados, tornando-os mais facilmentc interpretáveis. Além disso, baseado nesta visualização. o usuário pode querer retornar ao algorit mo de mineraçào de dados e reexecutá-lo utilizando diferentes parâmetros de cntrada.

A figura 2.19 ilustra como se dá a integração de técnicas de Visualização no processo de mineração, segundo a proposta de Ankerst e Keim [Ank 2001]. Nela, observa-se que a "Visualização Fortemente Integrada" determina uma abordagem em que a(s) técnica(s) de visualização permeiam todo o processo de extração de padrões 

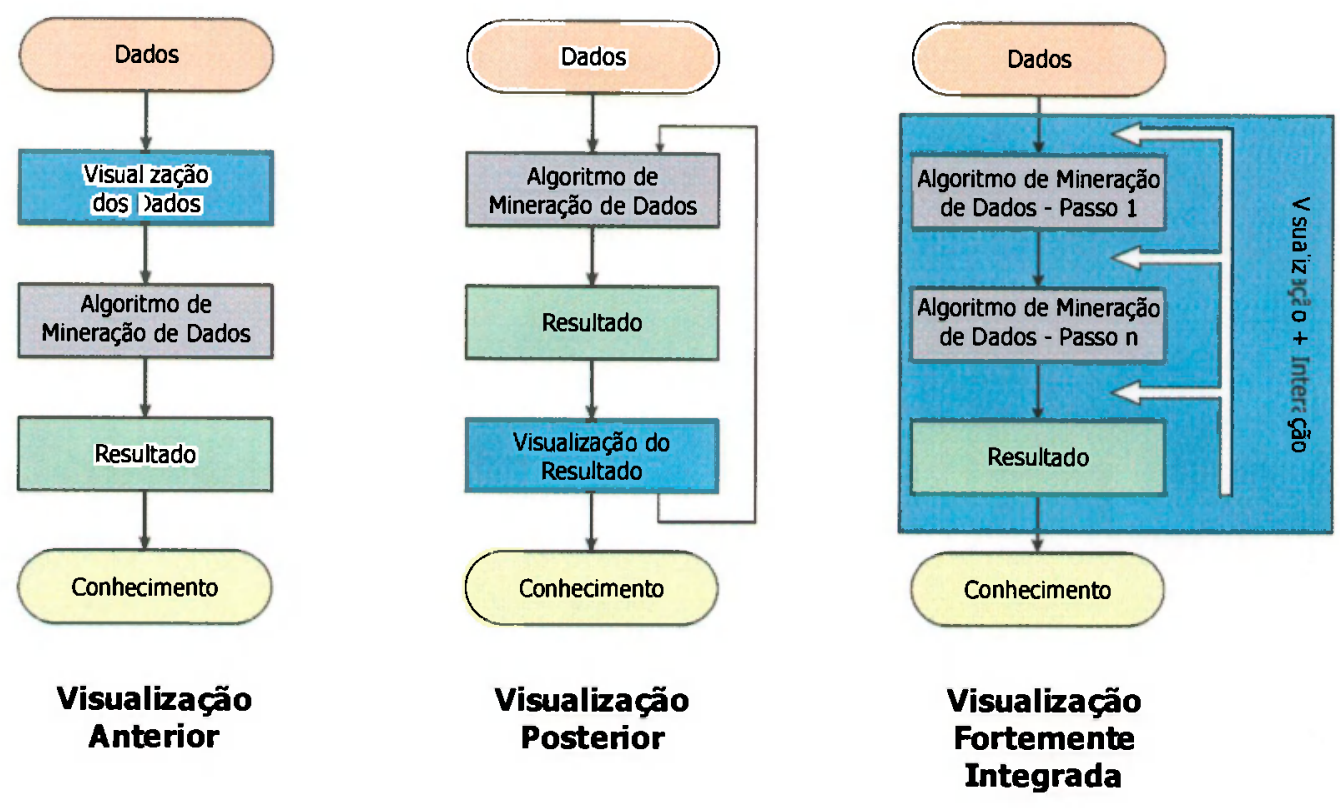

Figura 2.19 - Categorias de Mineração Visual de Dados [Ank 2001]

\subsection{Sumário}

Este capítulo tratou de aspectos envolvidos com Visualização e Mineração de Dados, e da atual tendência de tentar integrá-los, originando a chamada Mineração Visual de Dados.

A Visualização pode ser descrita por meio de modelos de referência que descrevem o processo de mapear dados e informações em um formato gráfico, integrando o usuário ao longo de todo este processo. Quando as informações a serem mapeadas são abstratas, a Visualização é chamada de Visualização de Informação. Os conjuntos de dados apresentam características essenciais para a escolha das técnicas de visualização. Estas, por sua vez, podem ser agrupadas em categorias que definem os principais aspectos inerentes às técnicas aí inseridas.

Mineração de Dados é um passo particular da Descoberta de Conhecimento em Bases de Dados, o qual corresponde a um processo que transforma dados brutos em informação útil. Mineração de dados é considerada como o núcleo deste processo, representando a pesquisa e análise de grandes volumes de dados, identificando estruturas regulares e irregulares.

Mineração Visual de Dados mostra-se particularmente útil quando o processo de mineração requer grande integração com o usuário e esta integração se mostra bastante 
complexa. Como Visualização pode ser explorada para integrar o usuário por meio de representações visuais, mineração de dados pode ser claramente beneficiada por um ambiente de descoberta que integre as capacidades únicas do ser humano de percepção ao poder de processamento dos computadores. 


\section{CAPÍTULO 3}

\section{Mecanismos de Interação}

Já foi mencionado que a Visualização vale-se de representações visuais e de mecanismos de interação. Especificamente, a Visualização de Informação procura combinar aspectos de computação gráfica, mineração de dados e interfaces usuário-computador. Os recursos de interação proporcionam os meios para que a técnica de visualizaçào atenda de forma eficiente e eficaz às necessidades de interatividade e iteratividade do processo de descoberta [Rib 1999; Won 1999].

As técnicas de interação contribuem para superar o problema de escalabilidade visual provocado pela limitação fisica dos dispositivos para apresentação de grandes volumes de dados [Fic 2000]. Tais técnicas permitem também, a exploração dinâmica dos dados, inclusive com a visualização simultânea e conjunta de diferentes representaçòes grálicas [Shi $200 \mathrm{la}$ ]. Isto faz com que os dados sejam observados sob várias perspectivas, sendo um mecanismo relevante e necessário para explorar os pontos fortes e minimizar o cfeito dos pontos fracos das diferentes técnicas de visualização [Kei 1996; Eic 2000]. Acrescenta-se a isto o fato de que, quando múltiplas visualizações de um mesmo conjunto de dados são usadas para explorá-lo, de modo que elas estejam ligadas e coordenadas para que ações sobre uma das visualizações provoquem ações equivalentes nas demais, provê-se mais informação do que com o uso de um único tipo de visualização [Nor 1999; Kei 2000; Kei 2002]. 
Os mecanismos de interação inerentes à Visualização serão discutidos neste capítulo. A seçào 3.1 destaca a funçào da interaçâo humana em todo o processo de visualização. Va seçăo 3.2 discute-se a determinação de elementos visuais para viabilizar a interação, e na seção 3.3 são analisadas as tarefas essenciais de interação e as transformações visuais responsáveis pela correta percepção do usuário. Finalizando este capitulo, a seção $3 . t$ apresenta aspectos relevantes para 0 projeto e uso adequados de técnicas de interação, e apresenta as técnicas mais populares, devidamente classilicadas segundo o modelo de referència que delineia todo o capitulo, destacando a técnica C'omsmlias Dimàmicas.

\subsection{Interação Humana}

No modelo de referència de Visualização apresentado na figura 2.I, a interação humana determina (1) as transformaçóes dos dados, (2) o mapeamento visual, que transforma dados tabelados em representações visuais (ou estruturas visuais), e (3) as transformações visuais, que criam as imagens (ou visões) exibidas ao usuário. Enquanto as representaçōes visuais combinam a organização espacial dos dados (posicionamento, composição, alinhamento, etc.), marcadores visuais na tela (pontos, linhas, áreas, volumes) e propriedades gráficas (cor, forma, textura, etc.) [Mac 1986; Car 1999], as transformaçōes visuais realizadas sobre estas representaçōes objetivam mostrar informações adicionais sobre elementos do conjunto de dados, por meio da alteração de parâmetros geométricos da representação, tais como escala e rotação.

Mendonça \& Almeida [Men 2001] salientam que, em algumas ferramentas, a implementaçào eficiente de interação faz com que a exploração de dados seja feita tão facilmente que o próprio usuário consegue detectar novos padrões de interesse sem algoritmos especificos para isso. Segundo eles, tais ferramentas de exploração visual de dados devem apresentar as seguintes funcionalidades

- Permitir o uso de diversos atributos visuais para produzir gráficos multidimensionais facilmente interpretáveis;

- Permitir a navegação interativa sobre a representação visual e o controle interativo das suas características; 
- Permitir o controle interativo dos dados apresentados.

Dentre as funcionalidades apontadas, observa-se que a segunda corresponde às transformações visuais apontadas por Card et al. [Car 1999], ou seja, às tarefas de usuário responsáveis por gerar as diferentes imagens a partir das representações visuais

O que se percebe a partir do delineamento das funcionalidades da Interação em Visualização é que, além da preocupação sobre os efcitos que promovem sobre as imagens e sobre os dados, cla também deve cuidar da adequação dos elementos visuais

\subsection{Atributos Visuaìs e Interação}

Visualização de informaçào está diretamente ligada às propriedades de percepção visual humana. Da mesma forma, a efetiva interação entre usuário c representação visual, a fim de promover cognição, depende da adequação desta última às características e limitações próprias do sistema perceptivo do ser humano [Car 1999]. Todavia, definir precisamente elementos visuais que promovam a máxima eficácia do processo de Visualização é uma tarefa difícil e, afora o conhecimento já consolidado em áreas que tratam destes aspectos (fisiologia, psicologia, etc.), a adaptação em sistemas interativos costuma ser uma tarefa essencialmente empírica

Para maximizar a identificaçào de aspectos relevantes nas imagens, deve-se ter especial preocupação com a forma de exibição da informação [Men 2001], o que permitirá também interações de usuário mais eficientes. Por exemplo, para que o usuário possa rapidamente localizar pontos relevantes em uma imagem, estes têm que estar representados de forma diferenciada dos demais, viabilizando a tomada de decisões do usuário, c rcsultando na identificaçâo de novas tarefas de interesse. $\Lambda$ figura 3.1 apresenta alguns modos de representar um item de informação de maneira que ele se destaque de outros. Porém, há representações que tornam a identificação mais custosa (figura 3.2), as quais são indesejáveis, dado ao fato de que a busca pela informação é mais demorada [War 2000; Men 2001] 


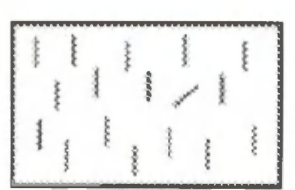

Orien tação

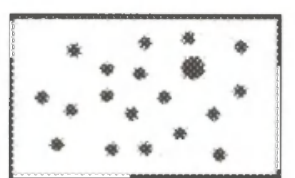

Tamanho

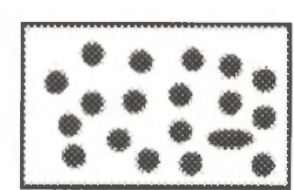

Forma

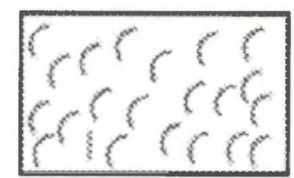

Curvatura

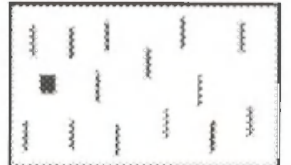

Forma

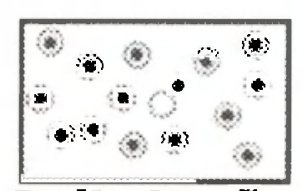

Delimitação

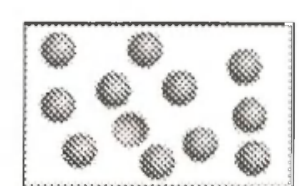

Concavidade

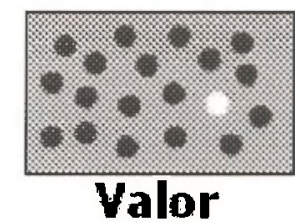

Figura 3.1 Atributos visuais que promovem fácil distinção entre elementos [Men 2001$]$

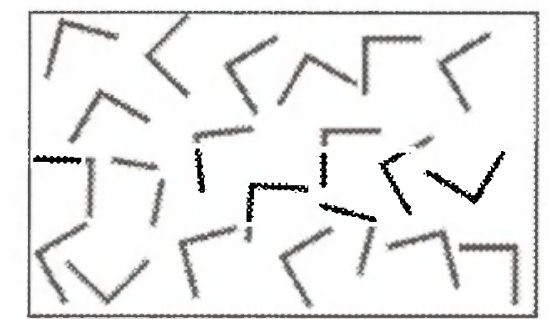

União

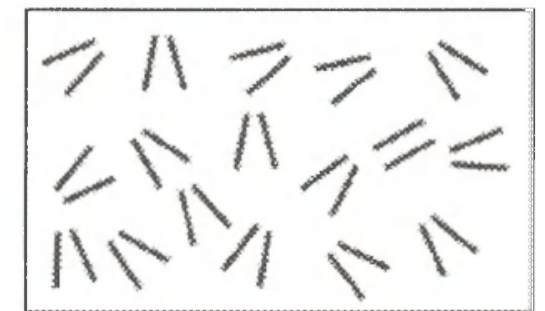

Paralelismo

Figura 3.2 Atributos visuais de dificil distinção [Men 2001]

Além da observação destes aspectos, deve-se atentar às características de adaptação à própria natureza dos dados. Certos tipos de informações são melhor adaptadas a determinados tipos de codificação [Mac 1986; Car 1999]. Por exemplo, valores contínuos são melhor mapeados em posições ao longo de um eixo; dados categóricos devem receber símbolos ou formas diferentes, enquanto dados numéricos devem receber tamanhos diferentes; etc.

\subsubsection{Cores}

A escolha de mapeamentos de cores perceptualmente adequados aos dados e às tarefas de visualização a serem executadas sobre eles é um aspecto crítico em Visualização [Tut 1998]. Em Visualização de Informação, este aspecto tem uma conotação ainda mais importante, dada a dificuldade do próprio mapeamento dos dados abstratos. A exemplo do que foi visto na seção 
2.1.2.2, a escolha das cores (no caso, uma escala) que irão compor as representações visuais é capaz de determinar o sucesso (ou não) dos resultados de uma técnica.

A abordagem mais comum para o mapeamento de valores dos dados para cores é a de aplicar matizes diferentes para promover distinção entre valores nominais, enquanto valores quantitativos devem receber luminosidades diferentes. Assim, num exemplo de aplicação em técnicas multidimensionais, os matizes poderiam mapear uma dos atributos nominais, e a variação de luminosidade mapearia outro atributo quantitativo relacionado à categorização determinada pelo atributo com valores nominais. Desta maneira, uma única cor pode representar dois atributos ao mesmo tempo.

Outras abordagens podem ser adotadas de acordo com os objetivos de uma determinada técnica. Por exemplo, Keim [Kei 1995; Kei 2000], quando discute a escala utilizada em suas técnicas orientadas a pixels, afirma que a escala adotada, HSI (Hue, Saturation, Intensity), foi concebida para tratar o problema de mapear distância para cor, em que o brilho seria o parâmetro que iria definir esse novo modelo de cor. A figura 3.3 apresenta uma comparação do modelo HSI, com os modelos de cor RGB (Red, Green, Blue), HSV (Hue, Saturation, Value) e HLS (Hue, Lightness, Saturation) - modelos clássicos utilizados em Computação Gráfica. Observa-se que a escala HSI apresenta um crescimento uniforme do brilho, o que não acontece com as demais escalas.

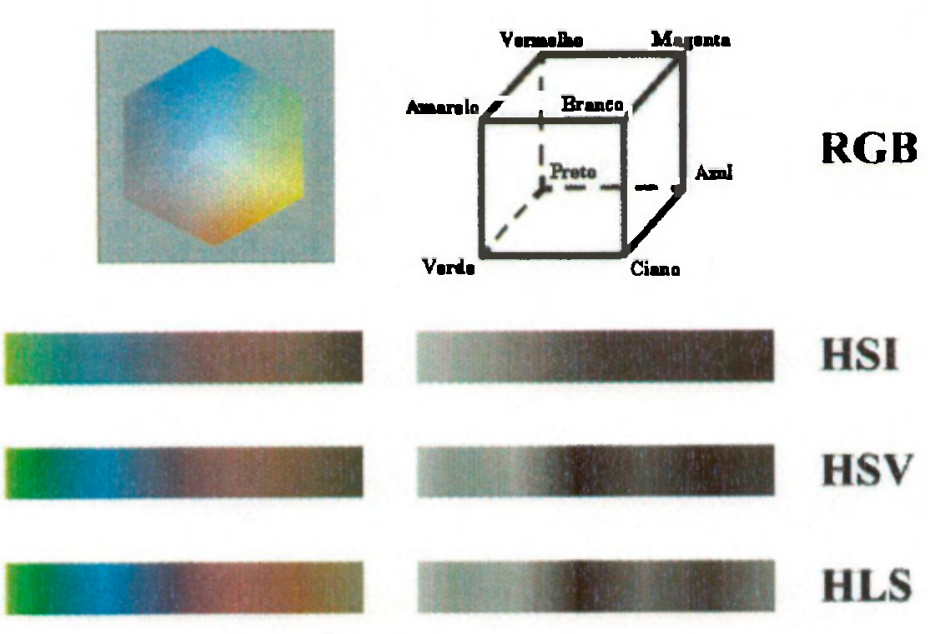

Figura 3.3 - Escalas de cores geradas por diferentes modelos [Kei 1995] 
Na adoção c/ou criação de escalas de cores (normalmente, quando se quer representas dados quantitativos), alguns parâmetros podem determinar sua eficácia. Levkowitz e Herman [Lev 1992] definiram três propriedades desejáveis para escalas de cores

- Ordem. As cores utilizadas para representar os valores devem ser percebidas à medida em que preservem a ordem dos valores (dos dados numéricos). A relação entre as cores deve ser: $c_{1}$ percebida como anterior a ... $c_{i} \ldots$ percebida como anterior a $c_{n}$;

- Uniformidale e distancia representativa. As cores utilizadas devem preservar a distância entre o valor que elas representam. Ou seja, para qualquer $1<=i, j, m, n<=N$, se $v_{i}-v_{j}$ $=v_{m}-v_{n}$, então é desejàvel ter $p d\left(c_{i r}, c_{j}\right)=p d\left(c_{m}, c_{n}\right)$, onde $p d\left(c, c^{\prime}\right)$ é a distancia percétida entre $c \mathrm{e}$ $c^{\prime}$ :

- Limites. A escala de cores não deve criar limiares perceptíveis que não existem nos dados numéricos (deve manter uma representação continua).

Afora o mapeamento dos valores dos dados para cores, outras preocupações na escolha de modelos de cores para Visualização dizem respeito à própria físiologia humana. A distribuição não igualitária das células perceptivas no olho humano, o grau de sensibilidade c faixa do espectro visivel que cada uma está adaptada, a formação das cores no cérebro humano pela junção das componentes espectrais, são apenas uma parte da complexidade associada à percepçào cromática humana. que determinam as variações de sensibilidade às cores e, em muitos casos, mais grave, a erros de interpretação [War 2000]. Ilusões de ótica como as causadas pela aberração cromática figura 3.4-(os diferentes comprimentos de onda da luz são focados em diferentes distàncias dentro do olho) são exemplos destes erros. Além disso, há ainda outros fatores de natureza cultural que determinam se a escolha do modelo de cor maximiza a percepção do usuário, tratando a correspondência entre as cores mapcadas e como o usuário as interpreta naturalmente. Desta forma, no mapcamento de cores no uso de técnicas de Visualização, deve-se ter atenção a estes diferentes fatores. 


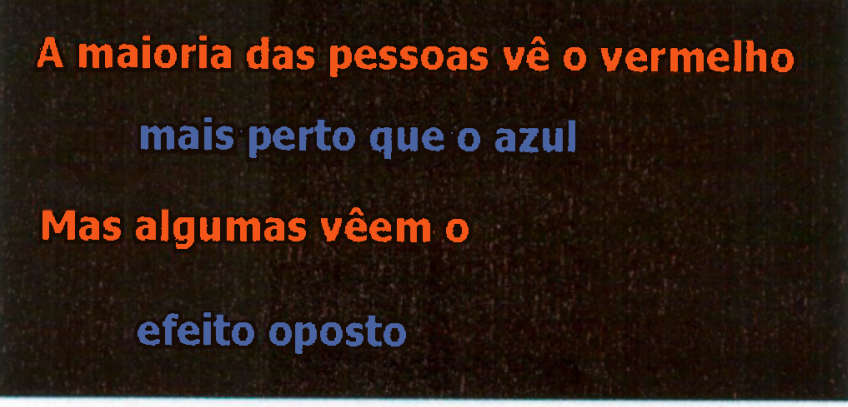

Figura 3.4 - Para a maioria das pessoas, o vermelho avança e o azul retrocede [War 2000]

\subsection{Tarefas de Usuário e Transformações Visuais}

Uma representação visual estática, por si só, normalmente não é suficiente para oferecer as condições necessárias e desejadas para a melhor compreensão de grandes conjuntos de dados [Fre 2001]. Deve-se disponibilizar funções pelas quais o usuário possa explorá-los e analisá-los, o que pode ser feito por meio de tarefas sobre a representação visual. Novos aspectos do conjunto de dados podem ser, então, observados com as transformações na representação visual geradas por tais tarefas.

Independentemente dos tipos de tarefas, os sistemas de visualização devem oferecer meios que permitam limitar a quantidade de informações que os usuários recebem, mas, ao mesmo tempo, mantenha-os informados sobre o espaço total de informação [Fre 2001]. Conjuntamente, é necessário possibilitar formas de manipulação do conjunto de dados, tanto geométricas quanto analíticas.

Em 1996, Schneiderman [Shn 1996] identificou e classificou sete tarefas, em um alto nível de abstração, que uma aplicação de visualização deveria prover:

- Visão Geral. Apresentação de uma visão geral de toda a coleção de dados. Estratégias de visão geral englobam imagens amplas de cada tipo de dado para formar a coleção inteira. A visão geral fica adjacente a uma visão detalhada e contém um delimitador de região de observação (normalmente, um retângulo) para controlar esta visão detalhada. A aplicação continuada desta estratégia permite aos usuários alcançarem altos fatores de zoom por meio de imagens intermediárias. Esta visão deve mostrar como os objetos estão relacionados, porém está sujeita a parâmetros limitantes impostos pelos próprios limites de equipamentos gráficos e do 
sistema perceptivo humano. A visão geral do conjunto de informações é útil ao usuário, pois diminui o tempo de busca, auxilia na sua localização e na escolha do próximo passo.

- Zooming. Visão em detalhe de um item ou conjunto de itens de interesse Tipicamente, o usuário quer visualizar maiores detalhes da imagem para superar as limitações da tcla (zoom geométrico) ou tem interesse em observar melhor alguma porção da coleção (zoom semântico) [Her 2000]. Os fatores que determinam o zoom são o foco e o fator de zoom. () zoom pode ser ativado por uma barra de controle, pelo ajuste do tamanho de um delimitador de região de observação, ou pela indicação de um ponto de localização (foco) seguido de comandos de zoom (fator) de acordo com a preferència do usuário [Shn 1996]

- Filtragem. Eliminação de itens sem interesse, para reduzir o tamanho do conjunto de dados. Com a possibilidade de controlar o conteúdo da tela, eliminando itens que não quer ver, o usuário pode enfocar rapidamente o seu interesse. Normalmente, filltragem é agregada a técnicas de zoom e é determinada pela associação dos atributos de controle a botôes, shiders ou widgets. É necessária uma rápida atualização da tela, mesmo quando sejam mostrados dezenas de milhares de itens.

- Dekalhe por kemanka. Apresentação de detalhes de um item ou grupo de itens após a sua seleção. Ocorre pela necessidade dos usuários visualizarem detalhes de item(ns) em particular, enquanto estão explorando o conjunto de informaçōes. A abordagem usual é simplesmente clicar no objeto de interesse e surgir uma janela $p o p-1 p$ com os valores dos seus atributos associados

- Relaçòes. Observação de relacionamentos entre os itens. Quando descobrem um item de interesse, os usuários podem pedir informaçōes de outros itens com atributos similares. Em outra situação, ao invés de ser fornecida esta relação, os itens de uma visualização poderiam ser determinados como sendo parte do mesmo processo ou evento. Isto pode ser realizado com a seleção de un item, seguida do destaque dos itens relacionados

- Históricos. Manutenção de um histórico de açôes para dar suporte às operaçōes de desfazer, repetir e refinamento progressivo. Como exploração de informaçào é um processo com muitos passos, é importante guardar um histórico de ações do usuário e permitir que ele possa manipulá-lo. Porém, freqüentemente as visualizações não suportam histórico de ações ou o suporte destas açōes é ineficiente ou incompleto. Excmplo disto é quando comandos de 
navegação e zoom só são desfeitos pela sequência de operações oposta à que originou a visão atual, ao invés de estar disponível um histórico que, quando manipulado pelo usuário, retroagisse para estados anteriores.

- Extração. Extração dos resultados das operações de visualização. Estes resultados podem ser subconjuntos de informações ou parâmetros de consulta. Após a obtenção dos itens de seu interesse, o usuário pode extrai-los para salvar em arquivo (de modo a facilitar o seu uso posterior), para configurar controles da própria aplicação, ou separá-los do contexto atual para uma análise mais específica.

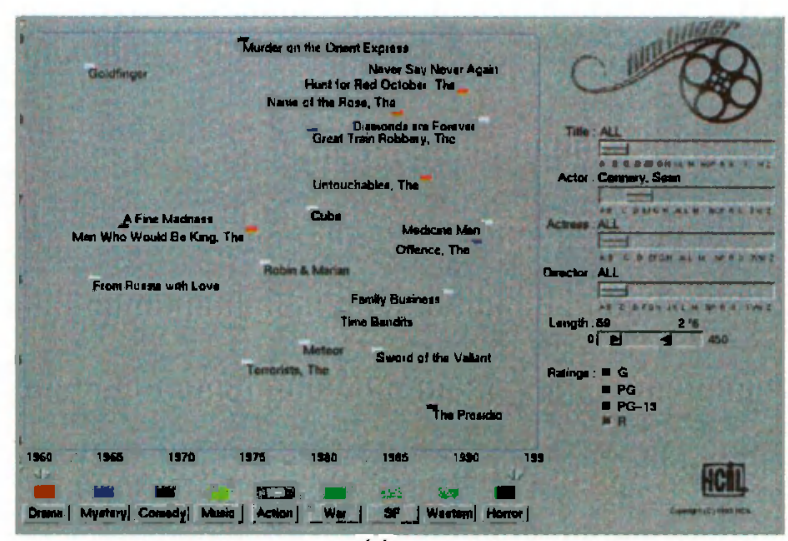

(a)

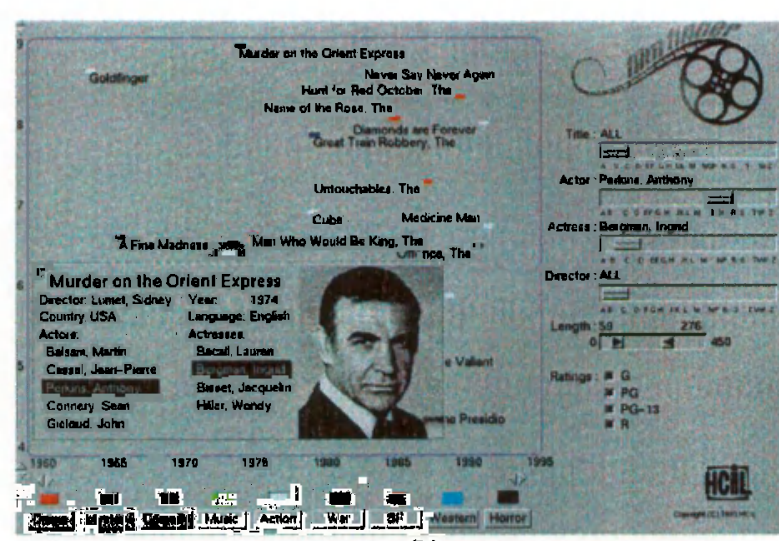

(b)

Figura 3.5 - Captura de tela da Aplicação FilmFinder [Ahl 1994]

De forma mais específica, não classificando as interações de visualização como um todo, mas, sim, as transformações visuais. Card et al. [Car 1999] classificaram em três os tipos de transformações mais comuns:

- Sondagem. Usa a localização de um item (ou itens) na representação visual para mostrar informações adicionais relativas ao(s) mesmo(s), a partir das tabelas de dados. A localização de item(ns) de interesse dá-se de forma dinâmica, normalmente por meio de sucessivos posicionamentos de um cursor sobre os objetos. Por exemplo, a figura $3.5 b$ mostra o FilmFinder após o usuário examinar um ponto no scatterplot (a figura $3.5 a$ mostra a aplicação antes deste evento). A janela pop-up resultante da operação "detalhe por demanda" apresenta os detalhes sobre o filme mapeado pelo ponto. Em visualização de objetos 3D pode-se examinar planos de corte para acessar o interior dos objetos; 
- Controle de ponto de observeçáo. Executam zoom, pan (movimento estável de uma regiāo de observação sobre uma imagem bidimensional de maior tamanho) e clip do ponto de observação. Uma técnica que provê controle do ponto de observação é a chamada "Visão geral + detalhe" [Shn 1996], na qual usam-se duas janelas para fornecer uma visão geral para orientação do usuário dentro do conjunto de informações como um todo e uma visão detalhada de uma parte desse conjunto que interessa mais ao usuário. Normalmente, a região de interesse toma o campo de visão principal e o restante do conjunto de dados é mantido em área à parte. A figura 3.6 apresenta a seqüência de mensagens em um programa executando o algoritmo "Bubble Sort", na qual tem-se uma visão geral de todo o conjunto de mensagens na janela inferior, e uma visão em detalhes do trecho selecionado na janela superior

As visões de uma apresentação que utiliza visão geral + detalhe podem ser mostradas uma de cada vez (time multiplexing) ou podem ser exibidas ao mesmo tempo em partes diferentes da tela (space multiplexing) [Car 1999].

- Distorções. Modificam as representações visuais para criar visões "foco+contexto", em que a visão geral e a detalhada são combinadas em uma única representação visual (figura 3.7). São exemplos de técnicas que utilizam distorções: Fisheye (figura 3.8) - mostra uma área de interesse ampla e detalhada, e as demais áreas sucessivamente menores e com menos detalhes; Perspective Wall (figura 3.9) - dados fora da área focal sâo perspectivamente reduzidos de tamanho; Hyperbolic Tree (figura 3.10) - distorce um largo leiaute de árvore, por meio de uma transformação hiperbólica que mapeia um plano em um circulo, contraindo os nós da árvore bem mais que a raiz [Lam 1996]. 


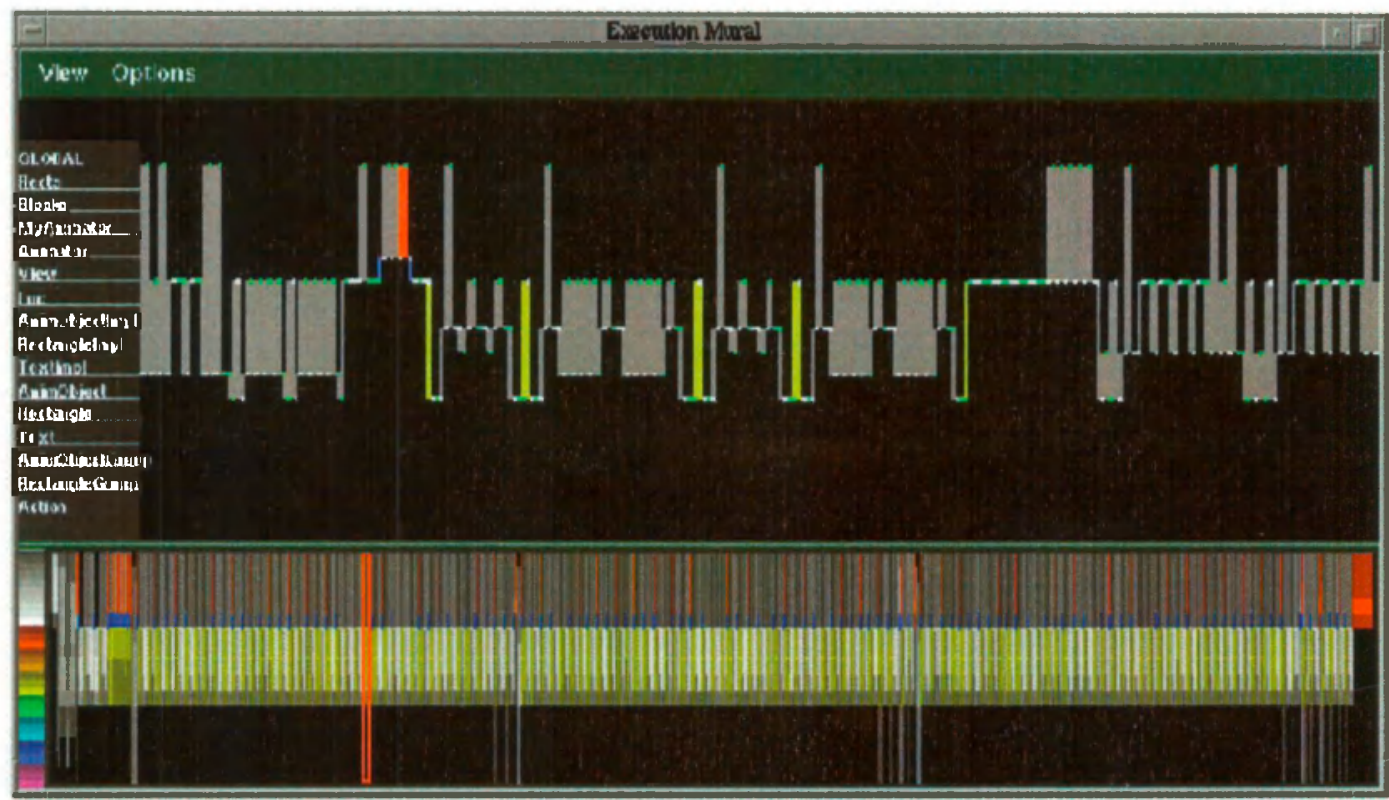

Figura 3.6 - "Information Mural" usando visão geral+detalhe para visualizar uma longa sequência de mensagens geradas por um programa rodando um Bubble Sort [Jer 1995]

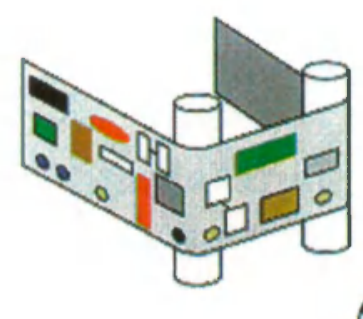

(a)

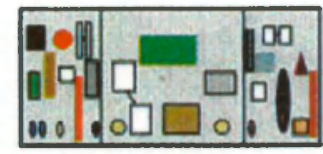

(b)

Figura 3.7 - (a) Princípio de funcionamento e (b) Visão do usuário em uma técnica de distorção [Spe 2001]

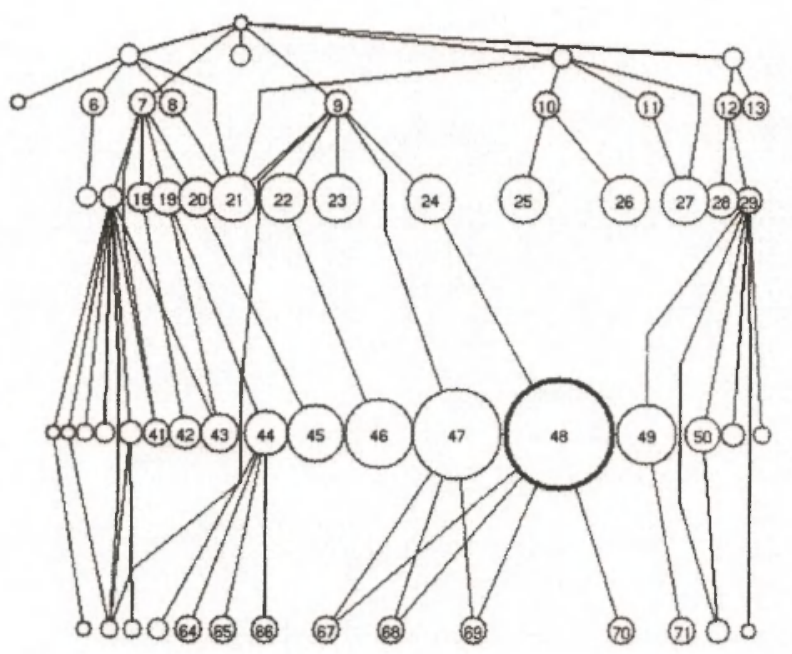

Figura 3.8 - Aplicação da técnica Fisheye [Sar 1993] 


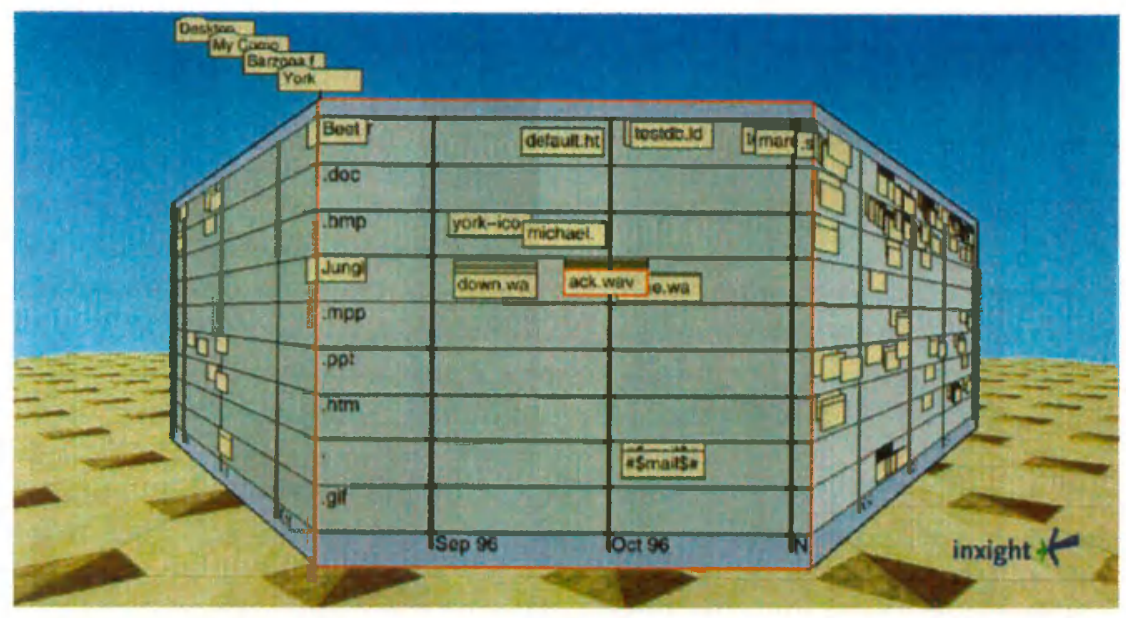

Figura 3.9-Perspective Wall [Spe 2001]

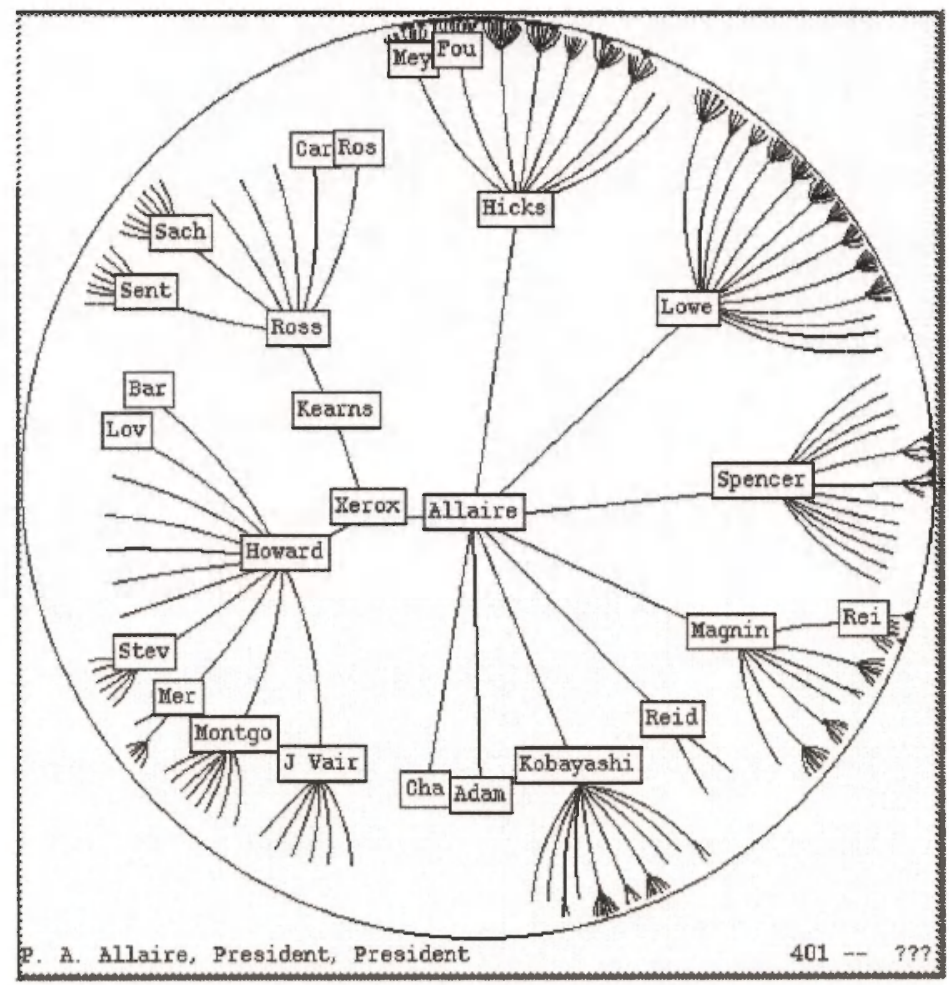

Figura 3.10 - Estrutura em árvore de um site, vista na técnica Hyperbolic Tree [Ank 2001]

\subsection{Técnicas de Interação}

Card et al. [Car 1999], em abordagens mais conceituais, preocuparam-se em classificar as técnicas de interação de acordo com as alterações que provocam nos dados e nas formas visuais 
(seção 3.4.2). Contudo, alguns autores tiveram maior preocupação com a ênfase na necessidade de novas abordagens interativas para dar suporte a trabalho envolvendo grandes conjuntos de dados. Thomas et al. [Tho 1999] denominam como "Higher Order Interaction Techniques" o conjunto de técnicas de interação que permite ao ser humano interagir com milhões de unidades de informação, em alternativa às interfaces WIMP (Window, Icon, Menu, Pointer) [Fol 1990].

Eles apresentam exemplos de técnicas para ambientes interativos, das quais destacam-se as ilustradas na figura 3.11. O item (a) mostra mais de um milhão de informações, em uma aplicação usada em Engenharia Genética, para engenharia dinâmica de novas formas biológicas. Ela combina técnicas de relacionamento foco+contexto, e as intituladas "progressive disclosure" (mudança dinâmica do paradigma visual) e "Relative positioning" (proximidade visual entre informações chave). O item (b) apresenta uma técnica que confronta dados coletados experimentalmente com os que foram teorizados (supostos), em uma análise de consumo de energia. A superfície transparente ilustra a teoria, enquanto a superfície sólida ilustra o consumo real de energia em um período de três semanas. Da comparação gerada pela combinação de ambos os valores, o usuário obtém os requisitos necessários à percepção para a tomada de decisão.

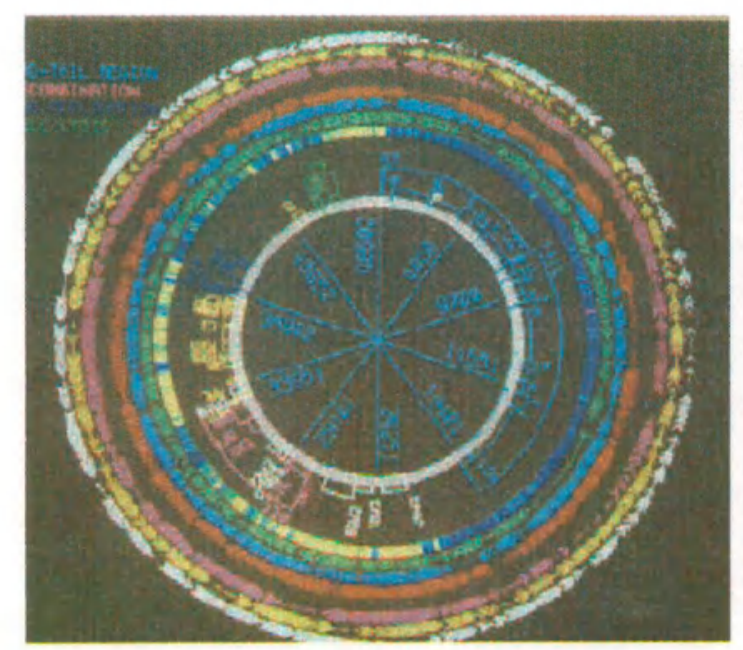

(a)

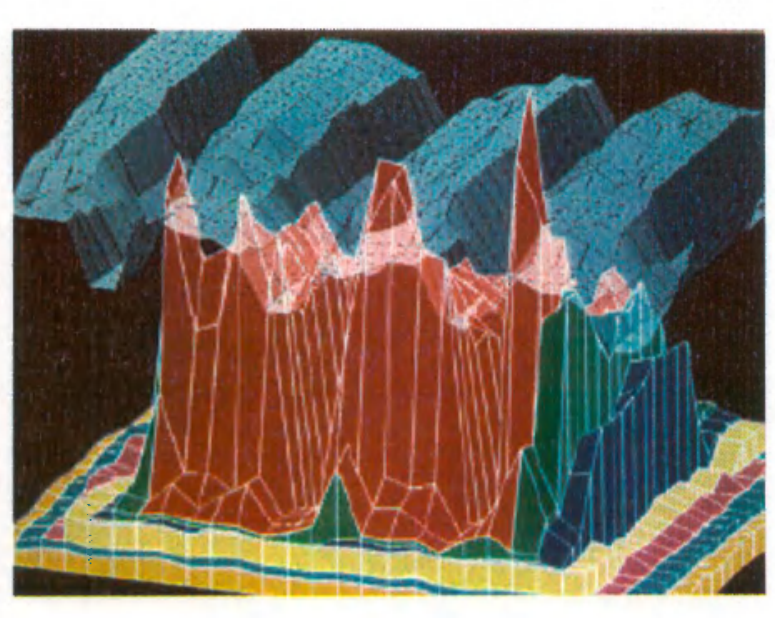

(b)

Figura 3.11 - Ambientes Interativos: (a) Sistema de Engenharia Genética Cage/Gem e (b) HOIT Teoria/Experiência [Tho 1999] 
Independente da forma que são implementadas, conjugando ou não diferentes mecanismos, as técnicas de interação que visam suportar grandes volumes de informações devem atentar a algumas consideraçôes (seção 3.t.l), a fim de evitar problemas comuns causados pelas limitações dos dispositivos visuais.

\subsubsection{Aspectos Relevantes}

O crescente desenvolvimento de técnicas de visualização tem-se dado, em geral, baseado em implementações experimentais avaliadas de forma empírica e isolada [Fre 2001] aplicadas em contextos e escopos específicos. Mesmo com a existencia de diversas diretrizes clássicas [Tuf 1983: Tuf 1990] e uma preocupação constante com os aspectos de projeto típicos da área de interação usuário-computador, alguns aspectos das representações visuais transformam-se em problemas se mecanismos de interação nâo forem projetados para minimizar o seu impacto no processo de percepçào. Aspectos como oclusão de objetos, desordem visual e desorientação visual, dificultam a interpretação das informaçōes pelo usuário [Fre 2001]

A oclusão de objetos caracteriza-se pelá sobreposição de alguns elementos por outros quando existe um grande volume de informaçòes. Uma solução eficiente para amenizar a oclusão visual em algumas visualizações bidimensionais é utilizar jitter, promovendo uma pequena perturbação aleatória na localização dos objetos, de maneira a "espalhá-los" sobre uma determinada área [Cle 1994]

$\Lambda$ desordem visual é decorrente da dificuldade de reconhecimento e interpretação de um excesso de elementos presentes na visualização, não necessariamente sobrepostos, causando uma sobrecarga no sistema cognitivo do usuário. Algumas técnicas utilizam recursos como sombra e transparência para permitir ao usuário a localização mais clara dos objetos. Para minimizar a oclusão de objetos e desordem visual podem ser utilizados mecanismos básicos de manipulação geométrica, como rotação, mudança de escala e translação dos objetos.

Quando o usuário tem difículdade na manutenção da atenção por ocasião de troca de ponto de observação e retorno a situaçõcs anteriores, tem-se aí caracterizado o problema da desorientação visual apresentado por algumas técnicas. Técnicas como foco+contexto tentam minimizar esta desorientação evitando que informações desapareçam (reduz-se sua dimensão) e 
apresentando transiçōes suaves animadas entre dois momentos no processo interativo [Car 1999a]. Outro exemplo é a prática de zoom animado, para ajudar o usuário a preservar seu senso de posição e contexto [Shn 1996]

O tratamento destes aspectos é essencial no processo de avaliação de técnicas de visualização, e pesquisas nesta árca devem integrar a avaliação de aspectos de percepção [War $2000]$ com técnicas de avaliação de interfaces [Nie 1994], por meio da determinação de critérios, fatores e métricas que permitam ao projetista avaliar o conteúdo de informação percebido pclo usuário.

Conforme Wong [Won 1999], em ambientes de VDM, particularmente, é necessário que se observe, além de princípios como reutilizaçào e segurança, outros que se referem à interaçào do usuário

- Simplicidade. Simples significa que, embora seja o menor sistema possível, seja suficientemente funcional e poderoso. Isso pode ser alcançado com a utilização de mecanismos de entrada intuitivos e amigáveis, assim como saidas intuitivas e fáceis de interpretar; o emprego de imterfices eficazes entre o ser humano e a informação; o uso de estruturas de dados adequadas para favorecer pesquisas rápidas e contiáveis; e, finalmente, com a execução de um número minimo de passos para chegar ao resultado;

- Automomia para o usuario. Ao invés de aceitar decisōes automáticas pelo algoritmo de DM, o usuário deve ser capaz de analisar as abstrações visuais e obter introspecção sobre os dados;

- (omfiabilicade. () sistema deve fornecer uma estimativa de erro ou precisão para as informaçōes projetadas em cada passo, para compensar uma eventual imprecisão de análise provocada pela falta de observação dos possíveis problemas gerados pela inadequação de uma determinada técnica ao contexto

\subsubsection{Classificação de Técnicas de Interação}

Muitas técnicas de interação para visualização de informação são, essencialmente, uma maneira de selecionar visualmente subconjuntos de objetos contidos em uma tabela de dados. 
Elas são usadas para localizar dados, revelar padrões nos dados, ou selecionar os argumentos a serem aplicados às transformações [Car 1999]. Conforme o modelo de referência da figura 2.1, a presença da interação humana determina uma inerente classificação em relação às modificações que causa. As técnicas de interação mais conhecidas podem ser, então, categorizadas da seguinte forma [Car 1999]:

- Interação com Transformações dos Dados.

- Consultas Dinâmicas (Dynamic Queries) [Ahl 1994; Fis 1995] é essencialmente uma técnica de filtragem, baseada em controles visuais para executar consultas o conjunto de dados. Assim como no FilmFinder (figura 3.5), ferramentas comerciais de exploração visual de dados bastante difundidas, implementam consultas dinâmicas. Este é o caso dos softwares comerciais Spotfire ${ }^{\circledR}$ e do MineSet ${ }^{\circledR}$ (figuras $3.12 a$ e $3.12 b$, respectivamente). A próxima seção apresenta maiores detalhes desta técnica;

- Como já apresentado na seção 3.3, Detalhe por. Demanda expande um pequeno conjunto de objetos selecionados para revelar informações sobre seus atributos.

- Brushing é utilizada com múltiplas visualizações de algum conjunto de dados [Cle 1994]. Quando se destaca um item ou conjunto de itens em uma das visualizações, o mesmo acontece automaticamente nas demais (figura 3.13).

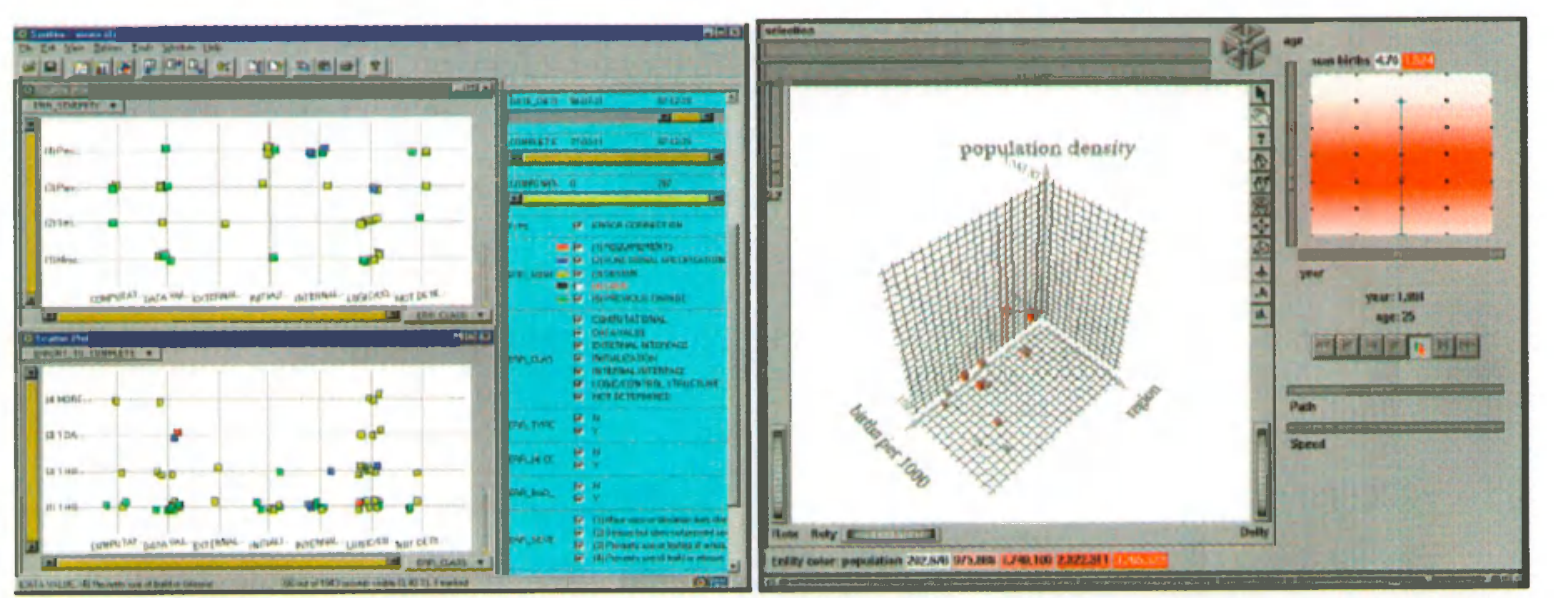

(a)

(b)

Figura 3.12 - Captura de tela das aplicações (a) Spotfire ${ }^{\circledR} e(b)$ MineSet $^{\circledR}$ [Men 2001] 


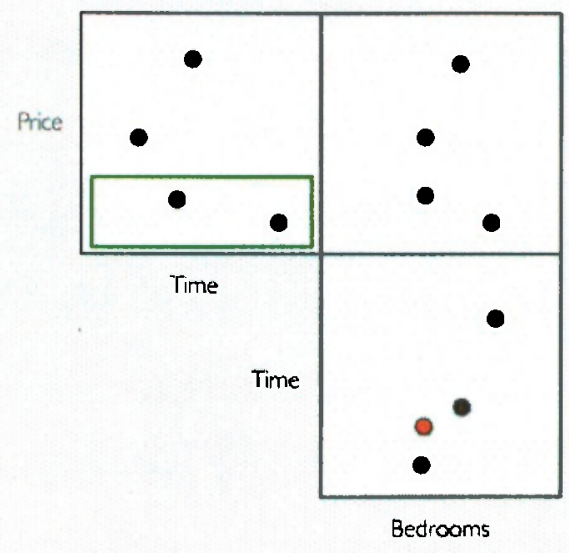

Figura 3.13 - Princípio de Funcionamento da técnica Brushing [Spe 2001]

\section{- Interações com Mapeamentos Visuais.}

- Uma técnica comum, usada por sistemas de visualização comerciais para mapear dados para uma forma visual, é conhecida como Dataflow. Nela, a idéia básica é usar uma representação explícita (ex.: diagramas nó-relacionamento) para representar o mapeamento.

\section{- Interações com Transformações Visuais}

- Seleção direta refere-se ao conjunto de esquemas para destacar e selecionar objetos e grupos de objetos. De alguma forma, elas destacam a aparência da representação visual para identificar o conjunto de objetos que poderá ser usado em uma ação.

- Movimento de câmera é a mudança da posição do observador em um espaço 3D. Por meio de um novo ângulo de visão, o usuário pode observar elementos omitidos.

- Magic Lens [Fis 1995] são "sondas" que dão uma visão alternativa de uma região na representação visual. Ela seleciona objetos por meio da combinação da delimitação de regiões de interesse na distribuição dos objetos, com alguma técnica de seleção, tal como consultas dinâmicas. Uma característica interessante é que as lentes podem ser sobrepostas para criar consultas mais complexas (figura 3.14).

- Visão Geral + detalhe e Zoom, já apresentadas na seção 3.3, são técnicas também bastante difundidas. 


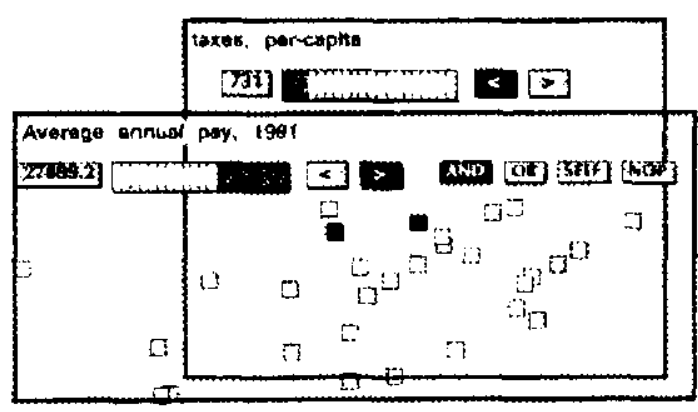

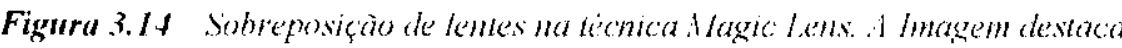

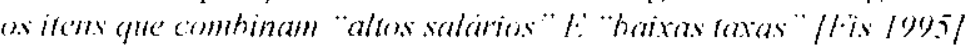

\subsubsection{Consultas Dinâmicas}

A técnica denominada "Consultas Dinâmicas" é consolidada como um recurso poderoso de filtragem, em que controles visuais são associados a parâmetros que permitem determinar, em baixo nivel, a execução de consultas sobre o conjunto de dados. O resultado da interação com tais elementos reflete imediatamente no mapeamento utilizado na visualizaçăo, sendo mostrados os itens de dados que atendem às seleções especilícadas visualmente, e omitidos os demais. Filmlinder $[\Lambda \mathrm{hl}$ 1994], por exemplo, utiliza Consultas Dinâmicas como elemento de controle. A figura 3.5 h ilustra como Consultas Dinâmicas funcionam como meio visual para determinar conjunçòes. Por exemplo, no caso da figura ter-se-ia: (Ator="Anthony Perkins") AND) (Atriz. "Ing̣rid Bergman") AND ((Duração > 59 min) AND (Duração 276 min))

I: indescjável submeter usuários finais que, em sua maioria, não detèm conhecimento especifico em linguagem SQL (Sirmetured (Guery Lamgmage), ao aprendizado de formulação de consultas nesta linguagem. Mesmo as atuais ferramentas para a construção de expressões boolianas complexas são inviáveis diante da dificuldade de uso. Outro fator que desencoraja sua adoção ć a nào imediata concordância entre a linguagem natural e a linguagem booliana. Excmplificando, a expressão "A\D" (em inglês), numa linguagem natural expande as opções (ex.: "isso" E "aquilo"), mas na linguagem booliana estreita o conjunto de dados, já que significa uma intersecção [Shn 1996]

Mesmo que o usuário final trabalhe com a especificaçào de valores previamente determinados dos atributos (o que reduz bastante o número de erros na elaboraçào de consultas), o uso constante, principalmente quando a quantidade de dados é muito grande, é uma tarefa 
também desmotivante, além de dificultar a observaçào de padrōes éou exceçòes nos dados. Por conseguinte, a formulação de consultas pela elaboração de comandos em linguagem especifica nào é adequada à Análise Exploratória de Dados.

A abordagem de Consultas Dinâmicas favorece e aplica os principios da manipulação direta em ambientes de bases de dados [Shn 1983]

- representação visual dos componentes da consulta;

- apresentaçào visual dos resultados;

- controle de consultas rápido, incremental e reversivel;

- seleçào por apontamento, não por digitação;

- feedhack continuo e imediato

Desta forma, Consultas Dinâmicas operam normalmente associadas a técnicas de Visualização. Elas podem revelar propriedades globais ao mesmo tempo em que auxiliam os usuários na obtençào de respostas a perguntas especificas [Shn 1996]. Inicialmente, é exibido 10 do o dominio de informação na Visualização e, em seguida, e possivel restringir ou destacar os elementos que mapeiam a informaçào correspondente à consulta. A abordagem mais comum è associar um controle visual a cada atributo que parametriza a consulta

Très lipos de controles básicos são: controles de valores de dados com apenas dois estados (verdadeiro ou falso): normalmente, botões; controles de faixas continuas de dados como Ramge Slicker [Car 1994] (figmra 3.15a), e controles de dados descontinuados: como check box. Há tambèm controles especificos que podem ser implementados, como o Alphas/icter [Ah] 1994a] (figura 3.15 b), mas os diferentes tipos de seleção que um mesmo controle pode oferecer. tornando seu modo de opcração bastante flexível, permite que seu uso seja mais generalizado. Como exemplo, o controle Ramge Shicker normalmente é usado para a seleção de intervalos de dados pela especificação de dois extremos, mas quando estes dois extremos estão juntos podem selecionar os valores de forma pontual. Todavia, os controles devem estar adaptados ao tipo dos valores e à cardinalidade (a quantidade de valores distintos dentro do mesmo conjunto de dados -.- dimensòes) dos dados, para que se possa garantir a eficiência 


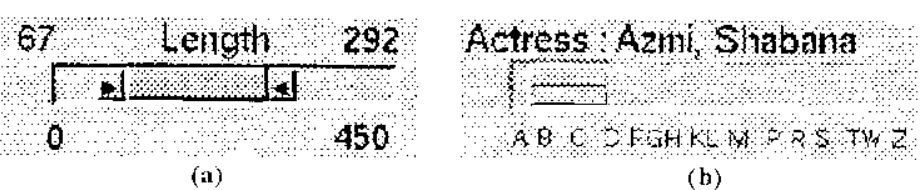

Figura 3.15 (a) Range Slider; (b) Alphaslider /Car 1994)

Uma desvantagem atribuída a Consultas Dinâmicas é implementar somente consultas simples que sào junções ou disjunçôes. Os resultados são executados com o uso de lógica $\mathrm{E}$, considerando que esta lógica abrange a maioria das ocorrências de consultas [Ahl 1994]. Todavia, estudos apresentados por Ahberg e Shneiderman [Ahl 1994; Shn 1994] concluiram que, nas situações que a lógica OU é requerida, o usuário se mostra satisfeito (ou até mesmo prefere) gerar sequências de consultas. Fsta abordagem para consultas, em que predominam lógica $\mathrm{OU}$, permitem que os usuários vejam o tamanho do resultado de suas consultas, tornando possivel comparações dentre estes resultados, ampliando o conhecimento sobre os dados. Além disso, acaba por encorajar a "navegação" nos dados desejável em ambientes de Análise Exploratória. Vale notar que o atestamento do alto nivel de satisfação dos usuários com o uso de Consultas Dinâmicas, em diversas áreas de aplicação, é bastante recorrente na literatura

\subsection{Sumário}

Este capitulo apresentou os mecanismos de interação concernentes à Visualização, destacando as funções da interação humana e atributos visuais, as tarefas de interaçâo e transformações visuais, e aspectos importantes no projeto de técnicas de interação, bem como as técnicas mais populares.

A interação humana gerencia todo o processo de Visualização, mantendo-se diretamente relacionada com as imagens que serão geradas para a interpretação dos dados. A interpretação é beneficiada pelo uso adequado de atributos visuais, por navegação interativa, e controle das características da representação visual e dos dados apresentados.

As tarefas realizadas pelo usuário no contexto de Visualizaçăo podem ser sintetizadas em sete tarefas básicas: visão geral, zooming, filtragem, detalhe por demanda, relações, histórico e 
extração. As transformações visuais criam as imagens a partir da representação visual e podem ser sondagem, controle de ponto de vista ou distorções

Algumas tecnicas tem sido criadas para lidar com grande quantidade de dados Principalmente nos projetos destes tipos de técnicas, é necessário dar atenção a alguns fatores que dificultam a interpretação das informações, tais como oclusão de objetos, desordem visual e desorientação visual. Fim ambientes de VDM, deve-se observar princípios como simplicidade, autonomia para o usuário, confiabilidade, reutilização e segurança

As técnicas populares de interação para Visualização de Informação podem ser naturalmente classificadas de acordo com as modificações causadas pela interação humana no processo de Visualização. Consultas Dinâmicas é uma técnica de interaçâo bastante difundida, dada as caracteristicas adequadas ao ambientes de manipulação direta em bases de dados 


\section{CAPÍTULO 4}

\section{Exploração Visual de uma Base de Dados Pluviométricos}

As áreas de aplicação de VDM são bastante diversas. Nas diferentes áreas do conhecimento, um mesmo conjunto de dados pode dar margem a novas descobertas $\mathrm{cm}$ diferentes sub-árcas ou áreas correlatas, com amplos beneficios. Especificamente, para exemplificar a importância e a diversidade de áreas em que dados geográficos podem ser empregados, pode-se citar a ecologia, gerenciamento ambiental, saúde pública, logística de negócios, turismo, controle de tráfego, etc. [Cha 2000]. A fim de identificar e avaliar as potenciais contribuiçōes de VDM, cste projeto utiliza, particularmente, dados geográficos associados ao estudo de climatologia, cujo entendimento, por sua vez, pode resultar em beneficios diretos no planejamento da agricultura, preservação ambiental, etc.

Este capitulo caracteriza o domínio geográlico ante questòes que o tornam único e de dificil tratamento, se comparado a outras áreas do conhecimento, e como as técnicas de Visualização podem auxiliar na solução de tais questões. Tal enfoque é tratado na seçŭo t.1. $\Lambda$ seção +.2 apresenta o desenvolvimento deste projeto, descrevendo as tarefas identificadas ante os objctivos estabelecidos, a aplicação implcmentada e o projeto do ambiente de Visualização que definiu as caractcrísticas que guiaram a implementação 


\subsection{VDM e Dados de Domínio Geográfico}

Para uma eliciente aplicaçào de técnicas de VDM, deve-se levar em consideração os dilerentes aspectos inerentes aos domínios, contextos ou áreas em que serâo aplicadas. Tais aspectos determinam não só as particularidades, distinções quanto aos objetivos e adequação das metodologias a serem utilizadas. mas, também, as dificuldades de adaptação destas técnicas ao contexto [Won 1999]. Fmbora exista grande interesse nos bencfícios esperados do emprego de VDM a dados obtidos de medições de fenômenos geográficos, sua natureza espacial/temporal dificulta a escolha dos recursos que viabilizem a compreensão dos fenômenos [Mac 2000]. A descoberta de conhecimento em grandes volumes de dados geográficos, apresenta dificuldades $\mathrm{c}$ características únicas, determinadas pela própria natureza destes dados.

\subsubsection{Dados Geográficos}

Os algoritmos clássicos de DM assumem que os dados são independentes, mas objetos espaciais apresentam relaçòes entre si devido ao seu posicionamento relativo, com possivel influência de uns sobre outros [Lst 1999; Cha 2000]. Esta é uma das principais particularidades dos dados geograticos.

Dados espaciais trazem embutidas informações relativas a posições, distância e direção, derivadas da relação de adjacenncia entre os objetos espaciais que representam, as quais devem ser consideradas em sua análise [Kop 1996; Est 1999]. Mineraçòn de Dades Lisyaciais (Spatial Iara Mining - SDM) [Kop 1996] objetiva o entendimento de tais tipos de dados, descobrindo relacionamentos entre objetos espaciais. considerando, inclusive, atributos não espaciais. Entre suas técnicas [Kop 1996: Kop 1998], pode-se citar a mineraçäo basceader em generalizaçào, na qual a extração de conhecimento é realizada sobre um esquema de generalização dos dados (descrição geral dos dados por meio da agregação de suas dimensões, abstraindo-os para um nível conceitual mais alto), e associaçóes espaciais realizadas de forma análoga às de dados convencionais (regras de associação buscam descobrir associaçōes relevantes entre atributos, tal que a presença de alguns atributos implica na presença de outros na mesma relação) 
Como exemplo de outros grupos de técnicas, estão (a) agrupamento (chusfering) espacial para localizar agrupamentos de objetos com atributos similares, e (b) detecção de tendèncias espaciais, observando mudanças regulares em atributos não espaciais ao longo de um caminho composto por objetos adjacentes [Kop 1996; Est 1999].

Além da naturcza topológica, conjuntos de dados espaciais podem conter descrições de fenômenos ou eventos que se repetem ao longo do tempo, a cxemplo das ocorrências climáticas A presença de múltiplas instàncias de um mesmo evento caracteriza uma componente temporal no conjunto, ressaltada até mesmo pelo caráter das medições. Essa componente fornece informaçōes sobre a duração de um evento e sobre a ocorrência de relação de um evento com outros, podendo servir também para descobrir padröes nestes eventos [Mac 2000].

\subsubsection{Dificuldades e Unicidade}

Segundo Gahegan [Gah 2001], a descoberta de conhecimento em dominios geográficos apresenta uma série de características que a tornam de difjcil realização e lhe conferem propriedades únicas. Como a própria geografia é uma disciplina integrativa, os dados geograficos abrangem uma larga faixa de perspectivas e interesses, que vão desde fatores físicos a sociais, além dos originados pela integração destes dois aspectos.

Da união desta gama de perspectivas com o crescimento da infra-estrutura para reunir informações, surgem os seguintes problemas [Gah 2001]:

- Complexidade associada ao volume de dados. Geografia é uma disciplina farta em dados. Além dos bancos de dados geográficos já existentes, de proporções na ordem de lerahyles; estão sendo construídos outros bancos com atributos espaciais e temporais (por exemplo, médicos e financeiros) que podem permitir o descobrimento ou confirmação de conhecimento geográfico [Mil 2001];

- Complexidade aswociada ao próprio dominio. Sinais relevantes e interessantes contidos nos dados, normalmente, ficam escondidos por padrões mais fortes (mais claramente observados) que precisam ser removidos primeiramente. A origem de grande parte desta complexidade está na co-dependência existente entre uma diversidade de escalas e por diferentes causas [Rod 2001]. Como exemplo, a natureza cíclica de muitos sistemas geográficos 
(fenômenos diários, sazonais, etc) impõe fatores nos dados, que podem encobrir muitas variações mais localizadas e que seriam também interessantes:

- Complexidade camsada por variaçoes locars. Sistemas referentes à Terra são tão intrinsecamente interconectados que é dificil isolar uma análise aplicada a uma parte do sistema, já que csta é afetada por outros aspectos não modelados;

- Complexidade camsada pela canmulaçion e amostragem de dados. Embora os dados estejam disponíveis em volumes crescentes, ainda tem-se que recorrer, freqüentemente, a fenômenos substitutos ao de interesse, ao invés de medidas diretas. Além disso, muitas vezes os dados são agregados espacialmente e temporalmente, o que aumenta os problemas de interpretação, causando enormes entraves para algoritmos de detecçào de agrupamentos (clusters). Assim, a própria forma com que os dados sào amostrados difículta o processo de extração de conhecimento;

- Dificuldade em formalizar o dominio. Uma das principais dificuldades associadas às atividades de KDD no dominio geográfico é a própria complexidade deste dominio. Até o momento, não há modelos conceituais de geografia accitos universalmente, e os modelos existentes na atualidade, comercialmente implementados em "ciência de informações geograficas", variam significantemente entre si, muitas vezes em termos de abordagens fundamentais e filosóficas [Gah 200I]. Isto acarreta três diferentes problemas: (a) como os dados são, com freqüência, intrinsecamente não-comensuráveis, eles não podem ser diretamente comparados ou combinados; (b) é difícil aplicar conhecimentos geográficos formais no processo de descoberta de conhecimento, posto que tal conhecimento não está prontamente disponivel; (c) quando um novo conhecimento é descoberto, é dificil representá-lo formalmente

Miller e Jiawey [Mil 2001], e Yuan et al. [Yua 2001] apresentam visôes alternativas destes problemas. Tomados conjuntamente, estes vários obstáculos confirmam a necessidade das atividades de descoberta serem situadas em torno de um cspecialista, o geógrafo. Fste é, pelo menos até o presente, o melhor recurso para o entendimento conceitual do dominio, pois é componente vital no reconhecimento e interpretação de padrões e estruturas [Gah 2001].

Apresentada a importância da presença do especialista no processo de KDD, o uso de técnicas que viabilizem a sua integração com o processo como um todo se torna claramentc necessário. Como discutido, a Visualização explora a capacidade humana de interpretação de 
representações visuais para detectar características dos dados associados [Gan 1996; Won 1999] A Visualização torna-se, então, particularmente poderosa, já que provê ao analista um instrumental que permite utilizar sua intuiçăo e conhecimento em uma análise exploratória, com nenhuma ou pouca pré-suposição sobre os dados [Goe 1999]. Um ciclo em que uma visualização direciona outras, de forma sucessiva, permite que o analista ganhe introspecção gradativamente, introduzindo esse conhecimento, bem como seus conhecimentos anteriores sobre o dominio, em estágios precoces do processo de extraçâo de conhecimento. Isso pode reduzir a quantidade de padrōes sem interesse e diminuir a complexidade do processo como um todo [Gan 1996]

A tahela 4.1 apresenta um sumario de diferentes tarefas de descoberta de conhecimento (descobrindo estruturas, relatando e representando as descobertas, validando sua significância e otimizando o desempenho computacional) sob o ponto de vista de diferentes comunidades acadêmicas [Yua 2001]. Dentre estas visòes, a Visualização é a que tem o melhor potencial para fortalecer a integração do usuário com o contexto

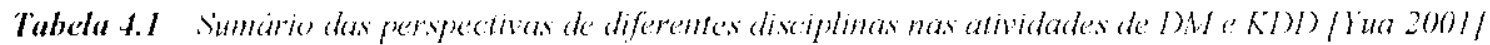

\begin{tabular}{|c|c|c|c|c|}
\hline & $\begin{array}{c}\text { Banco de } \\
\text { Dados }\end{array}$ & Estatistica & I. A. & Visualizaçāo \\
\hline $\begin{array}{l}\text { Descobrindo } \\
\text { Estruturas }\end{array}$ & $\begin{array}{l}\text { Regras de } \\
\text { Associação }\end{array}$ & \begin{tabular}{|l|} 
Análise de \\
Padröes Locais e \\
Testes Globais de \\
Inferência
\end{tabular} & $\begin{array}{l}\text { Redes Neurais, } \\
\text { Árvores de } \\
\text { Decisão }\end{array}$ & $\begin{array}{l}\text { Visualização } \\
\text { Exploratória, } \\
\text { Mineração Visual de } \\
\text { Dados }\end{array}$ \\
\hline $\begin{array}{l}\text { Relatando } \\
\text { Descobertas }\end{array}$ & $\begin{array}{l}\text { Listas de } \\
\text { Regras }\end{array}$ & \begin{tabular}{l|} 
Resumos \\
Estatisticos, \\
Significância e \\
Poder \\
\end{tabular} & $\begin{array}{l}\text { Estimação de } \\
\text { Probabilidade, } \\
\text { Ganho de } \\
\text { Informação }\end{array}$ & $\begin{array}{l}\text { Um Estímulo Dentro } \\
\text { do Domínio Visual }\end{array}$ \\
\hline $\begin{array}{l}\text { Representando } \\
\text { Descobertas }\end{array}$ & $\begin{array}{l}\text { Atualização de } \\
\text { Esquemas de } \\
\text { Metadados }\end{array}$ & $\begin{array}{l}\text { Modelos de Ajuste } \\
\text { Estatisticos, } \\
\text { Locais ou Globais }\end{array}$ & $\begin{array}{l}\text { Grafos } \\
\text { Conceituais, } \\
\text { Meta Modelos }\end{array}$ & $\begin{array}{l}\text { Compartilhado Entre } \\
\text { a Cena e o } \\
\text { Observador }\end{array}$ \\
\hline $\begin{array}{l}\text { Validando } \\
\text { Descobertas }\end{array}$ & $\begin{array}{l}\text { Prova de } \\
\text { Significância } \\
\text { Fraca } \\
\end{array}$ & $\begin{array}{l}\text { Testes Estatísticos } \\
\text { de Significância }\end{array}$ & $\begin{array}{l}\text { Aprendizado } \\
\text { Seguido de } \\
\text { Verificação }\end{array}$ & $\begin{array}{l}\text { Testes com Sujeitos } \\
\text { Humanos }\end{array}$ \\
\hline $\begin{array}{l}\text { Otimizando } \\
\text { Desempenho }\end{array}$ & $\begin{array}{l}\text { Reduzindo a } \\
\text { Complexidade } \\
\text { Computacional }\end{array}$ & \begin{tabular}{|l|} 
Redução de \\
Dados e \\
Estratégias de \\
Amostragem \\
Estratificadas \\
\end{tabular} & $\begin{array}{l}\text { Busca } \\
\text { Estocástica, } \\
\text { Métodos de } \\
\text { Gradiente } \\
\text { Ascendente } \\
\end{array}$ & $\begin{array}{l}\text { Métodos Hierárquicos } \\
\text { e Adaptativos, } \\
\text { "Grand Tour" }\end{array}$ \\
\hline
\end{tabular}




\subsection{Análise Exploratória aplicada a uma Base de Dados Pluviométricos}

O grupo de Computação Gráfica e Processamento de Imagens (CG\&PI) do ICMC vem estendendo sua experiência acumulada em Visualização Cientifica às atividades de visualização exploratória de grandes bases de dados. O presente trabalho se insere neste contexto e investigou o uso de ferramentas de visualização para apoiar o processo de extração de informações de uma base de dados $\mathrm{cm}$ domínio geográfico. Em particular, em consegüência de um projeto de doutorado $\mathrm{cm}$ andamento no CG\&Pl, intitulado "Abordagens Visuais para Suporte à Exploração e Análise de Dados com Atributos Espaciais" [Shi 2001; Shi 2001a], tem-se acesso à base de dados BcDAFE - Banco de Dados Pluviométricos do Estado de São Paulo versão l.0

A base BcDAEE foi utilizada para propor um modelo climático para uma região do oeste paulista, em um trabalho que utilizou diversas técnicas de análise de dados propostas por Flores [Flo 2000]. A base de dados é volumosa e contém muitos dados faltantes e/ou não consistidos (potencialmente incorretos), o que dificulta o processo de exploraçào e seleção de informaçòes de interesse pelos especialistas.

\subsubsection{O Problema da Classificação Climática}

Dados de precipitação pluviométrica diária (agrupados por mês), coletados em 1.660 postos pluviométricos do DAEE no estado de São Paulo desde o final do séc. XIX até 1997, estão armazenados na base de dados BcDAEE. Nesta base de dados, cada posto é identificado por um prefixo (D8-003, por exemplo), o qual é utilizado como um identificador para a sua tabela correspondente na base de dados. Em cada registro de uma tabela estão gravados os dados de um determinado mês/ano, sendo que o intervalo de anos varia de uma tabela para outra, dependendo dos dados disponiveis referentes ao posto correspondente. Isto se deve ao fato de que os postos não foram criados todos ao mesmo tempo e, ao longo de mais de um século, alguns tiveram a coleta interrompida por algum tempo, alguns foram desativados, etc. Além de uma tabela para cada posto, uma tabela adicional compõe a base de dados, contendo informações 
complementares fixas para cada posto, tais como prefixo, o município de localização, posição (longitude, latitude, altitude), dentre outras

O objetivo de uma classificação climática é cstabelecer um modelo para organizar dados climáticos e entender variações climáticas complexas [ $\Lambda$ yo 1991], caracterizando o clima de uma dada região, por exemplo. Devido à caracteristica multivariada de um fenòmeno climático, várias técnicas de estatistica multivariada são usadas para realizar uma classificação climática, tais como análise fatorial. análise de agrupamentos (chus/er) e análise de componentes principais [Aou 1983]. Diversos dados climáticos podem ser utilizados para a tarefa de classificaçăo climática. Aoud [Aou 1983] apresentou um projeto que utilizou parâmetros como temperatura, pluviosidade e umidade relativa. Os valores de precipitação pluviométrica da base de dados BcDAEE foram utilizados para a escolha de anos representativos para as categorias seco, chuvoso e usual, que constituiu um dos passos na tarefa de classificação climática conduzida por Flores [Flo 2000], cujo escopo total englobou, também, dados de altimetria e dos sistemas atmosféricos, visto que são necessários outros parâmetros além da pluviosidade para os procedimentos de classificação climática

\subsubsection{Escopo do Projeto}

No projeto de doutorado supracitado, Shimabukuro [Shi 2001] investiga o uso de ferramentas visuais para apoiar o processo de exploração e extração de conhecimento da base de dados BcDAEE, bem como de outras bases de dados com caracteristicas espaciais e temporais Este projeto de mestrado integrou-se ao projeto de doutorado de Shimabukuro, objetivando identificar, entender e avaliar as vantagens e limitações do uso de técnicas de Visualização de Informação do ponto de vista de um usuário final, quando aplicadas ao conteúdo da base de dados pluviométricos. Inicialmente, Shimabukuro utilizou sistemas de visualização de domínio público para esta tarefa. Em sua monografia de qualificação do doutorado [Shi 200]a], ele apresenta uma sintese de ferramentas para visualização multidimensional, dentre elas o OpenDX, XmdvTool e XGobi/Xgvis, que implementam técnicas de visualização e interação abordadas nos capímlos 2 e 3 deste texto. XGobi e XmdvTool são particularmente interessantes porque permitem visualizar e explorar dados multidimensionais utilizando, de forma integrada, técnicas 


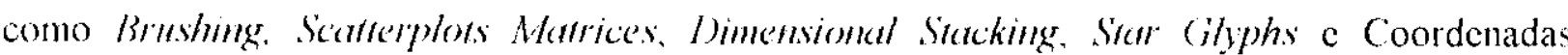
Paralelas.

Neste trabalho de mestrado, após o estudo bibliográlico sobre técnicas de Visualização de Informação e de Mineração Visual de Dados, buscou-se uma familiarização inicial com técnicas, sistemas e ferramentas de visualização multidimensionais, bem como com o conteudo da base de dados alvo da pesquisa. Lm seguida, fez-se a identificação das tarefas/procedimentos referentes às atividades de climatologia, a tim de identificar quais técnicas de visualização e interação seriam desejáveis para oferecer suporte a tais tarefas. Basicamente. o objetivo geral centrou-se na tarefa de seleção dos postos de coleta, que disponibilizassem dados significativos em termos de quantidade e confiabilidade, para posterior análise. Como, além do grande volume de dados, a base de dados disponivel apresenta variaçôes de completude e conliabilidade, a ideia inicial era fornecer os recursos visuais para favorecer a seleçào de porçós interessantes dos dados

Em reuniōes com o Prof. Flores foram identificados 3 procedimentos básicos que deveriam ser executados na base de dados de índice pluviométricos: (1) seleção dos postos, tendo como critérios a altimetria, presença ou não das medições e a consistência das medições presentes; (2) tratamento dos dados ausentes; e (3) agrupar todos os postos para que possam ser categorizados e. quando analisados $\mathrm{cm}$ conjunto $\mathrm{com}$ os outros fatores climáticos, gerar a classificaçào climática. As duas primeiras etapas podem ser mais bem enquadradas no contexto de Análise Exploratória, trabalhando-se diretamente na base de dados. A última etapa almeja a observaçào de padròes nos dados e requerer o uso de técnicas que enfatizem a lida com multidimensionalidade.

Segundo a classificação de Ankerst (seção 2.3), o uso de Visualizaçăo relacionada a esto conjunto de procedimentos configura a chamada "Visualização Fortemente Integrada". Este trabalho de mestrado deteve-se na proposta de soluçoòes para os dois procedimentos iniciais, o que o encuadra como "Visualização dos dados", caracterizado pela visualização sem prévia execução de algoritmos solisticados de mineração e pela ênfase na interação para promover controle sobre o espaço de busca do usuário.

Depois de identificadas as tarefas que definem o escopo de aplicaçào, desenvolveu-se uma aplicaçào para apoiar visualmente as tarelas de exploração visual de dados, por meio de um 
processo de prototipação. Uma preocupação constante na implementação diz respeito à generalidade/extensibilidade das soluçôes propostas. Desta forma, nota-se que este trabalho focalizou, inicialmente, as tarefas especificas adotadas por Flores na exploração analítica dos dados, mas as soluções propostas são extensiveis a outros conjuntos de dados com atributos espaciais e temporais.

\subsubsection{Arquitetura e Aspectos de Implementação do InfoVis}

Fm seu doutorado, Shimabukuro propõe um arcabouço para tratar Análise Exploratória Visual no projeto "InfoVis - Visualização de Informação Aplicada a Dados de Comércio Eletrônico e Climatologia" [Oli 2002], em desenvolvimento no grupo de CG\&lPI. O cscopo de Infolis abrange diversos trabalhos de doutorado e mestrado, sendo que o trabalho de mestrado aqui apresentado implementou propostas visuais para dar suporte ao processo de análise dos dados pluviométricos, integradas ao projeto Infol is, por meio da construção de componentes ${ }^{1}$. Vale ressaltar que o Infolis ainda está em desenvolvimento e, por isso, algumas de suas funcionalidades e caracteristicas ainda não estão disponiveis e/ou implementadas, visto que dizem respeito a projetos de pós-graduação recentemente iniciados. Todavia, como a arquitetura funcional básica já está definida. os trabalhos agregados ao Infolis seguem as suas definições

O projeto InfoVis insere-se no contexto de Visualizaçào Fxploratória de Dados e Mineração Visual de Dados, por meio de extensões de técnicas de visualização multidimensional, e no desenvolvimento de novas estratégias adequadas ao tratamento de grandes volumes de dados. A proposta consiste em |Oli 2002|

- aplicar técnicas e estratégias de análise visual em processos de exploraçâo e análise de grandes volumes de dados de diferentes dominios, para identificar e entender as limitações envolvidas na utilização das técnicas atuais nesse contexto; e,

- utilizar o conhecimento obtido para propor e disponibilizar, em uma plataforma aberta e acessivel via Imernet (mantendo-se a linha de projetos do grupo CG\&PI), recursos mais

"O termo "componente" 16) ambiente hefol "is significal um modulo de software que implementa una certa funcionalidiade 
efetivos para apoiar tarefas de analise e exploração de dados por usuários finais, i.e., especialistas que atuam em domínios diversos.

Durante a definição e desenvolvimento do projeto, algumas premissas foram estabelecidas para o Infolis [Oli 2002]:

- Independincia de plataforma. O sistema deve ser acessivel a um amplo espectro de usuários;

- Lxtensibilidade. Deve ser possivel atualizar a platalorma, com o acréscimo de novos componentes ou de versōes melhoradas de componentes já existentes, com baixo impacto no restante do ambiente:

- Acessibilidade. O sistema deve ser acessivel a um amplo espectro de usuários. A disponilização da plataforma na Web é uma maneira de ampliar a acessibilidade. Além de viabilizar a disponibilizaçào de recursos de visualizaçào para a comunidade de usuários interessada, o que também pode representar uma relevante contribuição para ampliar a sua utilização entre potenciais usuários, a amplitude da acessibilidade proporcionada pela $W e h$ deve facilitar a realização de testes e a colaboraçào direta com usuários finais

- Flexibilidade na configuraçăo. O ambiente deve suportar a geração de configurações diversas e personalizadas de aplicativos de visualização, de acordo com as necessidades de um domínio de aplicação ou um usuário em particular

- Integração de Múltiplas Visualizaçẽes. A possibilidade de explorar simultaneamente múltiplas visualizaçōes de um mesmo conjunto de dados é particularmente interessante em tarelas de análise de dados exploratória, e técnicas de Interação são as responsáveis pela integração entre essas visualizaçòes;

- Acesso a um complo conjumlo de fonter de dados. Para atender efetivamente um público amplo de usuários, o ambiente deve ser capaz de acessar dados de dilerentes formatos ou gerenciadores de bases de dados;

- Registro de Histórico. Processos de explorąão visual tendem a ser fortemente interativos e iterativos, e é comum que sejam feitas várias tentativas envolvendo diferentes parâmetros e técnicas antes que se obtenha um modelo visual interessante. Fsse histórico pode ser usado pelo próprio usuário para avaliar seu processo ou comportamento na exploração e 
análise dos dados, propiciando condições para um posterior refinamento desse processo. Outro uso para o histórico é permitir a outro usuário, local ou remoto, analisar ou replicar o processo, os resultados intermediários e a conclusâo final, emitindo, então, um parecer;

No ambiente Infolis, o usuario acessaria a plataforma disponibilizada na forma de um servidor de recursos de visualizaçào acessivel na Web. Conceitualmente, o usuário escolheria um conjunto de componentes de interesse e montaria um aplicativo ${ }^{2}$ de visualização que executaria localmente na máquina cliente, independentemente do sistema operacional. O processo de configuração de um aplicativo de visualização envolve duas tarefas [Oli 2002]: (1) a escolha dos componentes funcionais de interesse para o usuário final do aplicativo, de acordo com o domínio de aplicação; e (2) a definição de como essas visualizações podem ser 'ligadas', i.e., quais ações de interação serão refletidas simultaneamente em quais visualizaçòes

Para configurar seu aplicativo, o usuário precisa ter algum conhecimento, em nível conceitual, sobre a arquitetura e como ela opera, bem como sobre os recursos de interação suportados pelas técnicas de visualização implementadas. Entretanto, uma vez configurado um aplicativo segundo as necessidades de um certo grupo de usuários, a arquitetura torna-se transparente, bastando que os usuários finais tenham conhecimento operacional das técnicas que irăo utilizar. Não necessariamente esses usuários precisam conhecer a arquitetura da plataforma Deixar disponivcis no servidor aplicativos já finalizados, já testados e consolidados para uma determinada situação, é uma das opções de acessibilidade propostas por Infolitis

A arquitetura organizacional da plataforma Infolis define duas categorias de componentes: componentes do Núcleo Básico e componentes do Núcleo Funcional. O primeiro tipo de componentes caracteriza-se por scr comum a todos os aplicativos, já que promovem essencialmente operaçōes de gerenciamento da operacionalidade dos componentes funcionais Estes, por sua vez, são os responsáveis pelas funcionalidades propriamente ditas do ambiente de visualização, podendo ser (1) componentes de manipulação de dados, que implementam recursos para acesso a arquivos de dados ou gerenciadores de bases de dados externos, bem como recursos para filtragem, amostragem, seleção, e pré-processamento dos dados; (2) componentes de visualização, que implementam técnicas de visualização e seus recursos de interaçâo; ou (3) componentes de interação, que implementam estratégias de interação genéricas, i.e., aplićáveis a

\footnotetext{
${ }^{2}$ No sistema Infolix, um "aplicativo" é un conjunto de "componentes" traballando inter-relacionados.
} 
diferentes técnicas de visualização. O Núcleo Funcional pode ser Geral, quando está no servidor e inclui os componentes que implementam todas as técnicas desenvolvidas e integradas ao ambiente, ou Específicos, quando está sendo executado em máquina cliente por um usuário final e inclui as técnicas de interesse selecionadas. A figura +.1 apresenta uma visão de alto nível da arquitetura organizacional da plataforma Infolis

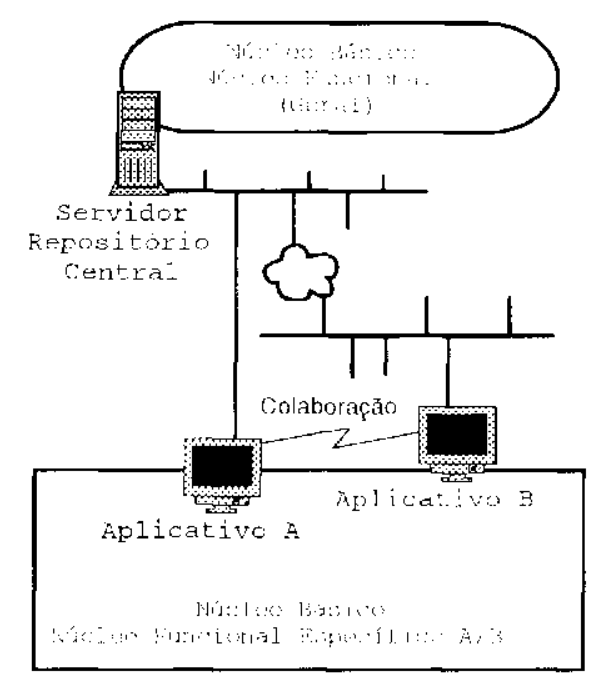

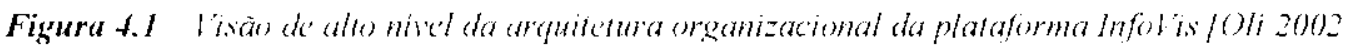

Os aplicativos IIffollis sâo compostos por quatro componentes do Núcleo Básico figurura 4.2): um Controlador da Interface Principal, um Gerenciador de Componentes, um Gerenciador de Ações, e um Gerenciador de Históricos. Estes componentes comunicam-se entre si e mantêm meios de comunicação com cada elemento do Núcleo Funcional. A comunicação entre os Componentes do Núcleo Funcional dá-se de forma indireta, já que é feita pelo Gerenciador de Ações

Cada Componente Funcional deve implementar Interfaces que definem os atributos e métodos necessários para que este componente possa interagir com os Componentes do Núcleo Básico. Na implementaçào, o componente deve manipular todas as variáveis e eventos que fazem parte de seu escopo de atuação. Num exemplo de procedimento normalmente executado na configuração de um aplicativo, o Gerenciador de Componentes instancia uma das classes de Componentes Funcionais definidas na arquitetura, criando um componente ativo (cada componente informa o conjunto de ações que é capaz de realizar e os parâmetros necessários à 
sua execução). A partir deste momento, o componente ativo é responsável por sua própria interação direta com o usuario. Caso este componente queira interagir com outro componente ativo, o Gerenciador de Açôes é acionado para registrar as açòes coordenadas executadas entre eles. Em paralelo, o Gerenciador de Histórico registra os eventos relevantes disparados durante a interação do usuário com um aplicativo. Quando o componente é desativado, o Gerenciador de Componentes registra a ocorrência e executa os procedimentos necessários para manter a aplicação estável. As interlaces que definem a integração dos Componentes Funcionais às aplicaçoes têm versōes iniciais, mas ainda estão em fase de detinição

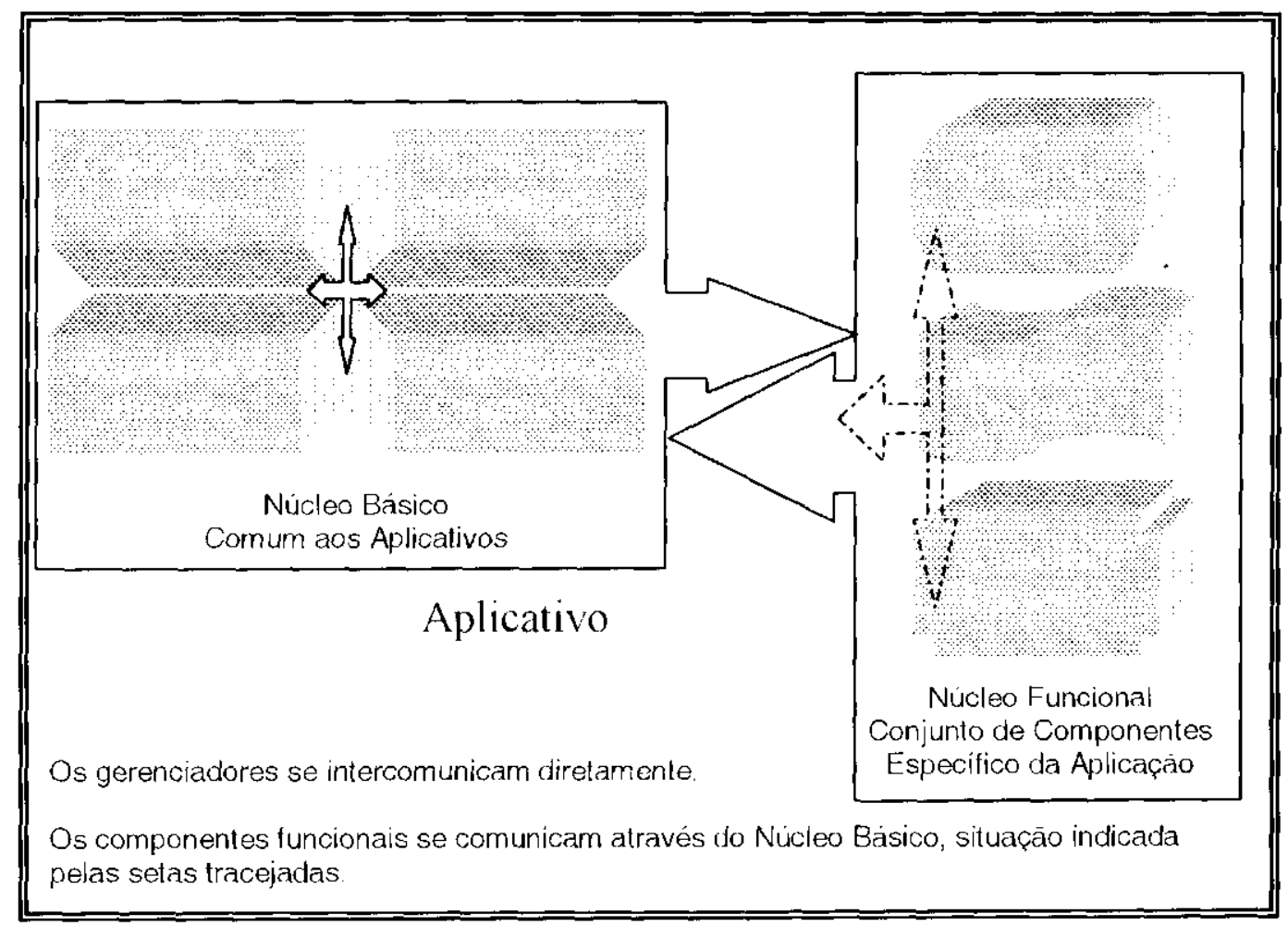

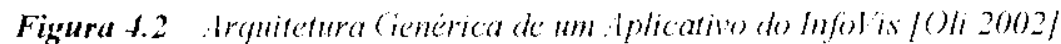

A linguagem Java está sendo utilizada para a implementação de Infolis, principalmente por contemplar várias das características definidas para o projeto. Dentre elas, a acessibilidade na $W e b$, acesso a dados distribuídos, ambiente colaborativo para que usuários possam trabalhar de forma conjunta, e a extensibilidade. são as que mais evidenciam as vantagens da plataforma Java, ora pela APIs (Application Program Interface) especializadas que a plataforma oferece, ora pelo mais eficiente suporte a requisitos tecnológicos (se comparada a outras linguagens) que a definição das caracteristicas traz embutidos (suporte a segurança, XML, etc.). 


\subsubsection{Implementação do Aplicativo de exploração Visual}

O desenvolvimento da aplicação foi norteado por diversos critérios, a fim de manter concordância com os objetivos especificados na definição do projeto de mestrado, c outros relativos à própria tecnologia adotada para o desenvolvimento. Esta seção apresenta o processo de desenvolvimento do aplicativo de exploração visual, identificando os diversos elementos que determinaram as decisões na escolha das soluções implementadas, e os resultados alcançados com estas soluções.

\subsubsection{Tratamento da fonte de dados}

A base de dados BcDAlEE acompanha um sistema próprio para visualização dos dados na forma de tabelas. Liste sistema é fornecido pelo Departamento de Águas e Energia Elétrica (DAEl), pertencente à Secretaria de Recursos Hidricos, Saneamento e Obras do estado de São Paulo. O arquivo da base de dados está em formato "mdb", mas, quando aberto no programa que gera e manipula este tipo de arquivo, o Microsoft ${ }^{\mathrm{k}}$ Access, os dados não podem ser visualizados por estarem com uma codificação própria. Isto quer dizer que a aplicação que acompanha a base consegue manipular os dados, mas uma manipulaçào direta dos dados sem o uso do sistema que acompanha a base nào é permitida. A figur 4.3 apresenta um exemplo de como os dados podem ser visualizados no sistema BcDAEE. Nesta figura, vê-se uma opfão para exportar os dados para um formato "txt", como mostra o exemplo abaixo (posto D8-(003).

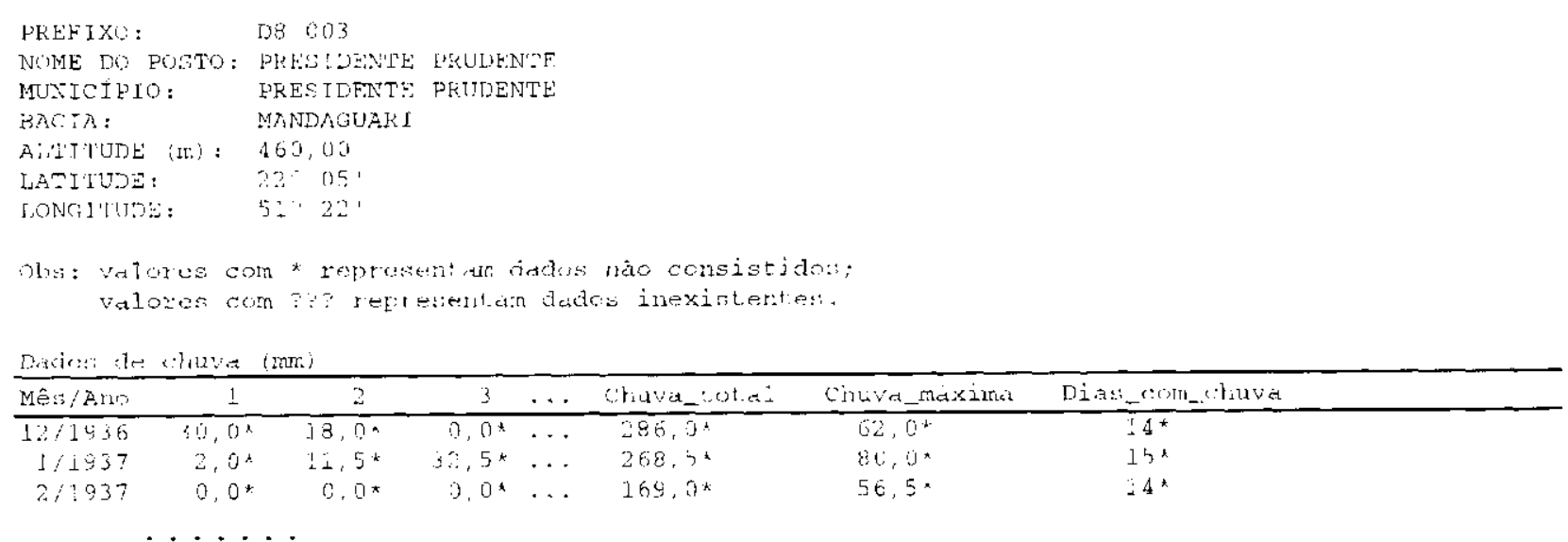




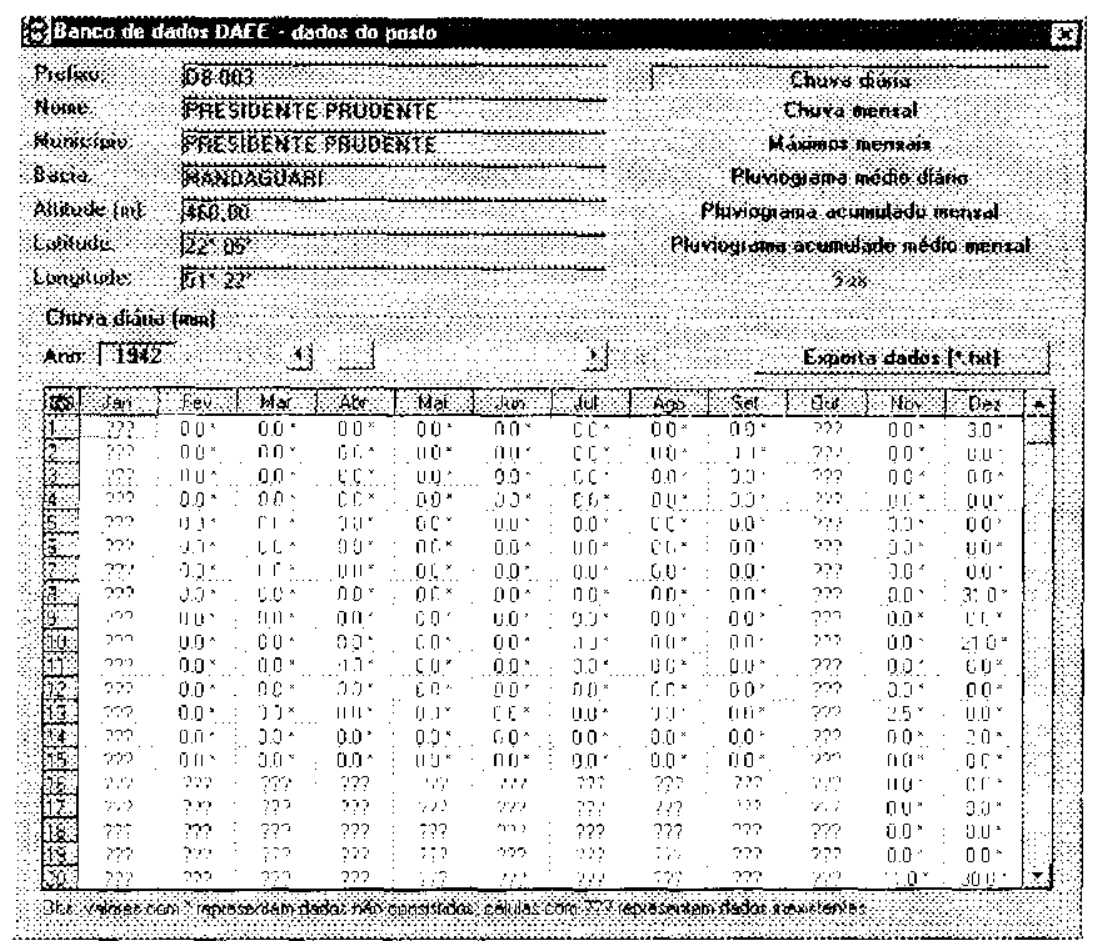

Figura 4.3 Dados do Posto Dsto-003

Ante a impossibilidade de acessar diretamente os dados e da inviável opção de exportar os dados de centenas de postos individualmente, Shimabukuro obteve junto an DAEL: um conjunto de arquivos de dados exportados da base original. Estes foram armazenados em arquivos "dat" (na verdade, um arcluivo no formato ASCll semelhante ao "txt"), em que cada posto estava associado a um arquivo com seus dados de precipitações diárias. Além dos arquivos correspondentes a cada posto, existia também um arquivo com informações gerais dos postos. Os arquivos de dados vinham no seguinte formato (exemplo do arquivo do posto D8-003):

33

Ano, Xes, $1,2,3,4,5,6,7,8,9,10,1,12,13,14,15,16,17,18,19,20,21,22,23,24,25,26,27,28,29,30,31$ $1936 ; 12=300 ; 180 ; 0 ; 0 ; 0 ; 0 ; 0 ; 69 ; 0 ; 0 ; 0 ; 0 ; 0 ; 100 ; 0 ; 90 ; 120 ; 90 ; 920 ; 0 ; 0 ; 290 ; 160 ; 0 ;$ 2,$120 ; 280 ; 0 ; 130 ; 0$

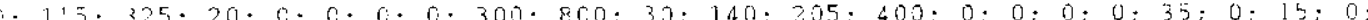

$240 ; 10 ; 0 ; 30 ; 0 ; 0 ; 0 ; 0 ; 0$

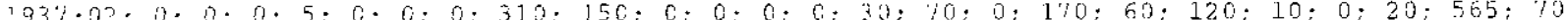

$30: 0 ; 0 ; 30: 9999 ; 99: 9 ; 9999$

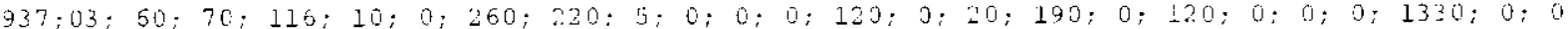

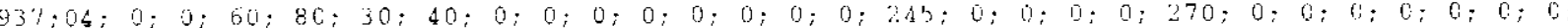

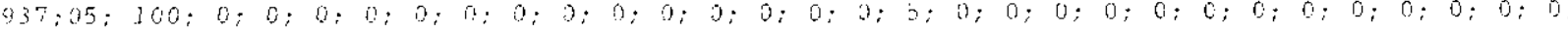

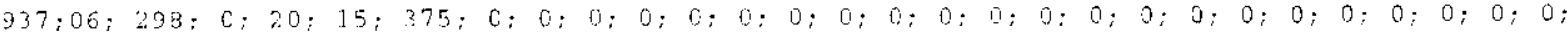

$937 ; 07 ; 0 ; 0 ; 0 ; 0 ; 0 ; 0 ; C ; 0 ; 0 ; 0 ; 0 ; C ; 0 ; 0 ; 0 ; 0 ; 0 ; 43 ; 0 ; 0 ; 0 ; 0 ; 0 ; 0 ; 0 ; 0 ; 0 ; 0 ; 0 ;$ 1): 
$193 \% ; 08 ; 0 ; 0 ; 0 ; 0 ; 0 ; 0 ; 0 ; 0 ; 0 ; 0 ; 0 ; 0 ; 0 ; 0 ; 0 ; 0 ; 0 ; 0 ; 0 ; 0 ; 0 ; 240 ; 320 ; 1 \% ; 0 ; 0 ; 0$ $130 ; 0 ; 0 ; 0$

$937 ; 09 ; 0 ; 0 ; 0 ; 0 ; 0 ; 0 ; 0 ; 0 ; 0 ; 0 ; 0 ; 0 ; 0 ; 0 ; 0 ; 0 ; 0 ; 0 ; 0 ; 0 ; 0 ; 0 ; 0 ; 0 ; 0 ; 0 ; 0 ; 0 ; 0$

$70 ; 9999,200$

1937,$10 ; 267 ; 0 ; 315 ; 0 ; 0 ; 0 ; 0 ; 220 ; 124 ; 0 ; 0 ; 0 ; 0 ; 122 ; 510 ; 0 ; 0 ; 0 ; 150 ; 42 ; 0 ; 0 ; 0 ; 0$

; $223 ; 0 ; 0 ; 0 ; 0 ; 0 ; 0$

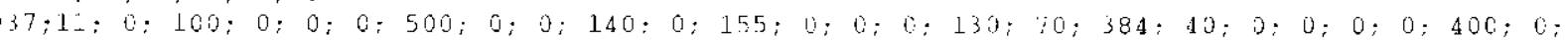

C. $10,0,9990$

1937,$12 ; 0 ; 120 ; 0 ; 0 ; 210 ; 50 ; 0 ; 23 ; 0 ; 20 ; 0 ; 0 ; 0 ; 0 ; 0 ; 0 ; 0 ; 0 ; 20 ; 60 ; 0 ; 0 ; 0 ; 0 ; 110 ; 0 ;$

1938;01; 9999; 9999; 9999; 9979. 9999. 9999: 9999: 9999: 9999. 9999. 9999: 9999; 3999; $9999 ;$ 9999; 9999; 9999; $9999 ; 9993 ; 9999 ; 9999 ; 9999 ; 9999 ; 9999 ; 9999 ; 9999 ; 9999 ; 9999 ; 9999 ; 9999 ;$

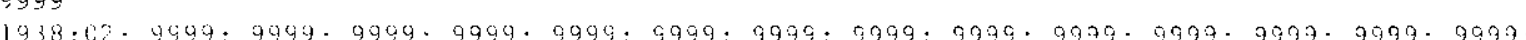

9999; 9999; $9999 ; 9999 ; 9999 ; 9999 ; 5999 ; 9999 ; 9999 ; 9999 ; 9999 ; 9999 ; 9999 ; 9999 ; 9999 ; 9999 ;$ 9999

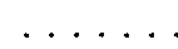

Desta maneira, foi necessário desenvolver um parser para tratar os dados e colocá-los em um formato padrão para que pudesse ser trabalhado pela aplicação. Definiu-se uma classe para armazenar as tabelas de dados, adotando un formato básico semeihante ao do formato de arquivos Arff [Wit 2000], chamada "TableNo" (figura t.f). A definição desta classe ć um passo inicial para uma coleçào de metadados que será definida para o sistema Infolis. Ela define o nome da tabela, o titulo de cada atributo (utilizando um array de Strings), e as colunas com os atributos de dados propriamente ditos (um array de objetos, em que cada objeto é um array com os dados - um arroly para cada atributo).

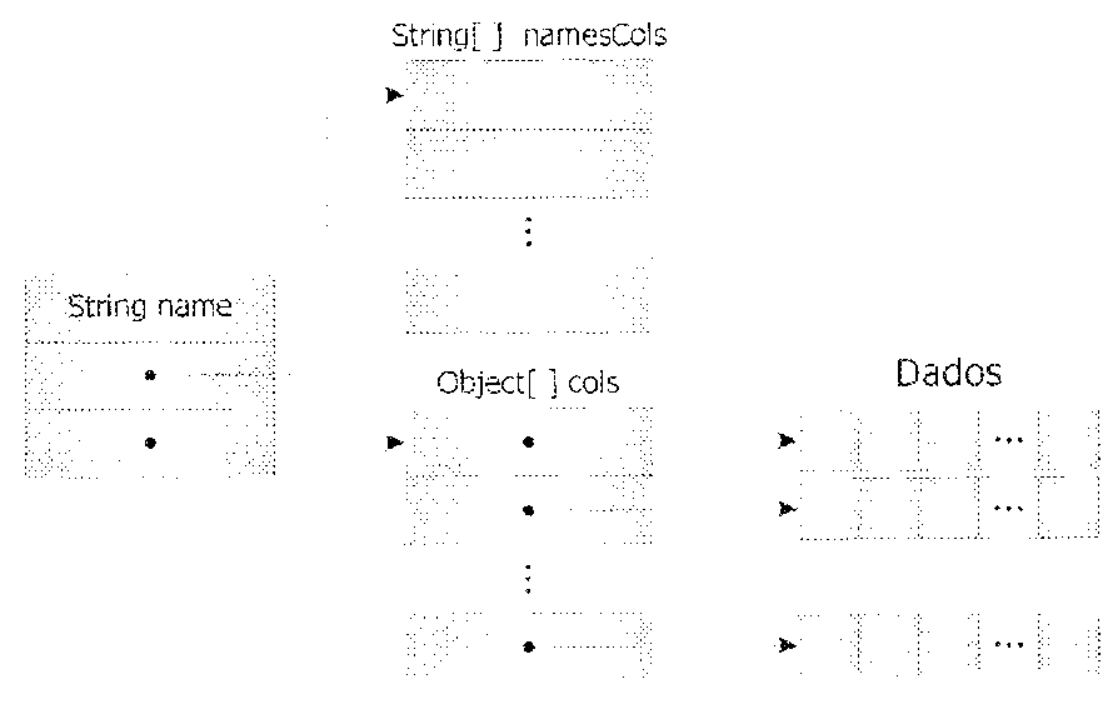

Figura t.3 Fistrulura da ('laswe Tahleto

Fm Java, pode-se trabalhar com arrays de objetos ou de primitivas (boolean, char, byte short, int, long. float ou $d m b / e)$. Embora Java forneça classes para armazenar e facilitar a 
exccução de tarefas comuns a cada uma das primitivas (ex.: classe "Integer" para imt, classe "Double" para domble), a manipulação de arrays de objetos tem um descmpenho inferior ao dos arrays de primitivas [Eck 2002]. Para maximizar o desempenho, nesta definição inicial para a criaçào de tabelas no InfoVis um atributo pode ser um array de um dos três tipos: imt, double, ou String. O único array de objetos é o de objetos String, porque esta classe traz vantagens significativas em relação ao uso da primitiva char (ex.: implementa manipuladores de substrings, conversores para outros tipos de primitivas, etc.)

Baseado no parser para tratar os dados das tabelas de cada posto, outro parser foi criado para tratar a tabela com os dados gerais dos postos. Um dos campos do arquivo "dat" desta tabela trazia um atributo multivalorado com os anos consistidos de cada posto. Desta forma, após a execuçào de todos os parsers, o que se tem é uma coleçào de objetos do tipo TableNo para cada um dos postos, um objeto TableNo para os dados gerais dos postos, e um objeto TableNo com os anos consistidos de cada posto. A figura t.5 ilustra como um desses objetos pode ser visualizado na plataforma Java, utilizando um componente JTable (componente da API Swing).

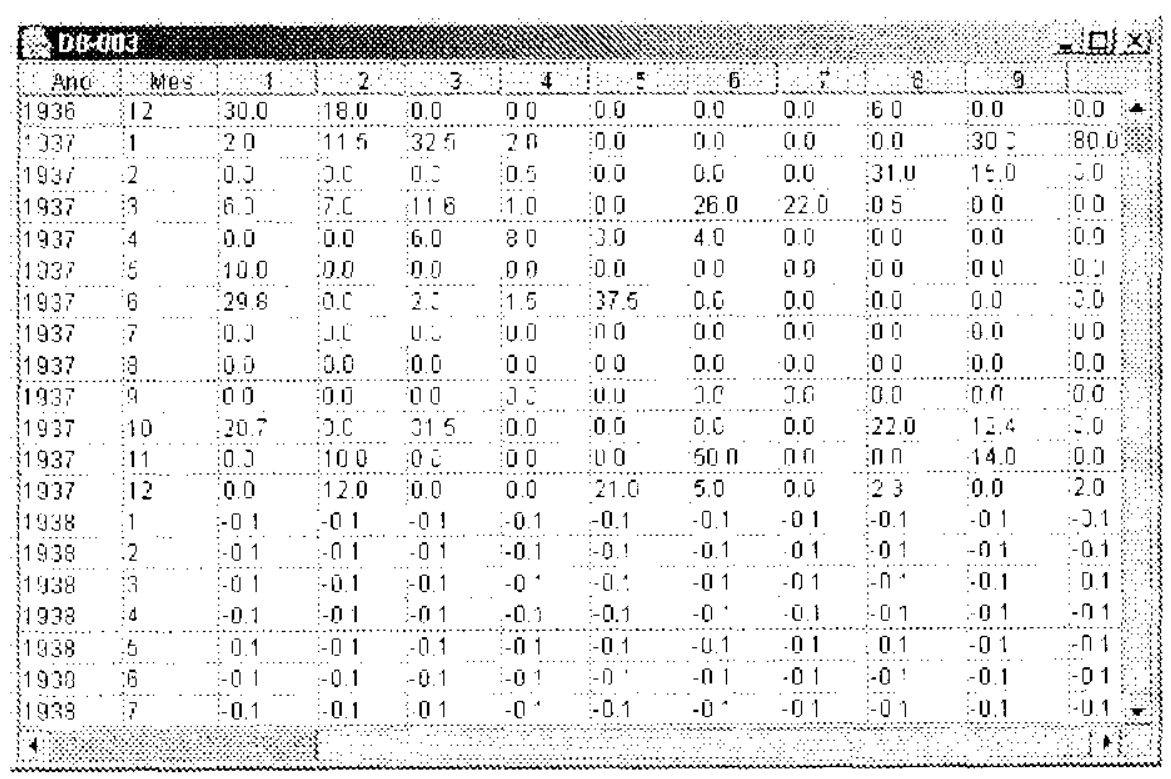

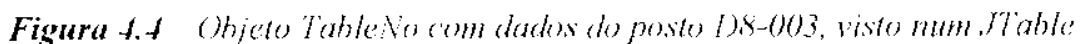

Uma vez criado o objeto, ele pôde ser serializado, i.e., o seu estado pode ser salvo e armazenado para recuperação futura. Desta forma, os parsers se encarregaram não só de tratar os arquivos "dat" e criar os objetos TableNo, mas também de gerar arquivos que salvassem os 
objetos em disco. Assim, cada objeto TableNo foi criado apenas uma vez, e quando necessário, basta recuperá-los do disco. Isto evita que, a cada vez que o aplicativo requisite uma fonte de dados, os dados correspondentes tenham que ser tratados e que objetos TableNo sejam instanciados, onerando o desempenho do sistema.

Os passos apresentados para preparar a base de dados antes de seu uso na aplicação, demonstram como é difícil propor uma solução genérica para pré-processamento dos dados, visto que a sintaxe e a semântica que as bascs de dados apresentam, podem variar muito. Lm exemplo simples é como variou a representaçào de mediçoes faltantes no tratamento de dados apresentado acima: no arquivo "txt" exportado pelo sistema BcDAEE era "???", no arquivo "dat" era "9999", até que adotou-se a representaçào do inteiro negativo "- I" (um valor indicativo de uma entrada fora da faixa de dados possiveis [Wit 2000]) na criação dos objetos TableNo. Entretanto, existem alguns formatos padrão em Mineração de Dados, tais como ARFF e C5.0, sugerindo que se proponham soluçoes para o tratamento de dados em arquivos em formatos específicos. Este não toi o caso encontrado na implementação deste trabalho, mas está previsto que o ambiente Infolis implemente algumas dessas opções, fornecendo parsers para estes e outros formatos de arquivos. Afora a formatação dos dados, uma característica implementada por Java favorece a utilizaçâo de fontes diversas para o sistema Infolis: uma flexível conexão a banco de dados externos, por meio da API JDBC ${ }^{\text {IN. }}$.

Entre as vantagens e características chaves de JDBC pode-se citar: acesso total a metadados (dados sobre os dados, tais como tipo, tamanho, etc), ausência de necessidade de instalações especiais (em ambientes distribuidos); compartilha a característica Java de ser fortemente orientada a objetos, encorajando a manutenção de uma hierarquia organizada de componentes; conectividade a uma ampla gama de servidores de bancos de dados; a documentação padrão das classes da linguagem Java facilita a identificação dos métodos que podem ser executados (universalidade); viabiliza a prototipação rápida, o que favorece a execução da "flexibilidade de configuração" desejada para o InfoVis. Outra característica do JDBC, comum às $A P / s$. Jor em geral, é sua concepção voltada à simplicidade, que nesse contexto diz respeito à forma natural/lógica de execução de procedimentos. Para a obtenção de dados de uma base de dados, por exemplo, é necessário: conectar à base, criar uma instrução (statememt), executar uma consulta e ver os resultados. Em vista das vantagens acima, fica claro que a adoçâo de tal tecnologia ven ao encontro das características desejadas para o ambiente 
Infolis. O tratamento de conectividade a bases de dados será alvo de outros trabalhos envolvidos no desenvolvimento deste ambiente, em que está prevista a criação de um módulo genérico, do tipo componente de manipulacão de dados, que faria conexão a bases de dados externas e construiria os objetos TableNo necessários

\subsubsection{Componente de Interaçäo: Consultas Dinâmicas}

Como bem observado por Shneiderman [Shn 1994], bases de dados geográficos săo candidatas naturais ao uso de Consultas Dinàmicas. Consultas Dinâmicas, associadas à visualização de mapas, oferecem meios para que as relaçòes espaciais entre os elementos mapeados sejam claramente observadas. Quando alguns parâmetros sào definidos nas Consultas Dinàmicas, selecionando guais elementos devem ser mostrados ou destacados no mapa (aqueles que correspondem à especificação dos parâmetros), relações como as de vizinhança entre esses elementos são trivialmente detectáveis.

As Consultas Dinâmicas implementadas recebem um objeto TableNo qualquer, contendo os atributos que definirão os filtros das consultas. Uma listagem é apresentada (figura $4.5 a$ ) com os atributos. À medida que os filtros são selecionados, a contiguração das Consultas Dinâmicas vai se adaptando (figura 4.5 b), para exibir os controles visuais correspondentes. Os controles dos filtros podem ser de dois tipos: Range Shider (figura t.6a), para controle de faixas de dados, ou um grupo de ( heck box (figura t.6b), para controles de dados discretos. A seleção do controle é feita por meio de um Memu Popup exibido ao clicar com o botào dircito do mouse sobre o filtro (figurat.oc)
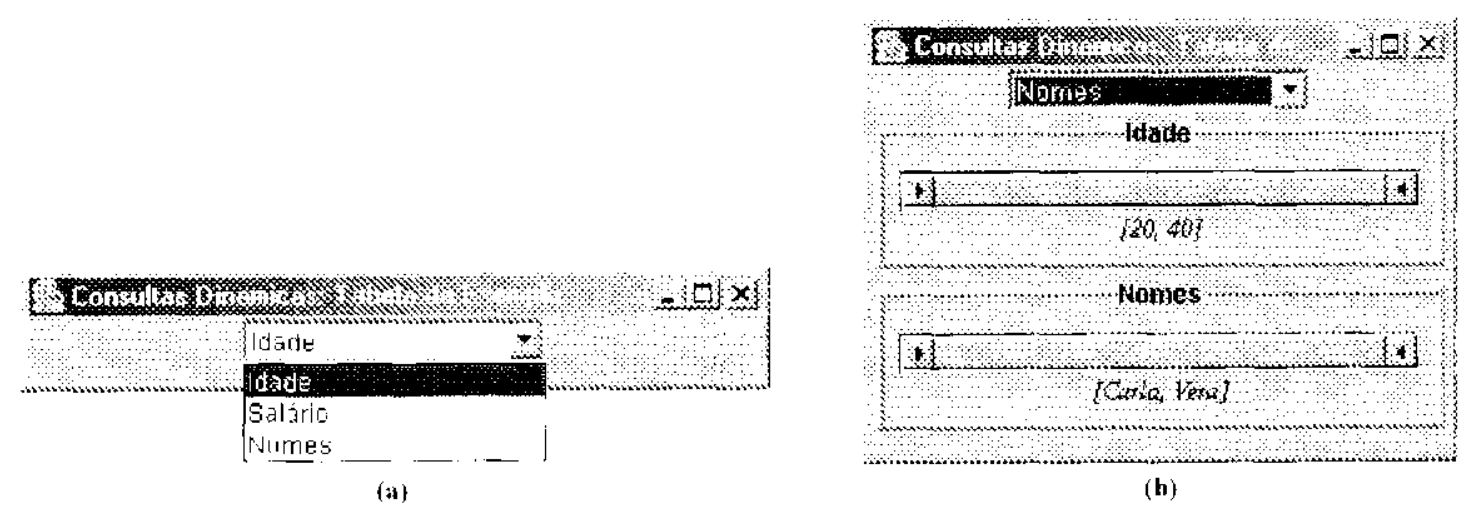

(b)

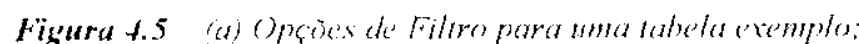

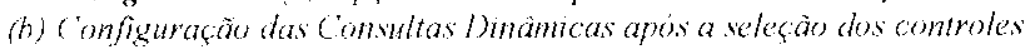




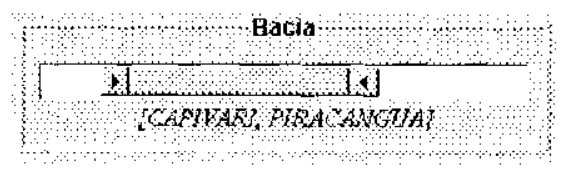

(i)

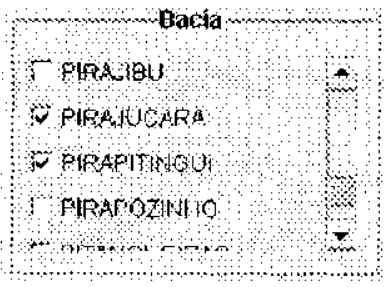

(h)

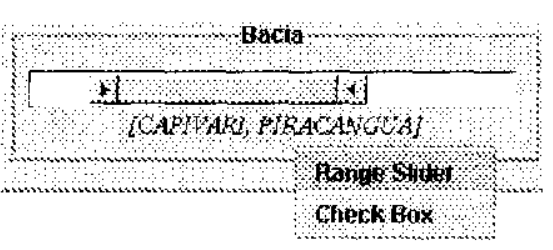

Figura t.o (a) Range Shider; (b) (irupo (heck Box: (c) Mom l'opup para excolha de controle

Com os dois tipos de controles implementados, pode-se utilizar qualquer conjunto de valores nos dados para parametrizar as consultas, não importando se os valores estão em seqüência ou não, ou deseja-se utilizar valores pontuais ou faixas de valores. O componente Range Slider foi totalmente implementado por se tratar de um componente de interface atípico.

Quando um filtro é selecionado para configurar as Consultas Dinâmicas, ele recebe o array com os valores do atributo correspondente, e cria uma estrutura de índice para manipular os itens de dados que correspondem à seleção do usuário. Shneiderman [Shn 1994a] discute estruturas de dados para implementar Consultas Dinâmicas. A estrutura adotada neste trabalho (figura 4.7 ), chamada "IndexEstru" é criada com os seguintes passos:

- ao receber o array com os dados do atributo, o filtro instancia um objeto da classe IndexEstru, passando este array como paràmetro;

- a classe IndexEstru copia o array que recebcu e cria um outro array para armazenar os indices do array de dados (ind);

- a classe IndexEstru ordena os dados do array copiado, ao passo que vai atualizando o array de indices ind com as novas posições dos elementos em decorrência da ordenação

- após a ordenação, a cópia do array de dados é descartada, ficando apenas o array de indices ind correspondendo aos indices do array de dados virtualmente ordenados. Isto significa que, percorrendo o array ind, o que se tem são "apontadores" para o array de dados numa sequència $\mathrm{em}$ que se obteria os dados ordenados;

- cria-se uma estrutura de indice para agrupar os valores distintos (indest), constituida de nós que armazenam o valor e a posição do índice que corresponde à primeira ocorrência deste valor 


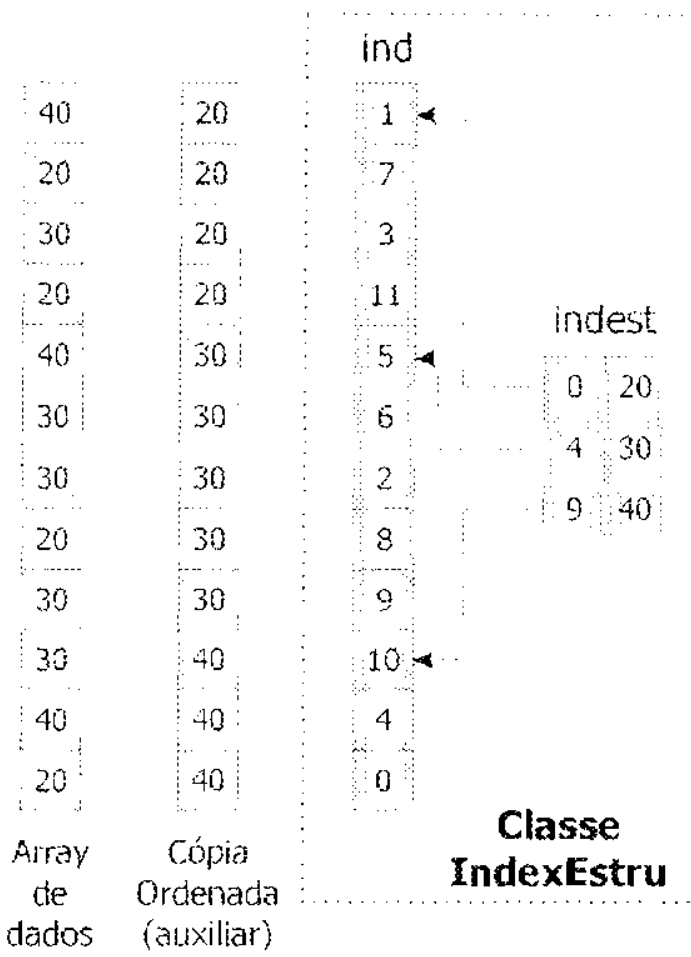

Figura d.7 Limutura da clasese Indextestru com valores de exemplo

Desta forma, a classe IndexEstru possui uma estrutura de índices composta por dois niveis: indest e ind (figura 4.7). A quantidade de nós do nivel indest determina a quantidade de valores distintos e, por conseguinte, determina (1) a granularidade do controle Range Slicter (razão entre a quantidade de espaço que os sliders, esquerdo e direito, têm para deslizar e a quantidade de valores que devem ser controlados), e (2) os elementos ('heck Box que comporão o grupo de controle

Na base de dados BcDAEE, a tabela de dados associada às Consultas Dinâmicas foi a que detém as informaçòes gerais dos postos. Os atributos da tabela sào: Prefixo, Nome, Municipio, Bacia Hidrográfica. Altitude, Latitude, Longitude, Ano Inicial (da coleta de dados), Ano Final e Intervalo (de anos consistidos). As Consultas Dinâmicas trabalharam conjuntamente a um mapa de distribuição cspacial dos postos, em desenvolvimento por Shimabukuro. No mapa, cada ponto refere-se à localização do posto no território do estado de São Paulo. A figura 4.8 traz exemplos de como a visualização reage às consultas executadas em filtros operando individualmente. 


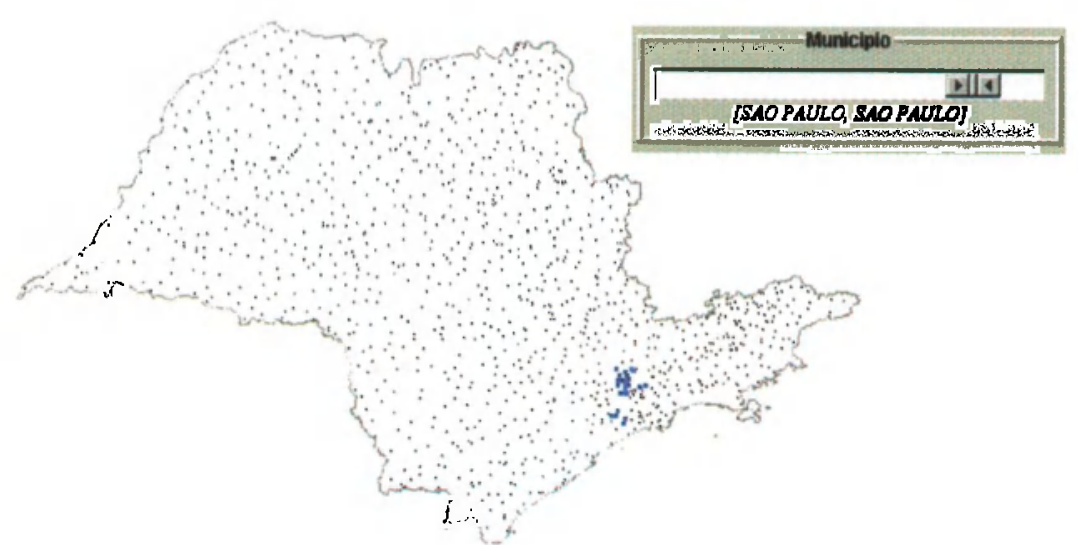

(a)

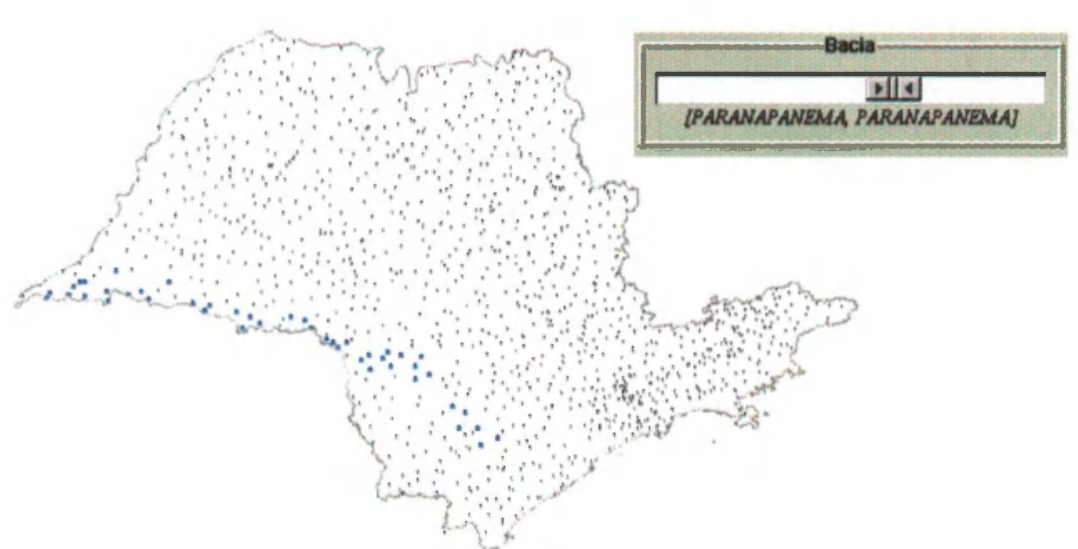

(b)

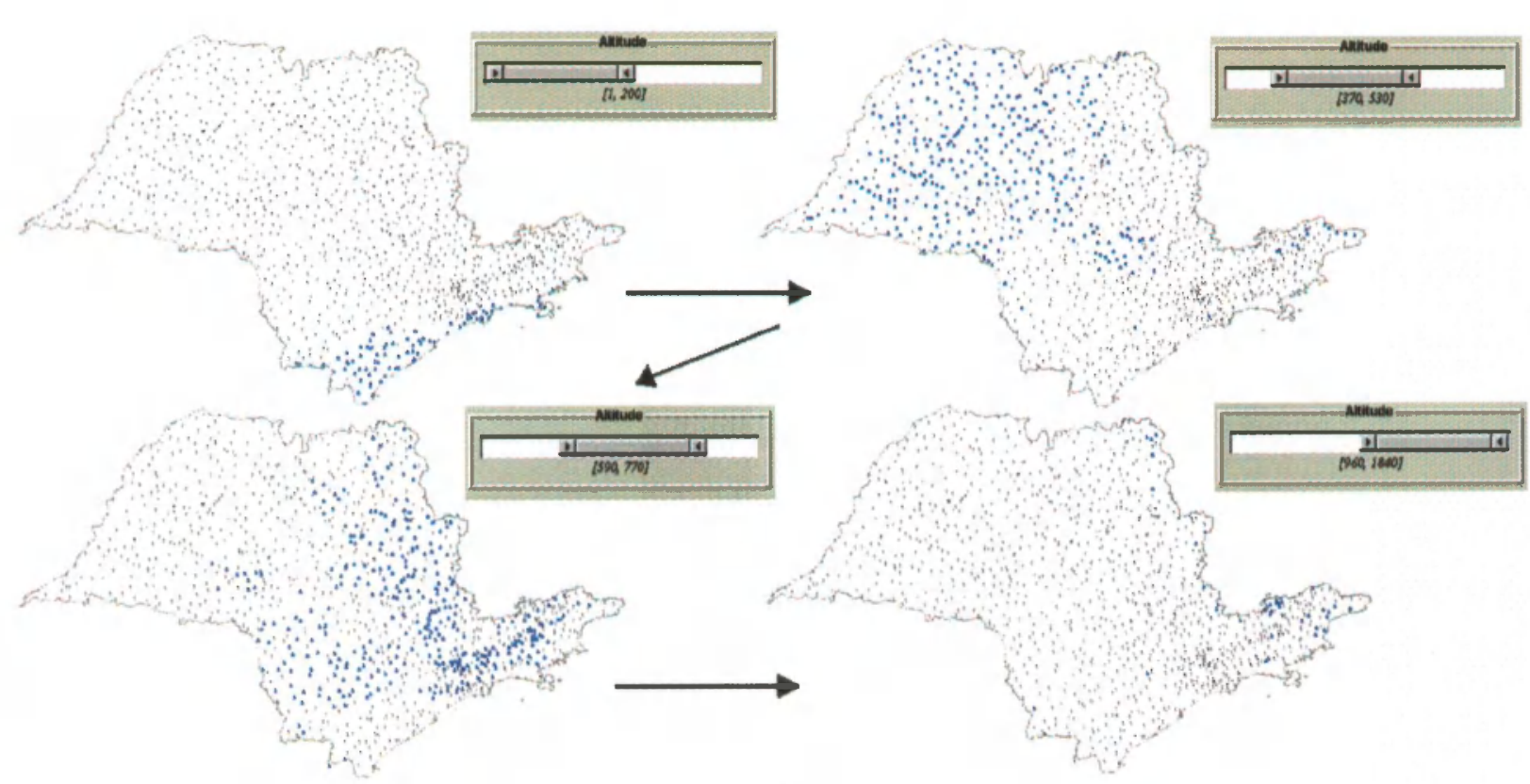

(c)

Figura 4.8 - Filtragens utilizando Consultas Dinâmicas: (a) seleção de um município; (b) seleção de uma bacia hidrográfica; e (c) sequência correspondente ao deslize do Range Slider do filtro de altitude 
São muitas as possíveis combinações dos parâmetros das consultas, e a junção de diferentes consultas torna a filtragem ainda mais eficaz. $O$ dinamismo da filtragem proporcionada pelo controle Range Slider é um fator ainda mais interessante, maximizando a detecção automática de porções de dados interessantes.

Como um dos critérios para a seleção dos postos é a altimetria, a filtragem ilustrada na figura $4.8 c$ mostrou-se particularmente relevante para o domínio da aplicação. Outro exemplo de visualização que permitiu melhor seleção de postos é apresentado na figura 4.9. Nesta figura, uma região é inicialmente delimitada, por meio da seleção de faixas de latitude e longitude, e, em seguida, são selecionados os postos que contém intervalos suficientes de anos com dados consistidos (acima de 30 anos).

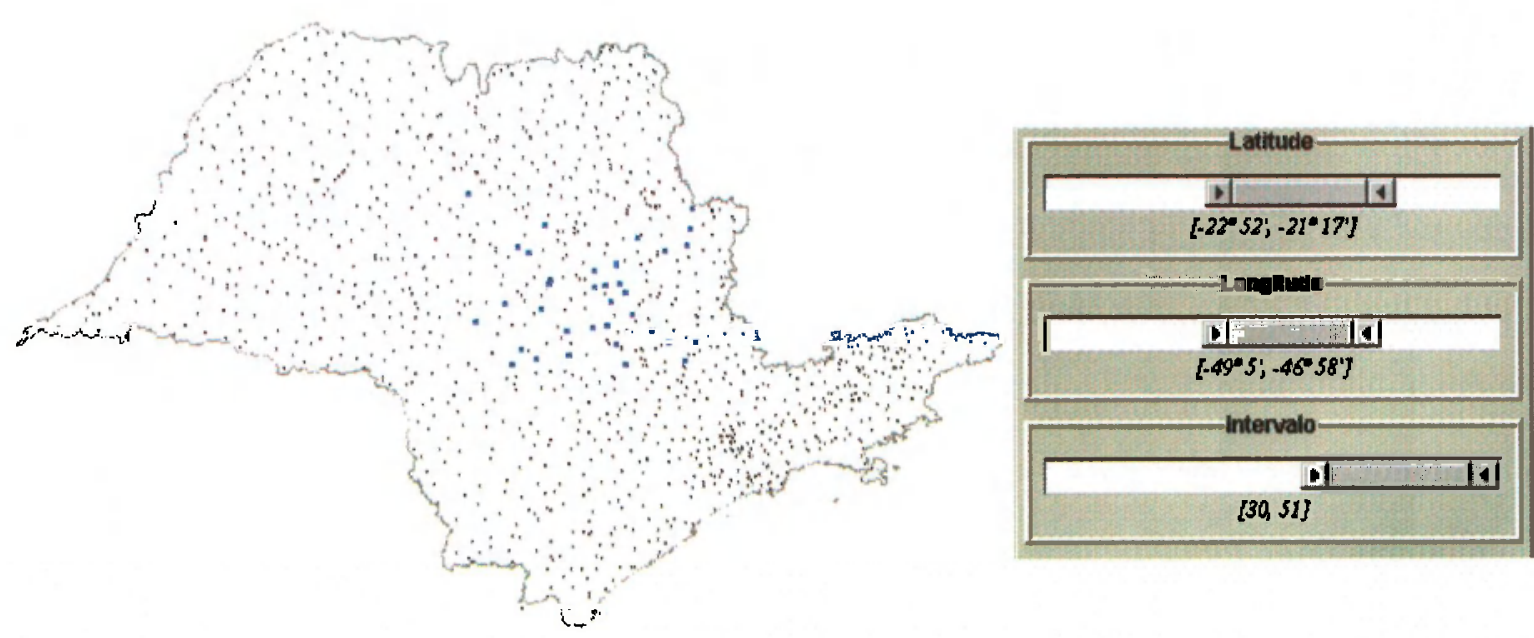

Figura 4.9 - Exemplo de seleção regional de postos com intervalo de anos suficiente para análise

Uma última consideração sobre Consultas Dinâmicas diz respeito ao desempenho do processamento. Na literatura, os artigos que abordam questões ligadas ao desempenho [Ahl 1994; Shn 1994; Shn 1994a], tais como a velocidade de atualização da visualização e estrutura de dados adequada, baseiam-se em recursos computacionais da época (quase dez anos atrás). A implementação não apresentou nenhum dos possíveis problemas apontados, podendo-se deduzir que as restrições apontadas eram resultadas pelas limitações computacionais da época. 


\subsubsection{Componente de Visualização: Técnica Orientada a Pixels}

Em sua qualificação de doutorado, Shimabukuro apresentou alguns testes iniciais utilizando visualizações para selecionar dados interessantes na base de dados BcDAEE. Um dos testes sugeriu uma forma de visualização simultânea de dados de vários postos, apontada como interessante para a observação de quantidade de anos consistidos. Esta visualização permitia compará-los, avaliando se a ausência de dados poderia ser suprida pelo preenchimento de informação obtida de postos vizinhos com características de altimetria semelhantes. Esta visualização (na verdade, uma "Visualização Múltipla") foi implementada neste trabalho de mestrado.

Após a observação de postos interessantes com o uso de Consultas Dinâmicas associadas ao mapa, a Visualização Múltipla pode ser acionada para visualizar os dados dos postos selecionados. A figura 4.10 apresenta uma Visualização Múltipla de quatro postos (é possível visualizar até 20 postos ao mesmo tempo). Em cada visualização, um pixel corresponde ao valor de coleta de precipitação de um dia. No arranjo apresentado, cada linha tem 366 pixels (dias do ano) e cada ano corresponde a uma linha (ao todo 110 linhas, correspondendo aos anos de 1888 a 1997).

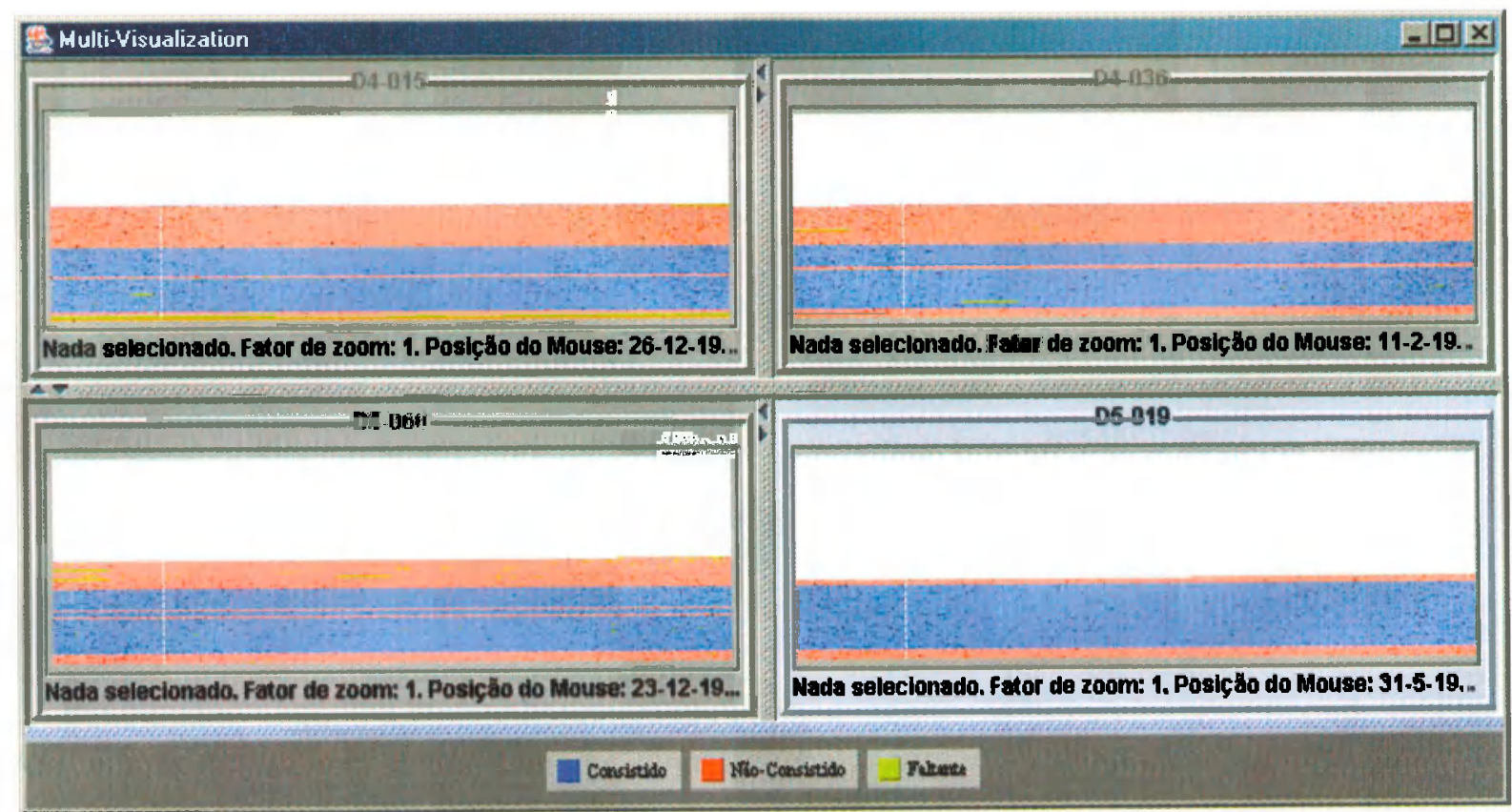

Figura 4.10 - Exemplo de Visualização Múltipla de quatro postos 
Na figura 4.10, observa-se um painel retrátil na parte inferior da janela, contendo múltiplos menus para determinar as cores que mapearão aspectos dos dados. No exemplo apresentado, os dados em azul estão consistidos, os em vermelho não estão consistidos, e os amarelos são dados faltantes. Os trechos em branco correspondem aos anos em que o posto ainda não existia. Observa-se também que há variação de luminosidade para mapear valores das precipitações. Entretanto, para que não se atinja extremos na luminosidade (nem branco, nem preto), limitou-se a variação de luminosidade aos $70 \%$ dos valores medianos. Numa observação imediata, percebe-se comportamentos sazonais: o começo e o final dos anos têm pouca luminosidade, indicando períodos mais chuvosos.

Como visto na seção 3.3, filtragem corresponde a separar, interativamente, o conjunto de dados em partes, e enfocar um subconjunto de interesse. Keim [Kei 2002] define que a filtragem pode dar-se de duas formas: especificando propriedades do subconjunto de dados (com é o caso das Consultas Dinâmicas), ou através de uma seleção direta (navegando nos dados). Na Visualização Múltipla, uma forma simples de visualizar somente os dados de interesse é associar a cor branca aos dados que não são de interesse.
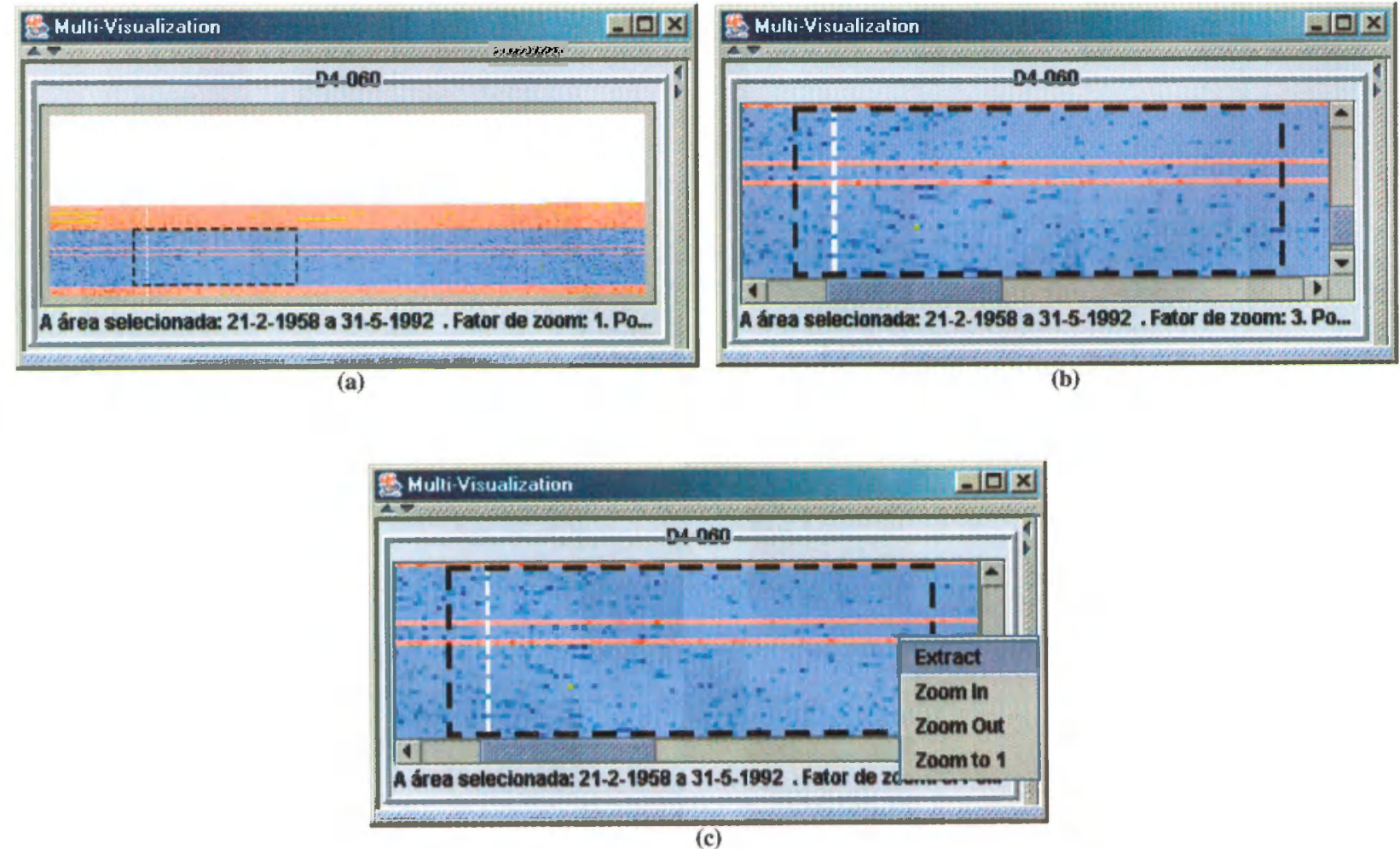

Figura 4.11 - (a) Área selecionada na Visualização dos dados de um posto (b) Imagem ampliada da região selecionada; (c) Opções do Menu Popup 
A Visualização Múltipla apresenta algumas interações inerentes. À medida que o mouse percorre a Visualização, a barra de status apresenta o dia correspondente à posição do pontciro do mouse. Quando se seleciona uma região na Visualização, a barra de status também fornece informaçôes sobre o periodo correspondente à seleção (figura $4.1 / a$ ). $O$ marcador de área selecionada pode ser movido ou redimensionalizado.

Pode-se aplicar zoom de diversas formas. Quando a tecla ( $/ \% /$ está pressionada e clica-se fora de uma área selecionada, o fator de zoom é incrementado a cada clique do mouse. Sc a tecla ( $\mathrm{H} /$ está pressionada e clica-se dentro de uma área selecionada, o fator de zoom é ajustado para ampliar a área selecionada para adequá-la às dimensões da porta de visão (figura $4 . / / h$ ). Se a tecla ( $\mathrm{t} / \mathrm{l} /$ está pressionada e o ponteiro do mouse é arrastado, a área selecionada neste arraste é que irá se adcquar à porta de visão. Os mesmos eventos promovem a diminuição da imagem, mas a tecla utilizada é a Shifi. Uma última forma de interagir com a área de seleção é através de eventos acionados por um Merm Popup (figura $4 . / / c)$

No Mem Popup, além das opçòes de zoom, a opção "Extração" é particularmente importante para o dominio da aplicaçào. Lila permite que os dados selecionados sejam extraidos da fonte de dados original, para posteriormente serem utilizados no preenchimento dos dados laltantes deste ou de outros postos. Descrito na seçü 4.2 .2 , este processo corresponde ao procedimento de tratamento dos dados ausentes.

\subsection{Sumário}

Este capitulo apresentou a problemática envolvida no tratamento de informações no dominio geográfico, e de como este trabalho de mestrado viabilizou técnicas de Visualização para apoiar procedimentos de tratamento de dados utilizados em processos de classificação climática.

Dados de dominio geográfico apresentam caracteristicas temporais e espaciais que dificultam a comprecnsão de fenômenos. Com volumes de dados cada vez maiores, geram-se complexidades de naturezas diversas, dificultando o processo de descoberta de conhecimento a 
partir destas bases. Como grande parte do conhecimento está sob o domínio de especialistas, a Visualização pode apoiar este processo, promovendo a inclusão do especialista

Num processo de classificaçào climática, uma base de dados com índices pluviométricos pode ser utilizada para fornecer um dos parâmetros que determinam as categorizaçŏes do clima. No caso da base de dados BcDAEE, com informações de postos de coleta em todo o estado de São Paulo, tem-se que executar procedimentos iniciais para tratamento dos dados interessantes, já que a base tem problemas de completude e consistência

Desta forma, este trabalho de mestrado implementou uma aplicação para tratamento dos dados, a fim de permitir, num estágio luturo, a percepção de padrões nos dados e agrupamentos dos postos com características semelhantes. A aplicação desenvolvida integra-se ao ambiente Infolis - um projeto em desenvolvimento no CG\&PI - ICMC para Visualização Exploratória de Dados e Mineração Visual de Dados. Foi desenvolvido um componente de interação que implementa a técnica "Consultas Dinâmicas" e um componente de visualização baseado em técnicas orientadas a pixels, promovendo "Visualizaçōes Múltiplas" (uma para cada conjunto de dados dos elementos distribuídos espacialmente - no caso, postos). 


\section{CAPÍTULO 5}

\section{Conclusões}

A aplicação de Visualização no contexto de Descoberta de Conhecimento em Bases de Dados mostra-se potencialmente útil, por promover a integração de dois fatores notórios: o grande poder de processamento de dados dos computadores e a facilidade dos seres humanos no reconhecimento de padrões visuais.

A vertente de Visualização que lida com a representação de dados abstratos, Visualização de Informação, por ser relativamente recente, tem seu processo de definição de conceitos, terminologia, taxonomia de técnicas, etc., ainda visivelmente incipiente. Grande parte das técnicas já consolidadas em Visualização de Informação envolve adaptações de técnicas e conceitos de outras áreas de conhecimento, tais como Geometria Computacional e Estatistica. Muitos tópicos permanecem em aberto para pesquisa de novas técnicas e proposta de definições conceituais que avancem a área e promovam consenso entre os pesquisadores.

Esta incipiente metodização de Visualização de Informação foi uma das dificuldades encontradas no estudo bibliográfico realizado para a exccução deste projeto de mestrado. A dificuldade em se estudar uma área ainda em fase de definição conceitual torna-se claramente visível, por exemplo, quando diferentes autores divergem sobre a categorização de uma determinada técnica. Não obstante, este trabalho preocupou-se em apresentar as diferentes visōes dos autores, mas dando destaque àquelas que tendem a se consolidar, já que são mais freqüentemente citadas na literatura. e trazem distinções conceituais claras e intuitivas. Assim, 
acredita-se que a abrangência conceitual e a concisão adotada neste trabalho tenham sido uma de suas contribuiçòes

Visualização integrada à Mineração Dados é um contexto ainda mais recente. Todavia, as experimentaçòes e os resultados que vem obtendo justificam o destaque que vem recebendo em bibliografia especializada, que, por sua vez, gera motivação para novos estudos. Este é um fator que impulsiona a aceleração do processo de definiçào da área

$\grave{A}$ medida que tal definição evolui, outras áreas do conhecimento poderão identificar vantagens ou possibilidade de uso em seu dominio. São muitas as áreas do conhecimento que valem-se de recursos computacionais para viabilizar ou aumentar a eficiência de procedimentos inerentes às suas análises. O domínio geográfico é um exemplo significativo, já que é caracterizado pelo grande acúmulo de informação, associado a uma grande complexidade destes dados. Neste domínio, a Visualizaçào mostra-se particularmente interessante por promover meios para inserir o conhecimento dos especialistas no processo de análise

Neste projeto foi concebido e implementado um aplicativo para a visualização de dados de uma base de dados pluviométricos, o qual está inserido na arquitetura do ambiente Infolvis um projeto em desenvolvimento no grupo de Computação Gráfica e Processamento de Imagens do ICMC. Objetivamente, as contribuições sobresselentes deste projeto de mestrado foram:

- tratamento do conjunto de arquivos que compõem a base de dados BcDAEE;

- definição de estrutura e meio de armazenamento eficientes para os dados tratados da base BCDAEL, acelerando o acesso ao conjunto de dados. A abordagem adotada pode ser estendida para qualquer conjunto de dados que venha a ser utilizado no Infolis;

- implementação da técnica de interação "Consultas Dinâmicas" na forma de um componente de interação para o ambiente Infolis. Assim, pode ser parametrizado por qualquer fonte de dados, e utilizado em conjunto com qualquer componente de visualizaçâo integrante deste ambiente;

- implementação de uma técnica de visualização baseada em pixels na forma de um componente de visualizacão para o ambiente Infol'is. Fla permite a visualização de grande quantidade de dados ao mesmo tempo, permite a comparação dos dados de diversos elementos espaciais, implementa recursos interativos que maximizam a integração do usuário, e, quando 
aplicada aos dados da base BclDAFE. permite manipulação dos dados para a execução de procedimentos necessários para a classificação climática (tratamento de dados faltantes)

Uma limitação deste projeto foi a não execução de testes com outras bases de dados. 0 principal fator que inviabilizou este procedimento foi a necessidade de efetuar um previo tratamento de arquivos originarios de outras bases de dados. e a falta de tempo hábil para tal.

Este projeto de mestrado é o primeiro egresso de vários projetos de pós-graduação em andamento vinculados ao Infolis. Assim, pode-se se citar algumas sugestōes de extensōes'.

- definição de um conjunto de metadados para os meios de armazenamento de dados no linfolis

- implementação de um assistente de importação de dados para serem visualizados no Infollis, utilizando JDBC para promover conectividade a diferentes tipos de fontes de dados;

- promover um ambiente colaborativo para usuarios dos aplicativos configurados no sistema;

- aproveitar a extensibilidade dos componentes da arquitetura, para implementar outras técnicas de interação e visualização. Por excmplo, implementar a técnica Magic Iéns estendendo o componente que implementa as "Consultas Dinàmicas",

- implementação de técnicas de visualização conhecidamente eficazes para visualização de dados multidimensionais, tal como "Coordenadas Paralelas", para ampliar o número de potenciais usuarios do ambiente.

\footnotetext{
Algumas destas sugestòes pertencem ao escopo de alguns projelos de pós-graduaçăo vinculados an Infol \%
} 


\section{REFERÊNCIAS BIBLIOGRÁFICAS}

[Ahl 1994] AHLBERG, C; SHNEIDERMAN, B. - Visual Information Seeking: Tight Coupling of Dynamic Query Filters with Starficld Displays. In: Human Factors in Computing Systems: Proceedings of the CHI '94 Conference. New York, 1994. p. 313-317.

[Ahl 1994a] Ahlberg, C.; Sineiderman, B. - The Alphaslider: A Compact and Rapid Selector. Proceedings of Human Factors in Computing Systems (CHI 94) ACM Press, 1994, p.365-371.

[Ale 1998] Alexakis, A.; Deftereos, M.; Samiotakis, Y. - Visualization Techniques In Statistics. The Parallel Coordinates Visualiser (PARCOVI). In; NTTS'98 International Seminar on New Techniques and Technologies for Statistics. Sorrento, Itália, 1998. Ph. Nanopoulos, P. Garonna, C Lauro (Eds). p. 19-24.

[Alv 2000] Alves, A.D.; OliveirA, M.C.F.; MiNGHIM, R.; NONATO, L.G. - Interactive Visualization over the WWW, Proc. Brazilian Symp. Computer Graphics \& Image Processing (SIBGRAPI'2000) IEEE Press, 2000, p. 259-266.

[And 1999] ANDrienko, G.; ANDRIENKo, N. - Knowledge-Based Visualization to Support Spatial Data Mining, IDA'99 LNCS 1642, 1999. Hand, D.L., Kok, J.N., Berthold, M.R. (eds.). p. 149-160.

[Ank 2000] Ankerst, M. - Visual Data Mining, Tese de Doutorado, Faculty of Mathematics and Computer Science, University of Munich, Munich, 2000.

[Ank 2001] ANKEKST, M. - Visual Data Mining and Exploration of Large Databases. Tutorial at PKDD'2001, Freiburg, Germany, 2001.

[Aou 1983] Aol AD, M.S. - Tentativa de Classificação Climática para o Estado da Bahia (Uma análise quantitativa dos atributos locais associada à análise qualitativa do processo genético) -.. IBGE, Rio de Janeiro, 1983.

[Ayo 1991] AYOADE, J. O. - Introdução à Climatologia para os Trópicos, $3^{a}$ Edição, Tradução de Maria Juraci Zani dos Santos, Revisão de Suely Santos, Editora Bertrand Brasil, 1991.

From the original "Introduction to climatology for the tropics", John Wiley \& Sons, 1983.

[Car 1994] CARR, D.A.; JOG, N.; KUMAR, H.P.; TEITTINEN, M.; AHLBERG, C. - Using Interaction Object Graphs to Specify Graphical Widgets. Technical Report CAR-TR-734, Department of Computer Science, University of Maryland, Maryland, 1996

ICar 1999] CARD, S.K.; MACKINLAY, J.D.; SHNEIDERMAN, B. - Information Visualization. In: Readings in Information Visualization - Using Visualization to Think. San Francisco, Morgan Kaufmann Publ., 1999. Card, S.K.; Mackinlay, J.D.; Shneiderman, B. (eds.). p. 1-34.

[Car 1999a] CARD, S.K.; MACKINLAY, J.D.; ShNEIDERMAN, B. - Focus+Context. In: Readings in Information Visualization - Using Visualization to Think. San Francisco, Morgan Kaufmann Publ., 1999. Card, S.K.; Mackinlay, J.D.; Shneiderman, B. (eds.). p. 307-309.

[Cha 2000] Chawla, S.; SheKhar, S.; WU, W.; Ozesmi, U. - Extending Data Mining for Spatial Applications: $\Lambda$ Case Study in Predicting Nest Locations, ACM SIGMOD Workshop on Research Issues in Data Mining and Knowledge Discovery, 2000

[Che 1996] CHEN, M.-S.; HAN, J.; Yu, P.S. - Data Mining: An Overview from a Database Perspective, IEEE Transactions on Knowledge and Data Engineering, v.8, n.6, p.866-883, dez. 1996. 
[Cle 1994] Cifvel.And W.S. - The Elements of Graphing Data. Revised Edition. New Jersey: AT\&T Bell Laboratories, 1994. $270 \mathrm{p}$

[Eck 2002] FCKHI, B. - Thinking in Java. 3. ed., Prentice Hall, 2002.

[Eds 1999] EDSALL, R. M (1999). The dynamic parallel coordinate plot: visualizing multivariate geographic data. Proc. 19th International Cartographic Association Conference, Ottawa, May 1999.

[Eic 2000] EICK, S.G. Visual Discovery and Analysis, IEEE Transactions on Visualization and Computer Graphics, v.6, n.1, p.44-58, jan./mar. 2000.

[Est 1999] Ester, M.; KRIFGel, H-P.; SANDER, J. - Knowledge Discovery in Spatial Databases, invited paper a German Conf. On Artificial Intelligence (KI’99), Bonn, Germany, 1999.

[Fal 1995] Falounsos, C.; LIN, K.-I. - FastMap: A Fast Algorithm for Indexing, Data-Mining and Visualization of Traditional and Multimedia Datasets. ACM SIGMOD, v.24, n.2, p.163-174, 1995

[Fay 1996] Fayynd, U.; Piatetsky-Shapiro, G.; SMyTh, P. - Knowledge Discovery and Data Mining: Towards a Unifying Framework. In: Knowledge Discovery and Data Mining, 1996. p. 82-88.

[Fay 1998] FAYYAD, U. Mining Databases: Towards Algorithms for Knowledge Discovery, Data Engineering Bulletin, v.21, n.1, p.39-48, 1998.

[Fis 1995] FISHKIN, K.; STONE, M.C. - Enhanced Dynamic Queries via Movable Filters. In: Human Factors in Computing Systems: Proceedings of the CHI '95 Conference. New York, 1995. p. 415-420.

[Flo 2000] FLORES, E.F. - Modelagem em Climatologia Geográfica: Um Ensaio Metodológico Aplicado ao Oeste Paulista, Tese de Doutorado, Instituto de Geociências e Ciências Exatas -- Unesp - Campus do Rio Claro, Março de 2000.

[Fol 1990] Foley, J.D.; VanDam, A.; Feiner, S.K.; HCgheS, J.F., Computer Graphies Principles and Practice, 2. Ed., Ed. Addison Wesley, 1990.

[Fre 1995] Fre.tTAS, C.M.D.S.; WAG.NeK, F.R. Ferramentas de Suporte às Tarefas da Análise Exploratória Visual. Revista de Informática Teórica e Aplicada, v.2, n. 1, p.5-36, jan. 1995.

[Fre 2001] FreitAs, C.M.D.S.; ChlBaChI, M.O.; LuzZARDI, P.R.G.; CAVA, R.A. Introdução à Visualização de Informações. Revista de Informática Teórica e Aplicada, v.8, n.2, p. 143-158, oul. 2001.

[Gah 2001] GahtGan, M. .. Data Mining and Knowledge Discovery in the Geographical Domain, White Paper : National Academies Computer Science and Telecommunications Board, GeoVISTA Center, Department of Geography, The Pennsylvania State University, Pennsylvania, 2001

[Gan 1996] Ganesh, M.; Han, E-H.; Kumar, V.; SHekhar, S.; Srivastava, J. - Visual Data Mining Framework and Algorithm Development, Technical Report TR-96-021, Department of Computer Science, University of Minnesota, Minneapolis, 1996

[Goe 1999] Gofbel., M.: Grufnwald, L. - A Survey Of Data Mining And Knowledge Discovery Software Tools, SIGKDD Explorations, ACM SIGKDD, v l(issue 1), June 1999.

[Han 1998] HAND, D.J. - Data Mining: Statistics and More ?, The American Statistician, v.52, n.2, mai. 1998

[Her 2000] Herman, I; Mel.anÇON, G; Marsilall, M.S. - Graph Visualization and Navigation in Information Visualization: $A$ Survey, IEEE Transactions on Visualization and Computer Graphics, v. 6, n. 1 p.24-42, jan./mar. 2000) 
[Hin 1999] HinNeburg, A; Kerm, D.A; WAWr YNIL'K, M.-- HD-Eyc: Visual Mining of High-Dimensional Data, IEEE Computer Graphics and Applications, v.19, n.5, p. 22-31, sct./out. 1999.

[Hof 1997] Hofman, P.; Grinstein, G.; Marx, K.; Grosse, I.; Stanley, E. - DNA Visual And Analytic Data Mining, $8^{\text {th }}$ IEEE Visualization'97 Conference, Phoenix, $A Z$, out. 1997.

[Hof 1999] HofFMAN, P.; GRINSTEIN, G. - A Survcy of Visualizations for High-Dimensional Data Mining. In: FAYYAD, U.; GRINSTEIN; G.G.; WIERSE, A. . A Information Visualization in Data Mining and Knowledge Discovery. San Francisco, Morgan Kaufmann Publishers, 1999. p.47-82.

[Ins 1985] INSELBERG, A.; DiMSDALE, B. - Parallel Coordinates: A Tool for Visualizing Multi-dimensional Geometry, Proceedings of the 1990 IEEE Symposium on Information Visualization (InfoVis'90), p. $361-375,1990$.

[Ins 1997] InSElberg, A. - Multidimensional Detective, Proceedings of the 1997 IEEE Symposium on Information Visualization (InfoVis'97), p. 100-107, 1997

[Jer 1995] JeRding, D.F.; STAsko, J.T. - The Information Mural: A Technique for Displaying and Navigating Large Information Spaces. Proceedings InfoVis'95, IEEE Press, 1995, p.43-50.

[Joh 1991] JOHNSON, B.; SHNEIDFRMAN, B. - TreeMaps: A space - filling approach to the Visualization of IIierarchical Information Structures. In: Proceedings of IEEE Visualization' 91. San Diego, 1991, p.284-291.

[Kei 1994] KEIM, D.A; KRIEGEL, H.-P.; SEIDL, T. - Supporting Data Mining of Large Databases by Visual Fcedback Queries, Proc. 10 ${ }^{\text {th }}$ Int'I Conf. Engineering, Houston, Texas, 1994. p. 302-313.

[Kei 1994a] KeIM, D.A., KrIEGEL, H.-P. -- VisDB: Database Exploration Using Multidimensional Visualization. IEEE Computer Graphics and Applications, p.40-49, set. 1994.

[Kei 1995] KeIM, D.A., KR!EgLl, H.-P. -- Issues in Visualizing Large Databases. Proc. Conf. on Visual Database Systems (VDB), Lausanne, Schweiz, 1995, In: Visual Database Systems, Chapman \& Hall Ltd., 1995.

[Kei 1996] KFIM, D.A; KRIEGLi, H.-P.; - Visualization Techniques for Mining Large Databases: A Comparison, IEEE Transacations on Knowledge and Data Engineering, v.8, n.6, p.923-938, dez. 1996.

[Kei 2000] KELM, D.A. - Designing Pixel-Oriented Visualization Techniques: Theory and Applications, IEEE Transactions on Visualization and Computer Craphics, v.6, n.5, p.59-78, jan./mar. 2000.

[Kei 2001] KEIM, D. A. - Visual Exploration of Large Data Sets. Communications of the ACM, v.44, n.8, p.3844, ago. 1979

[Kei 2002] KEIM, D. A. - Information Visualization and Visual Data Mining. IEEE Transactions on Visualization and Computer Graphics, v.8, n. I, p. 1-8, jan./mar., 2002.

[Kop 1996] Koperskı, K.; AdhIKAry, J.; HAN, J. - Spatial Data Mining: Progress and Challenges Survey Paper, Proc. ACM SIGMOD Workshop on Research Issues on Data Mining and Knowledge Discovery, Montreal, Canada, 1996.

[Kop 1998] KOPERSKI, K; HAN, J.; ADHIKARY, J. - Mining Knowledge in Geographical Data, Communications of ACM, 1998.

[Lam 1996] LAMPING, J.; RAO, R. - The Hyperbolic Browser: A Focus+Context Technique for Visualizing Large Hierarchies. Journal of Visual Languages and Computing, v.7, n. 1, p.33-35, 1996.

[Lev 1992] Levkowitz, I1.; Herman, G.T. - Color Scales for Image Data. IEEE Computer Graphics and Applications, v.12, n. 1, p.72-80, 1992 
[Mac 1986] MaCKINLAY, J.D. - Automating the Design of Graphical Presentations of Relational Information. ACM Transactions on Graphics, v.5, n.2, p.110-141, 1986

[Mac 2000] MACEACIIREN, A.M.; KRAAK, M-J. - Research Challenges in Geovisualization, forthcoming in Cartography and Geographic Information Science, v.28, n.1, 2001.

[Men 2001] MENIDONÇA, M.G.; ALMEIDA, M.O. - Uso de interfaces Abundantes em Informação para Mineração Visual de Dados. Relatório Téenico RT-NUPERC-2001-5/p, Núcleo de Pesquisá Interdepartamental em Redes de Computadores, Universidade Salvador, ago. 2001.

[Mil 2001] MILLER, H.J.; JiAwEI, H. - Geographic Data Mining and Knowledge Discovery: An Overview. In: Geographic Data Mining and Knowledge Discovery. H. J. Miller and J. Han (eds.), 2001.

[Nie 1994] NIEISEX, J.; MACK, R. L. - Usability Inspection Methods. New York, John Wiley \& Sons, 1994.

[Nor 1999] NORTH, C.; SHNI:IDIRMAN, B. Snap-Together Visualization: Coordinating Multiple Views to Explore Information, Technical Report CS-TR-4020, 1999.

[Oli 2002] Ol.jvejRA, M.C.F. - Projeto InfoVis - Visualização de Informação Aplicada a Dados de Comércio Eletrônico e Climatologia. Processo 01/07566-2 - Fundação de Amparo à Pesquisa do Estado de São Paulo (FAPESP) - Relatório Cientifico n" 01, set. 2002.

[Pia 1991] PIATETSKY-SIAAPIRO, G.; FRAWL.EY, W. - Knowledge Discovery in Databases, MIT Press, Cambridge, MA, 1991.

[Pic 1988] PICKIETT, R.M.; GRINSTEIN, G.G. - Iconographic Displays for Visualizing Multidimensional Data. Procecdings of IEEE Conference on Systems, Man and Cybernetics'88, Piscataway, NJ, 1988 p. $361-370$.

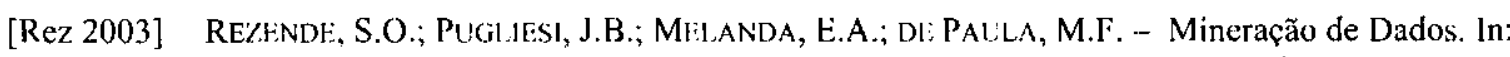
REZENDE, S.O. - Sistemas Inteligentes: fundamentos e aplicações. Barueri, SP. Manole, 2003.

[Rib 1999] Ribarsky, W.; KATZ, J.; JIA.vG, F.; IIOLlaND, $\Lambda$ - Discovery Visualization Using Fast Clustering, IEEF Computer Graphics and $\Lambda$ pplications, v.19, n.5, p.32-39, set./out. 1999.

[Rob 1991] RobertSON, G.C.; MACKINI AY J.D.; CARI), S.K. - Cone Tree: Animated 3D Visualizations of Hicrarchial Information. In: Human Factors in Computing Systems: Proceedings of the CHI '9l Conference. 1991.p. 189-194.

[Rod 2001] RoDDICK, J.F.; LEFs, B. - Paradigms for Spatial and Spatio-Temporal Data Mining. In: Geographic Data Mining and Knowledge Discovery. H. J. Miller and J. Han (eds.), 2001.

[Roh 1999] ROHRER, R.M.; SIBliR'r, J.L.; EBERT, D.S. A Shape-based Visual Interface for Text Retricval, IEEE Computer Graphics and Applications, v. 19, n.5, p.40-46, set./out. 1999.

[Sar 1993] SARKAR, M.; Brown, M.H. - Graphical Fisheye Views. Communications of the ACM, v.37, n.12, p.73-84, 1994.

[Sch 1998] SChroeider, W., MArtin, L., Iorf..sisi, B. - The Visualization Toolkit An Object-Oriented Approach to 3D Graphics, 2. Ed., Prentice Hall, 1998.

[Shi 2001] Shimabukuro, M. H. ; DL OlivelRa, M.C.F. -- Visual Data Mining. Projeto de Doutorado apresentado à CPG do ICMC, USP/São Carlos, 2001.

[Shi 2001a] SHIMABL:KliRo, M.H., DE OLIVt.IRA, M.C.F. - Abordagens Visuais para Suporte à Exploração e Análise de Dados com Atributos Espaciais, Monografia para o Exame de Qualificação apresentada à CPC do ICMC, USP/São Carlos, 2001. 
[Shn 1983] Shneiderman, B. - Direct Manipulation: A Step Beyond Programming Languages. IEEE Computer, v.16, n.8, p.57-69, 1983

[Shn 1994] ShNEIDERMAN, B. - Dynamic Queries for Visual Information Seeking. Technical Report UMCPCSD CS-TR-3022, 1994.

[Shn 1994a] SHneiderman, B.; JaIN, V. - Data Structures for Dynamic Queries: An Analytical and Experimental Evaluation. Proc. of the Workshop on Advanced Visual Interfaces, New York, 1994, p. 1-11.

[Shn 1996] ShNEIIDERAN, B. The Eyes Have It: A Task by Data Type Taxonomy for Information Visualizations. Proceedings of IEEE Symposium on Visual Languages, Boulder, CO, 1996. p. 336343

[Spe 2001] SPENCE, R. - Information Visualization, 1. ed., ACM Press, 2000.

[Tho 1999] Thomas, J.; COOK, K.; Crow, V.; Hetzler, B.; MAY, R.; MCQUerry, D; MCVEety, R.; Mil.l.ER, N.; NAKamURA, G.; NOWEL L, L.; WhITNEY, P. WONG, P.C. -. Human Computer Interaction with Global Information Spaces - Beyond Data Mining. In: Proceedings of British Computer Society Conference, 1999.

[Tuf 1983] TuFTE, E.R. - The Visual Display of Quantitative Information, Graphics Press, USA, 1983

[Tuf 1990] TUFTE, E.R. ‥ Envisioning Information, Graphics Press, USA, 1990

[Tut 1998] TUTIDA, S.M. - Mapeamento por Cores Baseado em Aspectos de Percepção Visual, Dissertação de Mestrado apresentada à CPG do ICMC, USP/São Carlos, 1998.

[War 1994] WARD, M.O. - XmdvTool: Integrating Multiple Methods for Visualizing Multivariate Data. Proceedings IEEE Visualization '94, Washington, DC, 1994, p.326-33.

[War 2000] WARE, C. - Information Visualization: Perception for Design, 1. ed., San Francisco, Morgan Kaufmann Publ., 2000.

[Weg 1990] Wegman, E.J. - Hyperdimensional Data Analysis Using Parallel Coordinates, Journal of the American Statistical Association, v.85, n.11, p.664-675, 1990.

[Weg 1996] Wegman, E.J.; Luo, Q. - High Dimensional Clustering using Parallel Coordinates and the Grand Tour, Technical Report No. 124, Center for Computational Statistics, George Mason University, 1996.

[Wit 2000] WitTEN, I.H.; FRANK, E. - Data Mining: Practical Machine Learning Tools and Techniques with Java Implementations, 1. ed., New Zealand, Morgan Kaufmann, 2000.

[Won 1997] WONG, P.C.; BERGERON, R.D. - 30 Years of Multidimensional Multivariate Visualization, Scientific Visualization - Overviews, Methodologies and Techniques, Gregory M. Nielson, Hans Hagan, and Heinrich Muller (editors), IEEE Computer Society Press, Los Alamitos, CA, USA, 1997, pp. 3-33.

[Won 1999] WonG, P.C. - Visual Data Mining, IEEE Computer Graphics and Applications, , v. 19, n.5, p.2021, set./out. 1999

[Yua 2001] Yuan, M.; Buttenfield B.; Gahegan, M.; MILler, H. - Geospatial Data Mining and Knowledge Discovery. A UCGIS White Paper on Emergent Rescarch Themes, 2001. 